\title{
Phospholipid binding and anticoagulant action of Annexin V
}

Citation for published version (APA):

Andree, H. A. M. (1992). Phospholipid binding and anticoagulant action of Annexin V. [Doctoral Thesis, Maastricht University]. Datawyse / Universitaire Pers Maastricht. https://doi.org/10.26481/dis.19920514ha

Document status and date:

Published: 01/01/1992

DOI:

10.26481/dis.19920514ha

Document Version:

Publisher's PDF, also known as Version of record

\section{Please check the document version of this publication:}

- A submitted manuscript is the version of the article upon submission and before peer-review. There can be important differences between the submitted version and the official published version of record.

People interested in the research are advised to contact the author for the final version of the publication, or visit the DOI to the publisher's website.

- The final author version and the galley proof are versions of the publication after peer review.

- The final published version features the final layout of the paper including the volume, issue and page numbers.

Link to publication

\footnotetext{
General rights rights.

- You may freely distribute the URL identifying the publication in the public portal. please follow below link for the End User Agreement:

www.umlib.nl/taverne-license

Take down policy

If you believe that this document breaches copyright please contact us at:

repository@maastrichtuniversity.nl

providing details and we will investigate your claim.
}

Copyright and moral rights for the publications made accessible in the public portal are retained by the authors and/or other copyright owners and it is a condition of accessing publications that users recognise and abide by the legal requirements associated with these

- Users may download and print one copy of any publication from the public portal for the purpose of private study or research.

- You may not further distribute the material or use it for any profit-making activity or commercial gain

If the publication is distributed under the terms of Article $25 \mathrm{fa}$ of the Dutch Copyright Act, indicated by the "Taverne" license above, 


\section{Phospholipid Binding and Anticoagulant Action of Annexin V}

Harry A.M. Andree 
CIP-DATA KONINKLIJKE BIBLIOTHEEK, DEN HAAG

Andree, Henricus Adrianus Maria

Phospholipid binding and anticoagulant action of annexin $\mathrm{V}$

/ Henricus Adrianus Maria Andree - Maastricht;

Universitaire pers Maastricht.- III.

Thesis Maastricht. - With. ref. - With summary in Dutch.

ISBN 90-5278-025-0

NUGI 743

Subject headings: annexins/prothrombinase/ ellipsometry

Cover: P.M. Frederik, M.C.A. Stuart, E.J. Boekema and C.F.M Maassen. 


\title{
Phospholipid Binding and Anticoagulant Action of Annexin V
}

\author{
proefschrift
}

ter verkrijging van de graad van doctor

aan de Rijksuniversiteit Limburg te Maastricht, op gezag van de Rector Magnificus, Prof. Mr. M.J. Cohen, volgens het besluit van het College van Dekanen,

in het openbaar te verdedigen op donderdag, 14 mei 1992 om 14.00 uur

door

Henricus Adrianus Maria Andree

geboren op 26 september 1963 te Kerkrade 
Promotor:

Prof. Dr. H.C. Hemker

Co-promotor:

Dr. W.Th. Hermens

Beoordelingscommissie:

Prof. Dr. G.J. van der Vusse Rijksuniversiteit Limburg, Maastricht

Prof. Dr. J.-M. Freyssinet Institut d'Hématologie et d'Immunologie, Strasbourg

Prof. Dr. Y. Nemerson Mt. Sinai Universily, New York

Dr. C.P.M. Reutelingsperger Rijksuniversiteit Limburg, Maastricht

Prof. Dr. R.F.A. Zwaal

Rijksuniversiteit Limburg, Maastricht

Financial supports by the Dr. Ir. J.H.J. v.d. Laar foundation and the Netherlands Heart Foundation for the publication of this thesis are gratefully acknowledged. 
The flickering needle jumps into red, New York crawls out of its bed.

The weary guests are asked to leave the warmth of all-night theater, having slept on pictures

that others only dream on.

The un-paid extras disturb the sleeping Broadway.

WALK to the left, DONT WALK to the right:

on Broadway, directions don't look so bright

Autoghosts keep the pace

for the cabsmans early race.

P. Gabriel, 1974

Aan mijn ouders. 


\section{Contents}

Chapter 1: Introduction 11

Blood Coagulation $\quad 11$

Annexin Family 16

Annexin V $\quad 22$

Ellipsometry $\quad 27$

Protein adsorption and flow $\quad 30$

Chapter 2: Testing protein adsorption models by off-null 39 ellipsometry: Determination of binding constants from a single adsorption curve

Chapter 3: Binding of annexin V to planar phospholipid bilayers

Chapter 4: Displacement of coagulation factor Va by annexin $V$

Chapter 5: Clusters of annexin V inhibit prothrombinase by 87 impairment of lateral mobility of coagulation factors

Chapter 6: Aggregation of phospholipid vesicles by a chimera with the $\mathrm{N}$-terminus of annexin I and the core of annexin $\mathrm{V}$

Chapter 7: Summary and concluding remarks

Curriculum Vitae

Dankwoord

Abbreviations and glossary 



\section{Introduction}

\section{BLOOD COAGULATION}

After vessel wall injury, bleeding must be stopped and circulation must be preserved or restored. These basic requirements need a process, called hemostasis, which is a complicated interplay of contractions of the vessel wall, deposition and activation of blood platelets, and blood coagulation. Blood coagulation involves a series of consecutive enzyme reactions which eventually result in the formation of a fibrin clot, sealing the damaged vessel wall $(1,2)$. Coagulation factors are represented by roman numerals, and activation is indicated by 'a'. For a survey of coagulation factors see Table I.

Table I: The coagulation proteins. Deficiencies termed: 1) parahemophilia 2) hemophilia A 3) hemophilia $B$.

Nomenclature

Gla main function

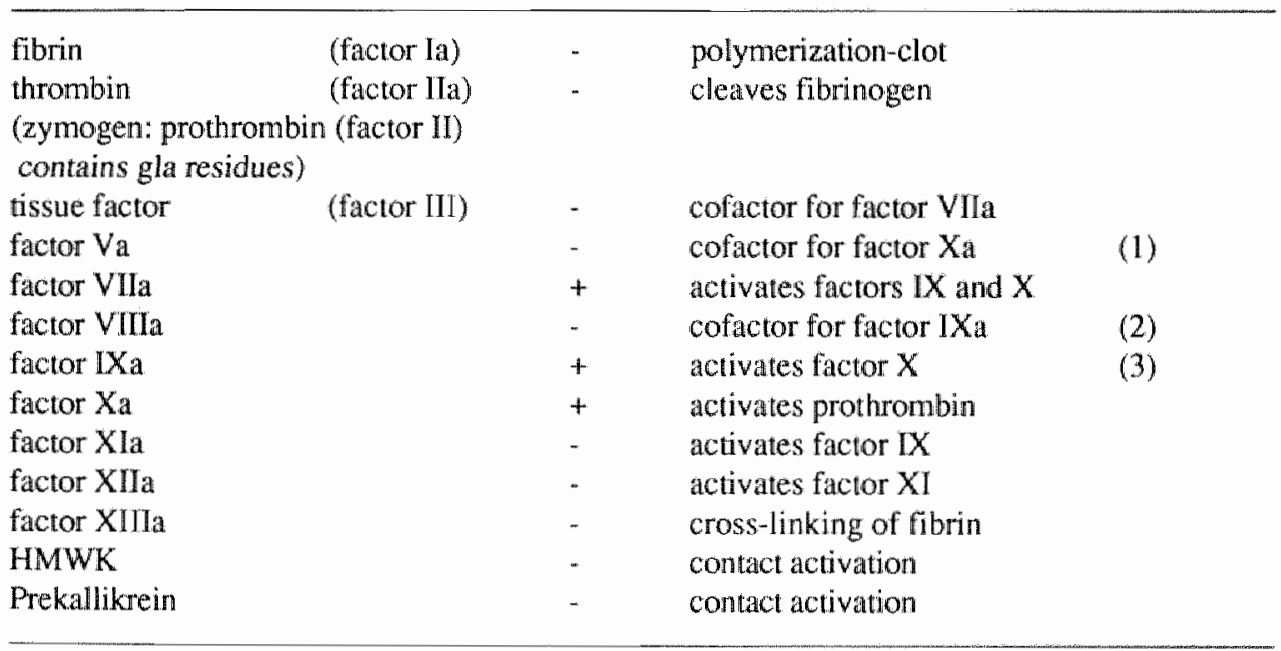




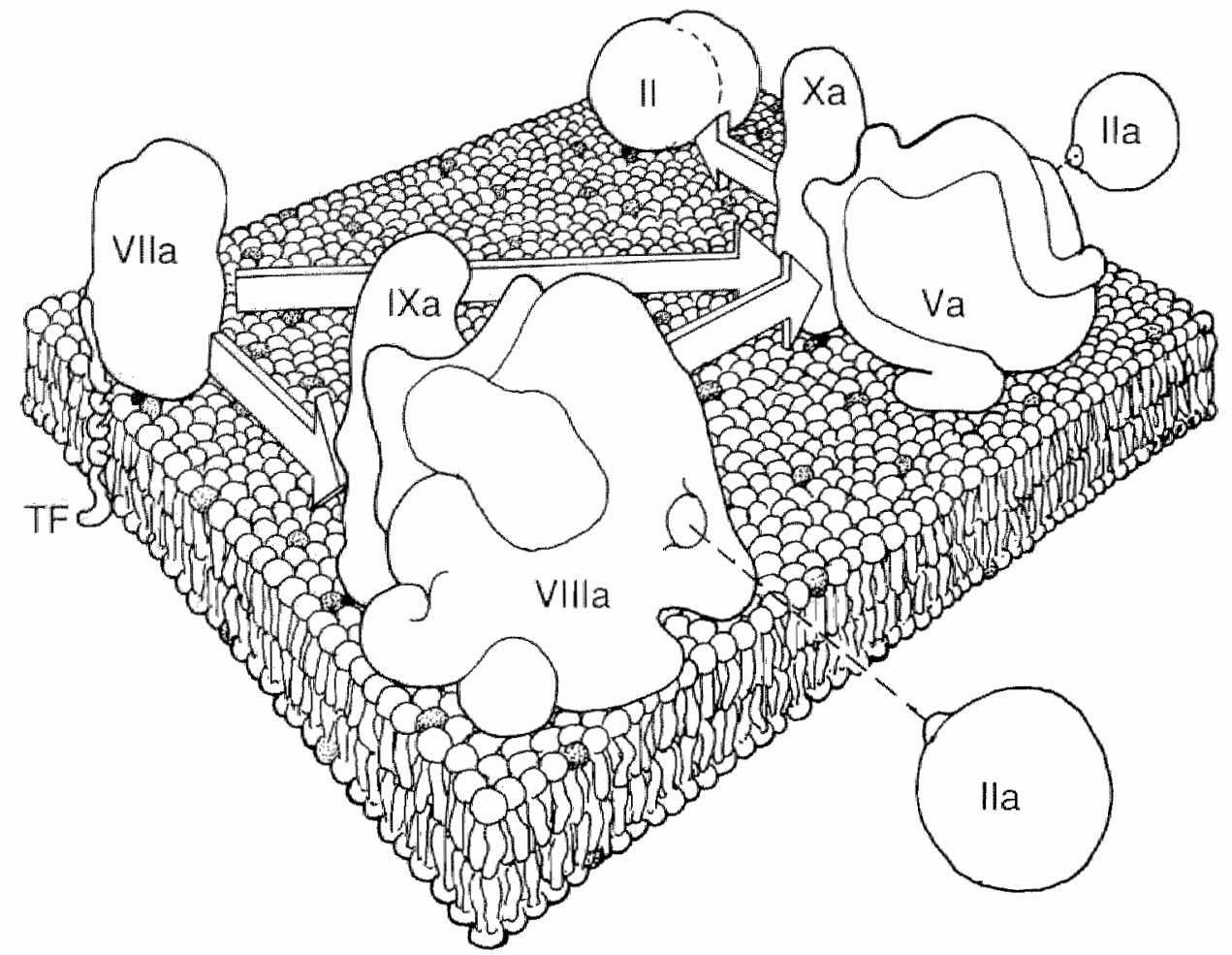

Fig. 1: The phospholipid dependent coagulation reactions. Arrows indicate the activation of the zymogens. Tissue factor binds factor VIIa (extrinsic tenase). Factor VIIa then activates the substrates factor IX and X. Factors IXa and $X$ a convert factor $X$ to $X a$ and prothrombin to thrombin, respectively. Thrombin, devoid of fragment $1-2$, does not bind to phospholipids. It activates factors VIII and $\mathrm{V}$, which will then bind factors IXa and Xa and form the intrinsic tenase and prothrombinase complex. (Drawing by Peter M. Frederik)

Initiation of coagulation - Coagulation starts with exposition of blood to tissue factor (TF), a transmembrane protein of tissue cells (Fig. 1). Activated factor VII (VIIa) binds tightly to tissue factor. This enzyme complex (also termed extrinsic tenase) is able to activate two zymogens: factor IX and factor $X$ (3). Factor $X$ is not only activated by TF-factor VIIa but also by factor IXa. Factor $\mathrm{Xa}$ in its turn will convert prothrombin (factor II) into thrombin (factor IIa). Thrombin is the enzyme that cleaves fibrinogen (factor I) into fibrin (factor Ia), which will then polymerize, entrap blood cells and form a 
clot. The fibrin polymers are cross-linked by factor XIII for stability of the clot. The activity of factor IXa and factor $\mathrm{Xa}$ is enhanced by two to three orders of magnitude after binding of these factors to the activated cofactors VIII and V (See Table II) $(4,5)$. The complexes of factors VIIla-IXa and Va$\mathrm{Xa}$ are also termed intrinsic tenase and prothrombinase, respectively. Thrombin is the pivotal enzyme in this process. Beside conversion of fibrinogen to fibrin it also activates factors VIII and V, leading to a burst of its own formation. The severe bleeding disorders of patients deficient in the cofactors show the crucial role of these proteins.

Lipids and blood coagulation - Coagulation proteins can be divided into three groups: $\gamma$-carboxy glutamic acid (gla)-containing zymogens with moderate calcium-dependent phospholipid affinity (factors II, VII, IX and X). Cofactor proteins with high affinities for phospholipid membranes, that form a tight complex with the gla-containing enzymes (tissue factor (TF), factors

Table II: Effect of cofactors on factor Xa activity. Kinetic parameters of prothrombinase in the presence of calcium. PL $=7.5 \mu \mathrm{M}$ phospholipid vesicles. The relative rates were calculated from $k_{\text {cat }} / K_{\mathrm{m}}$ (Taken from Rosing et al. (4) $)^{\#}$.

\begin{tabular}{lccr} 
& $\mathrm{K}_{\mathrm{m}}$ & $\mathrm{k}_{\mathrm{cat}}$ & Relative catalytic efficiency \\
\hline & $\mu M$ & mol lla $\mathrm{s}^{-1} \cdot$ mol Xa-l & \\
$\mathrm{Xa}$ & 84 & 0.011 & 1 \\
$\mathrm{Xa}, \mathrm{Vat}$ & 34 & 6.22 & 1,400 \\
$\mathrm{Xa}, \mathrm{PL}$ & 0.058 & 0.038 & 4,940 \\
$\mathrm{Xa}, \mathrm{Va}, \mathrm{PL}$ & 0.21 & 32.0 & $1,164,000$ \\
\hline
\end{tabular}

Table III: Binding parameters of coagulation factors\& .

\begin{tabular}{llll} 
& $\mathrm{K}_{\mathrm{d}}$ & $\Gamma_{\max }$ & Ref. \\
\hline & $n M$ & $\mu g / \mathrm{cm}^{2}$ & \\
Prothrombin & $160-300$ & $0.14-0.5$ & $13,14,113,114$ \\
Factor $\mathrm{X}$ & $100-200$ & $0.1-0.5$ & $13,115,116$ \\
Factor $\mathrm{V}$ & $0.01-300$ & 0.3 & $111,116,117,118$ \\
\hline
\end{tabular}

\footnotetext{
" $\mathrm{K}_{\mathrm{m}}=$ the concentration substrate that results in half-maximal saturation of the enzyme, $\mathrm{k}_{\mathrm{cal}}=$ the number of turnovers per enzyme molecule per time.

${ }^{\&} \mathrm{~K}_{\mathrm{d}}=$ concentration at which half of the binding sites are occupied, $\mathrm{r}_{\max }=$ maximal binding.
} 
Va and VIIla) and other factors. Phospholipid surfaces in vivo can be provided by subendothelial matrix, activated blood platelets or stimulated endothelial cells $(6,7) \mathrm{Va}$ and VIIIa) and other factors. Phospholipid surfaces in vivo can be provided by subendothelial matrix, activated blood platelets or stimulated endothelial cells $(6,7)$. Activation of platelets leads to secretion and exposure of anionic (procoagulant) phospholipids to the outer leaflet of the plasma membrane (8). The phospholipid surface tends to gather prothrombin, and by rapid two-dimensional diffusion, present it to the prothrombinase complex, which leads to a decrease of the $\mathrm{K}_{\mathrm{m}}$ value (9). It is obvious that prothrombin adsorption kinetics are quite important for thrombin generation at a phospholipid surface. In Chapter 2 a model free analysis is developed for the description of prothrombin adsorption kinetics to phospholipid bilayers. The phospholipid also keeps factor $\mathrm{Xa}$ at the surface and thereby enhances the assembly rate of prothrombinase $(10,11)$. The excessive high values of the catalytic efficiency $\left(\mathrm{k}_{\text {cat }} / \mathrm{K}_{\mathrm{m}}\right)$ for the activation of factor $\mathrm{X}$ by TF-VIIa and/or VIIIa-IXa, comparable to the value of $0.2 \cdot 10^{-9} \mathrm{M}^{-1} \cdot \mathrm{s}^{-1}$ found for prothrombinase, suggest that the same mechanism is operating in these reactions, although no experimental confirmation for this hypothesis has been presented. Calcium ions are required for the binding of factors Xa and IXa to a phospholipid surface, for the formation of complexes between enzymes and cofactors, and for the integrity of the activated factors $V$ and VIII.

Contact activation - In the test tube blood will also clot after addition of glass or kaolin. This was classically described as part of the intrinsic pathway of blood coagulation. It involves activation of coagulation factors XII (Hageman factor), XI, high molecular weight kininogen (HMWK) and prekallikrein and interacts with the previous scheme by activation of factor IX. Although this pathway may prove to be important after implantation of synthetic grafts, its physiological significance is still a matter of debate $(1,12)$.

Prothrombinase - The prothrombinase complex consists of factor $\mathrm{Va}$ and the gla-containing serine protease factor $\mathrm{Xa}$ bound to a phospholipid membrane. Factor Xa, activated by TF-factor - VIIa or factor IXa, has a moderate affinity for anionic phospholipids $\left(\mathrm{K}_{\mathrm{d}}=10^{-7}-10^{-6} \mathrm{M}\right)(13)$. Factor $\mathrm{Va}$ is activated from factor $\mathrm{V}$ by thrombin and contains a positively charged light chain and a negatively charged heavy chain held together by a calcium ion. The light chain is responsible for the lipid interaction, while both chains are required for complex formation with factor Xa. Factor Va binds with high 
affinity to phospholipid surfaces $\left(K_{d}=10^{-11}-10^{-9} \mathrm{M}\right)$ although higher $\mathrm{K}_{\mathrm{d}}$ s were also reported. Phospholipid bound factor Va binds factor Xa very tightly $\left(K_{d}=10^{-12}-10^{-9} \mathrm{M}\right)(11,14,15)$ and increases the catalytic efficiency of factor $\mathrm{Xa}$ by 3 orders of magnitude. Once factor $\mathrm{Va}$ is activated it controls prothrombinase activity (9). Prothrombin is also a gla-containing coagulation factor, with calcium-dependent binding to anionic phospholipids. It is rapidly converted to thrombin by prothrombinase. In Tables II and III the effect of the elements of prothrombinase on the thrombin generation and the affinities of the components for phospholipids are shown.

Anticoagulant pathways - Hemostasis is not just a collection of procoagulant reactions but rather a delicate balance between procoagulant and anticoagulant reactions. Blood coagulation can be inhibited by several anticoagulant pathways: irreversible inhibition of serine proteases, inactivation of factors $\mathrm{Va}$ and VTlla by protein $\mathrm{C}$, inhibition of TF by tissue factor pathway inhibitor [TFPI], and interference with phospholipid binding of coagulation factors. The first, well known, anticoagulant mechanism is the irreversible binding of serine protease inhibitors (SERPINS) to activated coagulation factors. Examples of SERPINS are antithrombin III, heparin cofactor II, antitrypsin, plasminogen activator inhibitors, etc. (16,17). Antithrombin III binds irreversibly to thrombin, factor $X a$ and factor IXa (18). The binding of SERPINS to coagulation factors is not stimulated by phospholipid surfaces. The activity of antithrombin III is strongly enhanced by heparins, and this effect is used in treatment and prevention of thrombosis. A second inhibitory pathway is proteolysis of coagulation cofactors. Protein $\mathrm{C}$ and protein $S$, two gla-containing phospholipid binding proteins, are involved in this activity. Protein $C$ is activated by the complex of thrombin and thrombomodulin at the intact endothelial cell surface. Activated protein $\mathrm{C}$ proteolytically degrades factors $\mathrm{Va}$ and VIlla, and the rate of this reaction is enhanced by anionic phospholipids and protein $S(19,20)$. Deficiency in protein $S$ leads to a severe thrombotic disorder, which is remarkable in view of the small in-vitro effect on the enzyme kinetics of protein C (21). A third anticoagulant pathway is provided by tissue factor pathway inhibitor (TFPI, also termed EPI (extrinsic pathway inhibitor), or LACI (lipoprotein associated coagulation inhibitor)). This protein binds with high affinity to factor $\mathrm{Xa}$, forming an inactive complex. This Xa-TFPI complex and TF-VIIa, form a quarternary complex, which results in complete inhibition of the TF-VIla 
activity (22). The last anticoagulant pathway acts through interference with protein binding to phospholipid surfaces. Proteins with high affinity for phospholipids may prevent binding of coagulation factors. Many proteins have this activity in vitro, including prothrombin fragment 1-2, factor $V$ a light chain, and lupus anticoagulant antibodies. However, in most cases even rather poor inhibition (10-50\%) requires high protein concentrations $(\sim 1 \mu \mathrm{M})(23-$ 25). Annexins, present an exception to this rule. These phospholipid binding proteins exert strong in vitro anticoagulant properties at low protein concentrations (See below). This feature makes this group of proteins interesting for the study of phospholipids in blood coagulation.

\section{ANNEXIN FAMILY}

The annexin proteins form a family of proteins binding calciumdependently to phospholipids. Ten different members of this family have presently been identified. They share the structural homology of a conserved core with a 4-fold internal repeat of 65-70 amino acids containing a 17 amino acid consensus sequence (26) and a variable $\mathrm{N}$-terminal domain (27). Annexin VI is the only member with an 8-fold in stead of a 4-fold internal repeat, probably caused by gene duplication (28). The primary sequences of the $1 \mathrm{st}$, $2^{\text {nd }}$, and $4^{\text {th }}$ repeats are well conserved while the $3^{\text {rd }}$ (and $7^{\text {th }}$ ) repeat shows more variation (29). In the last years these proteins were investigated by different laboratories for various purposes, which resulted in the use of confusing synonyms for identical proteins. Table IV summarizes the new consensus nomenclature (30) and the old synonyms. The molecular weight of most annexins (Table IV) is in the range $35-40 \mathrm{kDa}$. Annexin VII has a longer amino terminal tail of 167 amino acids and consequently has a higher molecular weight of $47 \mathrm{kDa}$. Several in vitro functions of annexins have been. reported. These include: inhibition of blood coagulation, inhibition of phospholipase activity, aggregation and fusion of phospholipid membranes, a role as substrate for phosphorylating enzymes, as part of the cytosceleton, and formation of calcium channels. In spite of the accumulated data concerning in vitro functions, the physiological role of annexins remains an unresolved question. 
Table IV: Consensus nomenclature of annexin proteins.

\begin{tabular}{|c|c|c|c|}
\hline Annexin I & $\begin{array}{l}\mathrm{M}_{\mathrm{r}}(\mathrm{kDa}) \\
38\end{array}$ & $\begin{array}{l}\text { pl } \\
6.8-7.9\end{array}$ & $\begin{array}{l}\text { Lipocortin I (119), p35 (120), Calpaciin } 111 \text { (84). } \\
\text { Chromobindin } 9 \text { (121), GIF, } 36000 \text { PLBP (122) }\end{array}$ \\
\hline Annexin II & 38 & $7.4-8.1$ & 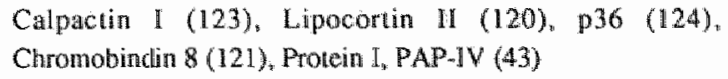 \\
\hline Annexin III & 36 & $6.1-6.3$ & Lipocortin III (125), PAP-III (43), 35-a Calcimedin (126) \\
\hline Annexin IV & 36 & $5.2-6.0$ & $\begin{array}{l}\text { Endonexin I (26), Protein II (127), 32.5K Calellectrin, } \\
\text { Lipocontin IV (125), Chromobindin 4 (121), PAP-II (43), } \\
\text { PP4-X, 35-B Calcimedin (126) }\end{array}$ \\
\hline Annexin V & 36 & $4.8-4.9$ & $\begin{array}{l}\text { VACa (75), IBC (92), PAP-1 (93), Lipocortin V (125), 35K } \\
\text { Calclection, Endonexin II (94), PP4 (90), 35-y Calcimedin } \\
\text { (126), Calphobindin I (92), Archorin CII (64), Chromobindin } \\
5 \text { (121) }\end{array}$ \\
\hline Annexin VI & 68 & 6.1 & $\begin{array}{l}\text { p68 (129), p } 70,73 \mathrm{~K}, 67 \mathrm{~K} \text { Calelectrin (28), Lipocontin VI } \\
\text { (125), Protein III, Chromobindin } 20(121) \text {, 67K Calcimedin, } \\
\text { Calphobindin II (128) }\end{array}$ \\
\hline Annexin VII & $47-52$ & 7.0 & Synexin I, Chromobindin 11 (121) \\
\hline Annexin VIII & 36 & $5.2 \cdot 5.8$ & $\operatorname{VACB}(130), 33000$ PLBP $(122)$ \\
\hline Annexin LX & 35 & & $(66)$ \\
\hline Annexin $X$ & 35 & & (66) \\
\hline
\end{tabular}

Secondary and tertiary structure of annexins - The primary structures of most annexins are well established. Less information is available about secondary and tertiary structures. By analysis of primary sequence, Taylor and Geisow predicted the secondary structures of annexin I, II, and IV, to contain $5 \alpha$-helices per repeat (31), which corresponds to the secondary structure of annexin V (32). Preliminary $X$-ray crystallographic studies of annexin IV (33) and annexin VI (34) are now available, but no data on tertiary structure were given. Electron microscopy studies of phospholipid-bound twodimensional crystals of annexin IV, V and VI (35-37) were published showing differences between overall organization.

Calcium-phospholipid binding - Calcium binding is a general feature of annexins. Binding of calcium leads to conformational changes of annexin $\mathrm{V}$ (38). High calcium concentrations ( $1 \mathrm{mM}$ ) cause self-association of annexin VII (39). Addition of phospholipids increases the affinity of annexins for calcium (38). The calcium concentration required for half-maximal binding of annexins to pure phosphatidylserine (PS) or phosphatic acid (PA) is in the 
range from $0.2-16 \mu \mathrm{M}$ and increases in the order annexin $\mathrm{II}<$ annexin $\mathrm{I}<$ annexin $\mathrm{VI}<$ annexin IV, annexin III, annexin $\mathrm{V}(40)$. This calcium concentration is increased by addition of phosphatidylcholine (PC). Cytosolic calcium concentrations are in the submicromolar range and increase when cells are stimulated. Changes in intracellular calcium levels may therefore provide a regulating mechanism for activities of some annexins.

Inhibition of phospholipase activity - Anti-phospholipase $\mathrm{A}_{2}$ activity was originally described for annexin I (41). It turned out that this was not an unique feature of annexin I and that other annexins were about equally potent inhibitors of phospholipases $(42,43)$. The mechanism of phospholipase $A_{2}$ inhibition is a point of controversy. Specific enzyme inhibition and phospholipid (substrate) binding are both advocated. Nona-peptides of annexin $I$ and $V$ with suggested homology with the phospholipase $A_{2}$ inhibitor uteroglobulin were produced. Specific inhibition of phospholipase $\mathrm{A}_{2}$ activity and anti-inflammatory effects by these nona-peptides were reported $(44,45)$. Van Brinsbergen et al. reported that the nona-peptides of annexin I showed no significant inhibition of phospholipase $A_{2}$ activity in vitro (46), although an anti-inflammatory effect in vivo was not excluded. The homology of the uteroglobulin-like nona-peptide and annexins was reported to be statistically insignificant and the tertiary structures of uteroglobulin and annexins are different (29). Only weak association of annexin I, IV, V and VI with phospholipase $A_{2}$ was found $\left(K_{d} \geq 3 \times 10^{-5} \mathrm{M}\right)$, insufficient to account for direct enzyme inhibition (47). Annexin I, V and VI inhibited calciumindependent phospholipases only in the presence of calcium (48). Phospholipid titrations showed that inhibition of phospholipase $A_{2}$ occurred only at low substrate (=lipid) concentrations (49). The cumulated data now indicate that coverage of the lipid by annexins is the key mechanism of phospholipase inhibition.

Aggregation of phospholipid vesicles and chromaffin granules by annexins - The annexins can be divided into two groups: annexins that stimulate ( $I, I$, VII, and VIII) or inhibit (V and VI) phospholipid aggregation $(40,50)$. Calcium-dependent aggregation of chromaffin granules purified from adrenal medulla by annexin VII was already described in 1978 (51). In this first report the aggregated granules showed a pentalaminar structure, indicating a close packing of annexin VII at the contact site of the granules. Electron microscopy showed aggregation of chromaffin granules by annexin 
VII, resulting in fusion if $4 \mu \mathrm{g} / \mathrm{m} \|$ arachidonic acid was introduced (39). At neutral $\mathrm{pH}(7.4)$ annexin VII can aggregate and induce fusion of phospholipid vesicles at $10 \mu \mathrm{M} \mathrm{Ca}^{2+}$, which was inhibited by addition of $\mathrm{PC}$ to the liposomes (52). At a lower $\mathrm{pH}(6.0)$ annexin VII could induce fusion of PS/PE liposomes at $0.1 \mu \mathrm{M} \mathrm{Ca}^{2+}$, which was also inhibited by addition of $\mathrm{PC}$ to the liposomes mixture (53). Two annexin II molecules together with two p11 (a member of the S-100 protein family) molecules can form a hetero-tetramer with phospholipid binding properties (54). This hetero-tetramer is also able to induce aggregation of chromaffin granules at less than $1 \mu \mathrm{M} \mathrm{Ca}^{2+}$ (55). In vitro, some annexins can clearly induce vesicles aggregation and membrane fusion at intracellular calcium concentrations. Annexin II restores secretion in permeabilized cells, and this effect is inhibited by an affinity-purified antibody against annexin II (56). This suggests a role for annexin II in exocytosis. A monoclonal antibody directed against the first repeat of annexin I inhibited annexin I-induced aggregation of phospholipid vesicles. A chimera of amino acids 41-118 (first repeat) of annexin I and amino acids 92-320 of annexin V induced calcium-dependent vesicle aggregation (57). It was therefore claimed that the first repeat of annexins has a function in vesicle aggregation. In Chapter 6 we will show that a protein with the $\mathrm{N}$-terminus of annexin $\mathbb{I}$ and the core of annexin $\mathrm{V}$ is also able to induce vesicle aggregation.

$N$-terminal domain - Several findings in the literature indicate that the $\mathrm{N}$-terminal domain of annexins is involved in protein-protein interactions and modulations of their functions. The $\mathrm{N}$-terminal domain of annexin $\mathrm{I}$ is directed away from the surface (58) and therefore available for protein interactions. The $\mathrm{N}$-terminal domain of annexin I can be cross-linked by tissue transglutaminase. Cross-linking is calcium dependent and stimulated by addition of PS liposomes (59). The binding site for pll of annexin II is located in its $\mathrm{N}$-terminal domain (54). Annexin II is complexed with another protein, $\mathrm{p} 41$, through its $\mathrm{N}$-terminal end. This annexin II-p41 complex stimulates DNA polymerase activity (60). Annexin I was phosphorylated at tyr-21 by pp60c-scr, pp50v-abl, EGF-receptor/kinase and ser-27 by protein kinase $C(61,62)$. Antibodies to the $\mathrm{N}$-terminus of annexin II can decrease calcium requirement for binding and can abolish or enhance phosphorylation by EGF-receptor tyrosine protein kinase (63). 
Localization of annexins - Annexins appear not only in mammals but also in birds $(64)$, insects $(65,66)$, simple eucaryotes $(67,68)$ and plants $(69)$. Various annexins can be found in many different tissues. A review of tissue and cellular localization of annexins is given in Table V. Annexin V seems to have the most wide distribution. This may, however, reflect the presence of endothelial cells in tissues, due to rich vascularization. At least 6 annexins could be purified from human placenta (70) with a yield of $60 \mathrm{mg}$ annexin per $\mathrm{kg}$ placenta, including $25 \mathrm{mg}$ annexin $\mathrm{V}$. Plasma concentrations of annexin $\mathrm{V}$ are low (0-5 $\mathrm{ng} / \mathrm{ml})$ and somewhat increased in patients with severe illness $(0-$ $28 \mathrm{ng} / \mathrm{ml}$ ) (71). Annexin I could be purified from peritoneal exudate (72), although this may be an artefact caused by cell damage. Annexin $V$ was found

Table V: Cellular localisation.

\begin{tabular}{|c|c|c|c|c|c|c|c|c|}
\hline Annexin & $\mathfrak{I}$ & II & III & IV & V & $\mathrm{VI}$ & VII & VIII \\
\hline Brain & & & & & & 132 & 132 & \\
\hline Placenta & 70 & 70 & 70 & 70 & 70 & 70 & & \\
\hline Aorta & & & 87 & & 102 & & & \\
\hline Liver & & & 1.41 & 126 & 126 & & 141 & \\
\hline Spleen & & 141 & 126 & 136 & $136 / 141$ & 141 & & \\
\hline Lung & 50 & 140 & 140 & 140 & 140 & 140 & 140 & 50 \\
\hline Kidney & & & & & 141 & 97 & 141 & \\
\hline Prostate & 74 & & & 74 & 74 & & & \\
\hline Mammary gland & & 131 & & & & 133 & & \\
\hline Ovary & & & & 126 & 126 & 126 & & \\
\hline Uterus & & & & 126 & 126 & 126 & & \\
\hline Falopian tube & & & & 126 & 126 & & & \\
\hline Adrenal medulla & $137 / 121$ & $137 / 121$ & & $137 / 12 !$ & 121 & $137 / 121$ & $137 / 121$ & \\
\hline Lens & & & & & 138 & 138 & & \\
\hline Thyroid gland & 89 & 89 & & & 89 & 89 & & \\
\hline Intestine & & 141 & & 441 & 141 & & & \\
\hline Heart & & & 139 & 139 & 139 & 139 & & \\
\hline Ductal epithelial & & & & & & 133 & & \\
\hline Sparm cell & & 134 & 134 & & & & & \\
\hline Fibroblasts & & 77 & 141 & & 141 & 23 & 1.41 & \\
\hline Leukocytes & & & & & & 71 & & \\
\hline Endothelial cells & & & & & 71 & & & \\
\hline Mononuclear cells & 135 & 1135 & 135 & & 135 & 135 & & \\
\hline Lymfocytes & & & & 141 & & 141 & & \\
\hline
\end{tabular}


in culture media of human oviduct (73). High concentrations of annexin I and $\mathrm{V}(10-40 \mu \mathrm{g} / \mathrm{ml})$ but not of annexin IV could be detected in seminal fluid secreted by the prostate (74). Thus annexins can be detected in extracellular compartments although they lack a secretory signal sequence (75). The low concentration of annexin $\mathrm{V}$ in plasma casts doubt on a physiological role of annexin $\mathrm{V}$ as a systemic blood coagulation inhibitor. However, endothelial cells have high intracellular annexin $V$ concentrations ( $5 \mathrm{mg} / \mathrm{g}$ protein) (71). The local effect of annexin $V$ release after cell injury still may be of physiological importance. Exogenously added annexin $\mathrm{V}(0.3-1 \mathrm{mg} / \mathrm{kg})$ displayed antithrombotic effects in rats without prolongation of the bleeding time (76) indicating a possible therapeutic effect.

A fourfold higher expression of annexin I and a lower expression of annexin $V$ was found in proliferating fibroblasts, compared to quiescent cells, while expression of annexin II and IV was relatively unchanged (77). This might indicate specialized annexin functions during the cell cycle.

Calcium channels - Annexin VI is able to modulate $\mathrm{Ca}^{2+}$-channel activity of sarcoplasmatic reticulum membranes (78). Annexin VII was shown to form specific calcium channel activity (79). In addition, annexin $\mathrm{V}$ formed voltage-gated ion channels with a selectivity for $\mathrm{Ca}^{2+}>\mathrm{Ba}^{2+}>\mathrm{Sr}^{2+}>\mathrm{Mg}^{2+}$ (80). Ion channel activity was suggested for the polar centre of annexin $\mathrm{V}$ (32). This ion channel activity would require the protein to penetrate the phospholipid bilayer and become a transmembrane protein. This seems to be supported by increased surface pressure after binding of annexin VI to lipid monolayers (35) and a greater yield in purification of annexin $V$ if triton $X$ 100 is added to the homogenate (81). It is, however, difficult to reconcile with the hydrophylic exterior of the molecule (32). It also contrasts with the reversible nature of annexin $\mathrm{V}$ binding upon calcium depletion (Chapter 3 , 82). Brisson et al. (83) compared the structure of phospholipid bound and soluble annexin $V$, and found few differences. They suggested that the increased surface pressure by annexin. VI binding and the formation of 'so called' voltage gated channels are caused by rearrangement of the phospholipid layers rather than insertion of the proteins into the lipid bilayer. Furthermore, the large number of annexin $\mathrm{V}$ molecules in fibroblasts and endothelial cells (71) compared to the small number of calcium channels argues against a main function of annexin $\mathrm{V}$ in calcium transport.

Structural functions - Annexins are also thought to play a role as part of 
the cytosceleton because of their actin binding capacity. The calcium requirement for this interaction, however, exceeds cytosolic levels $(38,84)$. Immunofluorescent studies showed annexin IV to be present at the basolateral membrane of rabbit enterocytes (85). Annexin I can be cross-linked by tissue transglutaminase (86). The cross-linked annexin I clusters are not solubilized by addition of EDTA or triton X-100. Sedimentation equilibrium analysis of annexins I, IV, $V$ and VI suggested monomer-dimer equilibria with dissociation constants of $0.3-1.3 \times 10^{-3} \mathrm{M}(47)$. The annexin II-pl1 tetramer shortened the length of growing actin polymers (87). In Chapter 5 we show that annexin $\mathrm{V}$ forms rigid clusters at phospholipid surfaces. These data suggest a structural function of annexins.

Substrates for enzymes - Annexins may serve as substrate for enzyme systems. Annexin I is a major substrate for the Epidermal Growth Factor Receptor kinase (88). Annexin I is phosphorylated in thyroid stimulating hormone treated cells by protein kinase C (89). Annexin I is cleaved at Trp-12 and Lys-26 by cathepsin D and calpain I. Annexin I (des 1-26) has a decreased calcium requitrement for binding to phospholipids compared to the native annexin I (59). Enzymes may thus be involved in controlling the annexin functions.

\section{ANNEXIN V}

Discovery and primary structure - Annexin $\mathrm{V}$ was first described by Bohn (81) as placental protein 4 (PP4) without attributed functions. More recent studies suggest that the preparations of Bohn et al. were contaminated with other proteins as is also suggested by a reported carbohydrate content of PP4 (81), while carbohydrates are absent in annexin V (75,90). Furthermore, the tissue distribution of annexin $\mathrm{V}$, as presented by Bohn et al. differed from the distribution shown in Table $V$. The first report of annexin $V$, purified from umbilical cord, revealing the anticoagulant properties of annexins, was published in 1985 (91). This paper is the first of a series of investigations on the anticoagulant effects of annexins. In 1987 and 1988 several laboratories determined partial amino acid sequences of annexin $\mathrm{V}$ fragments, and the complete amino acid sequence of annexin $V$ from cDNA libraries $(75,90,92$. 94). Human annexin $V$ was shown to contain 320 amino acids with a short 
acetylated $\mathrm{N}$-terminal end of 18 amino acids and four internal repeats of $67 / 68$ amino acids. It contains 54 acidic and 41 positively charged amino acids which explains its low isoelectric point $(\mathrm{pI}=4.8-4.9)(75)$. Annexin $\mathrm{V}$ does not contain a $\mathrm{N}$-glycosylation site nor a secretory sequence. Since it contains only a single cystein residue, intramolecular disulfide bridging is excluded. Recombinant annexin $\mathrm{V}$ was prepared by cDNA techniques and expressed in E. Coli $(75,95)$. The $\mathrm{N}$-terminal amino group in the recombinant protein is not acetylated in contrast to the placental protein, and this results in a slightly higher isoelectrical point (4.9 versus 4.8$)$. There were no significant differences in anticoagulant activity between recombinant and placental annexin $\mathrm{V}(75,95)$.

Secondary and tertiary structure - Three-dimensional crystals of annexin $\mathrm{V}$ were obtained $(96,97)$ but no tertiary structure was presented in these reports. Huber et al. (32), using X-ray crystallography at $2.5 \AA$ resolution of annexin $V$ crystals, showed that the molecular size is $64 \times 40 \times$ $30 \AA^{3}$ in the presence of calcium. The molecule is folded in 4 similar domains each containing five $\alpha$-helices wound into a right handed superhelix. Repeats I and IV and repeats II and III form subunits, strongly connected by hydrophobic parts of the helices. The centre of the molecule between the two subunits is polar, and could allow the formation of an ion channel. The molecule is folded like a funnel with a convex and concave side. Huber et al. (98) showed that annexin $\mathrm{V}$ contains 5 calcium binding sites at the convex part of the molecule. Annexin $\mathrm{V}$ offers five oxygen ligands for each of the first three calcium binding sites, and one is offered by the solvent. The seventh unoccupied coordination site may accept the phosphoryl moiety of an acidic phospholipid. It is therefore likely that annexin $\mathrm{V}$ binds with its convex side to the phospholipid membrane. This is in agreement with the close relation between tryptophan-186 and the lipid membrane (58). The two remaining calcium binding sites also bound lanthanum. Mosser et al. have shown that annexin V, bound at a phospholipid monolayer, forms two-dimensional crystals of repeated trimers (36). One annexin $V$ molecule is composed of two sub-domains of $40 \times 20 \AA$ each, consistent with the results of Huber et al. (32). In Chapter 5 we show that annexin $V$ clusters are sufficiently rigid to deform phospholipid vesicles into sharply edged structures with planar facets. Furthermore, clusters of annexin $\mathrm{V}$ appear to provide a fencing mechanism, which impairs lateral mobility of coagulation factors, explaining its strong 
anticoagulant effect.

Calcium-dependent phospholipid binding - In free solution annexin V binds calcium with a $K_{d}>0.5 \mathrm{mM}$, which value is decreased to $0.1 \mathrm{mM}$ upon addition of PS/PC liposomes (38). Annexin V in the presence of EDTA is heat stable, while in the presence of $1 \mathrm{mM} \mathrm{Ca}{ }^{2+}$ it is quickly denaturated at $56^{\circ} \mathrm{C}^{\circ}$. The conformation of annexin $\mathrm{V}$, as measured with UV differential spectrography, changed continuously with the calcium concentration, which at high calcium concentrations ( $>200 \mathrm{mM}$ ) leads to self-association $\&$. Halfmaximal binding of annexin $\mathrm{V}$ to vesicles with equimolar concentrations of $\mathrm{PS} / \mathrm{PC}, \mathrm{PE} / \mathrm{PC}$ and $\mathrm{PI} / \mathrm{PC}$ occurred at 40,53 and $300 \mu \mathrm{M} \mathrm{Ca}{ }^{2+}$, respectively (38). Compared to the other annexins, annexin $V$ requires the highest calcium concentration for binding to phospholipids (40). In Chapter 3 it is shown that the amount of calcium required for half-maximal binding is dependent on the composition of the phospholipid mixture. Binding of annexin $\mathrm{V}$ to phospholipid mixtures with a high proportion of $\mathrm{PC}$ requires calcium concentrations exceeding the intracellular levels.

Phospholipid binding affinity - Most studies on binding of annexins to phospholipids only measured calcium dependency and phospholipid specificity. Direct measurements of binding affinity are only available for annexin $\mathrm{V}$ and give only an upper limit for the $K_{d}$ value. High affinities $\left(K_{d}<0.1 n M\right)$ were reported for annexin $\mathrm{V}$ binding to phospholipid membranes $(75,82,99)$ and blood platelets $(100,101)$. The affinity decreased for increasing ionic strength (82). The number of annexin $\mathrm{V}$ binding sites on platelets increased if they were stimulated with thrombin, collagen or ionophore, but not with ADP or epinephrine. This indicates that binding of annexin $\mathrm{V}$ is a good marker for the exposure of acidic phospholipid by platelets. Annexin III, IV, V and a truncated form of annexin II were tested for phospholipid binding affinity, inhibition of phospholipase $\mathrm{A}_{2}$ and prolongation of activated partial thromboplastin time (APTT) (43). Annexin V proved to have the highest affinity for phospholipids. The affinity of these proteins for phospholipids correlated well with their in vitro activities.

\footnotetext{
Andree and Reutelingsperger, unpublished results.

* $\mathrm{PS}=$ phosphatidylserine, $\mathrm{PC}=$ phosphatidylcoline, $\mathrm{PE}=$ phosphatidylethanolamine, and $\mathrm{PI}$ $=$ phosphatidylinositol.
} 
Inhibition of prothrombinase - Already in the first report on the anticoagulant properties of annexin $\mathrm{V}$, this effect was attributed to interference with the phospholipid surface (91). Annexin $V$ was shown to be a very effective inhibitor of phospholipid bound factor Va-Xa complex activity $(42,91,102,103)$. In comparison to other annexins and other phospholipid binding proteins, it was the most potent prothrombinase inhibitor (23$25,42,43,102)$. Annexin $V$ displaced the greater part of prothrombin and factor Xa from liposomes (102) and of factor Xa from platelets (100). Therefore, it was assumed that its anticoagulant effect resides in displacement of coagulation factors from the phospholipid surface. In Chapter 4 we indeed demonstrate a rapid displacement of more than $99 \%$ of factor Va from a phospholipid surface. But in Chapter 5 we conclude that displacement of coagulation factors by annexin $\mathrm{V}$ is incomplete and insufficient to explain its anticoagulant effect, and hypothesize that two-dimensional crystals of annexin $V$ limit the lateral transport of coagulation factors across the surface.

Inhibition of tissue factor (TF)-factor VIIa activity - Several papers described the prolongation of diluted thromboplastin time by annexin $\mathrm{V}$ $(42,75,92)$. Inhibition appeared to be inversely related to the amount of thromboplastin (TF+phospholipid) added. Annexin $\mathrm{V}(1 \mu \mathrm{M})$ in contrast to Apo A-II was shown to inhibit the activity of TF-VIIa towards $\mathrm{X}$ and IX for $60-80 \%(104,105)$. Tissue factor pathway inhibitor (TFPI) was a more efficient inhibitor, decreasing TF-VIIla activity with $95 \%$ at $500 \mathrm{pM}$ concentration (105). Apparently, annexin V inhibits TF-VIIa activity by binding to the surrounding phospholipid surface.

Other functions of annexin $V$ - As mentioned in the general discussion of annexins, annexin $\mathrm{V}$ has a number of other functions, which include inhibition of phospholipase $A_{2}(42)$, actin binding (38), and the formation of calcium channels (80). Neither phosphorylation nor $\mathrm{N}$-terminal degradation of human annexin $\mathrm{V}$ was reported. However, bovine annexin $\mathrm{V}$ contains two bands with apparent molecular weights of 32 and $34 \mathrm{kDa}(102,106)$, both $\mathrm{N}$ terminally blocked, suggesting possible intracellular proteolysis. 

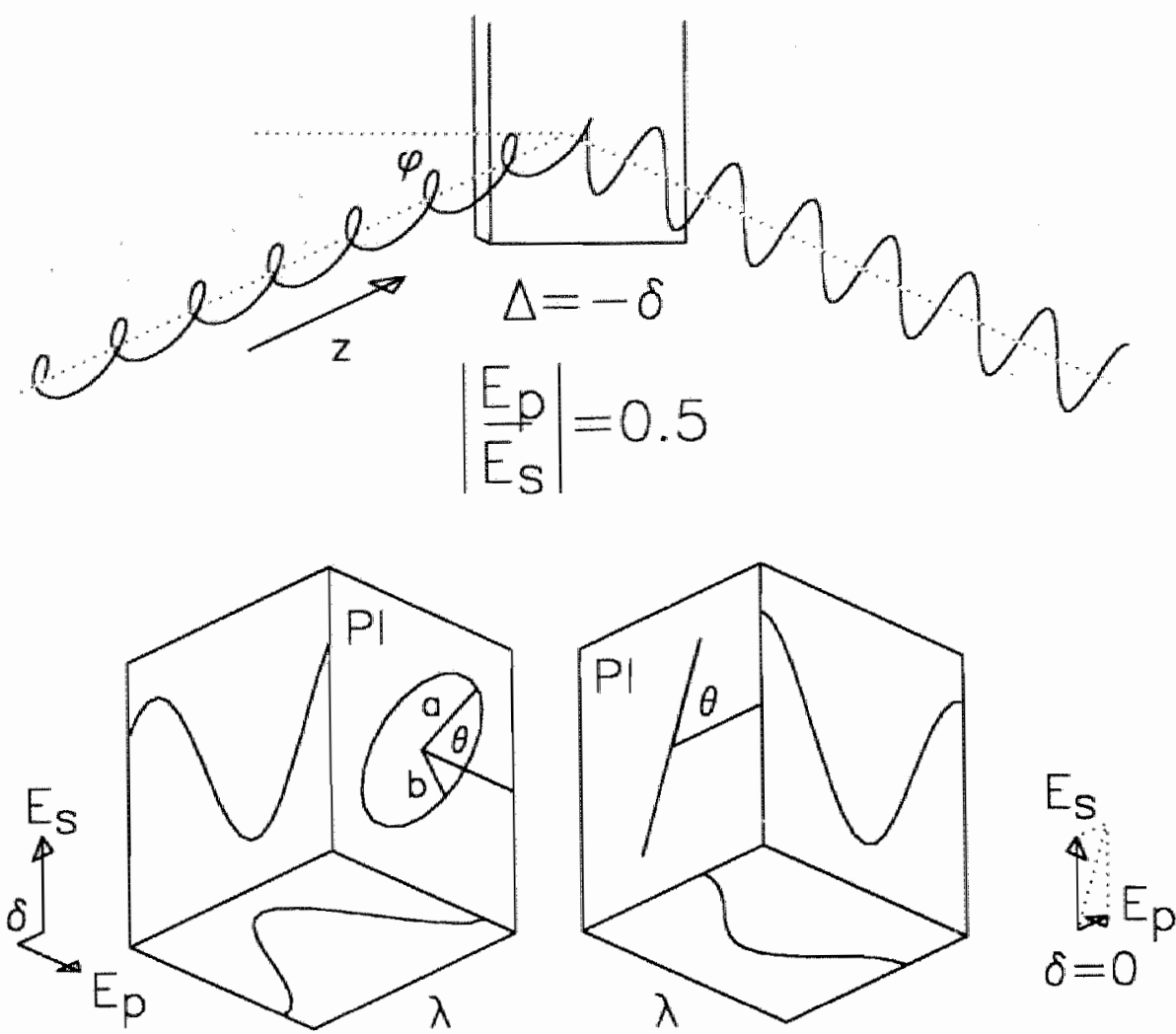

Fig. 2: Phase change of light upon reflection. Three dimensional vibration of light is shown prior to (elliptically polarized) and after reflection (linear polarized). Light propagates in the $z$ direction and makes an angle $p$ with the reflecting surface. Enlargement of the vibrations before and after reflection is shown in the boxes for one wavelength ( $\lambda$ ). The phase difference $s$ between the two vectors $E_{p}$ and $E_{\mathrm{s}}$ before reflection is $\lambda / 8$. The projection of the vibration in Pl (perpendicular to the direction of propagation) is an ellipse with angle $\left(\theta=45^{\circ}\right)$ and ellipticity $(\varepsilon=b / a)$. After reflection a phase difference $\Delta$ between $E_{p}$ and $E_{s}$ occurs which compensates the phase difference of the light before reflection $(\Delta=-\delta)$. The light after reflection vibrates in a plane (linear polarized light), which holds the sum vector of $\mathrm{E}_{\mathrm{p}}$ and $\mathrm{E}_{\mathrm{S}}$. Projection in $\mathrm{Pl}$ is represented by a straight line. In this example absorption of light in the plane of incidence occurred, which resulted in a decreased length of $E_{p}$, while $E_{s}$ remains unchanged: $\left|E_{p} r / E_{s} r\right|=$ $0.5 \times \| E_{\mathrm{p}} / \mathrm{E}_{\mathrm{s}}$ 


\section{ELLIPSOMETRY}

This section about ellipsometry and polarized light is included to provide some information on the technique employed in this study for the measurement of protein binding.

Polarized light - In an ellipsometer, the change of polarization of light after reflection from a reflecting surface (mirror) is measured. First, a coordinate system is defined. Light propagates in the z-direction and has an angle of incidence $(\varphi)$ with the reflecting surface. The plane of incidence is perpendicular to the reflecting surface and is parallel to the direction of propagation. The polarization state of the light is characterized by the ratio of the amplitudes of two electrical vectors $\left(\mathrm{E}_{\mathrm{p}} / \mathrm{E}_{\mathrm{S}}\right.$, where $\mathrm{E}_{\mathrm{p}}$ is parallel and $\mathrm{E}_{\mathrm{S}}$ is "senkrecht" (perpendicular) to the plane of incidence)" in a plane Pl perpendicular to $\mathrm{z}$, and a phase difference $(\delta)$ between these vectors along $\mathrm{z}^{\# \text {. }}$ Upon reflection the polarization state changes $\mathrm{E}_{\mathrm{p}}{ }^{\mathrm{r}}=\mathrm{R}_{\mathrm{p}} \cdot \mathrm{E}_{\mathrm{p}} ; \mathrm{E}_{\mathrm{s}}{ }^{\mathrm{r}}=\mathrm{R}_{\mathrm{s}} \cdot \mathrm{E}_{\mathrm{s}}$, i.e. the phase difference between the vectors is changed and the amplitudes of $E_{p}$ and/or $E_{S}$ may be diminished (light transmission or absorption). Reflection coefficients $\left(R_{p}\right.$ and $\left.R_{s}\right)$ are complex functions of the angle of incidence $(\varphi)$, wavelength of the light $(\lambda)$, complex refractive index of the reflecting surface $\left(\mathrm{n}_{\mathrm{s}}\right)$, refractive index of the buffer $\left(\mathrm{n}_{\mathrm{b}}\right)$, and refractive indices $\left(\mathrm{n}_{1}, \ldots, \mathrm{n}_{\mathrm{x}}\right)$ and thicknesses $\left(d_{1}, \ldots, d_{x}\right)$ of $x$ thin $(0.1-100 n m)$ films deposited on the reflecting surface. The effect of reflection on the polarization state is characterized by the quotient of the reflection coefficients

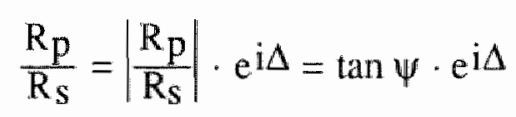

\footnotetext{
"The intensity of the light is equal to: $I=E_{p}{ }^{2}+E_{s}{ }^{2}$.

\#For elliptically polarized light, the projection of the light vibrations in PI (perpendicular on the direction of propagation) can be represented by an ellipse with major axis a and minor $a x$ is $b$ and an angle azimuth $\theta$ of the major axis $x$-axis (in the plane of incidence) and ellipticity $\varepsilon[\varepsilon=$ b/a]. If $\delta=0$, the light can be imagined to vibrate in a plane, which contains the sum vector of $E_{p}$ and $E_{5}$, and the projection of the vibration in Pl can be represented by a straight line $(\varepsilon=0)$. If for example the amplitudes of $E_{p}$ and $E_{S}$ are equal, and the $\delta=0.25$. $\lambda$ (wavelength of the light) the light is termed circular polarized. The projection in $\mathrm{Pl}$ is represented by a circle. Other combinations of $E_{p}, E_{S}$ and $\delta$ will often result in elliptically polarized light. For an extensive description of polarization see ref. (107).
} 
where $i=\vee-1$. By ellipsometry (see below) both variables $\left|R_{p} / R_{S}\right|(\tan \psi)$ and $\Delta$ can be determined from readings of analyzer $(A)$ and polarizer $(P)$. For a bare reflecting surface, without deposited films the values of $R_{p}$ and $R_{S}$ are equal to the Fresnel coefficients $r_{p}$ and $r_{s}$, functions of the optical constants of the reflecting surface and the angle of incidence $\varphi$. Reversely, the complex refractive index of the reflecting surface can be determined from $\psi$ and $\Delta$.

In case of a film deposited on the surface, $R_{p}$ and $R_{s}$ are functions of $r_{p}$ and $r_{S}$ of the reflecting surface and $r_{p}$ and $r_{S}$ of the film. The latter Fresnel coefficients are determined by the refractive index and thickness of the film. From measurements of $\mathrm{P}$ and $\mathrm{A}$ before and after deposition of material on the bare surface, the refractive index and thickness of the films can be calculated $(108,109)$. For films consisting of a mixture of buffer and protein the mass of adsorbed protein can be calculated from observed refractive index $\mathrm{n}$ and thickness $\mathrm{d}$ (expressed in $10^{-8} \mathrm{~m}$ ) using a modified Lorentz-Lorenz relation $(109,110)$ :

$$
\Gamma=\frac{3 d \cdot\left(n^{2}-n b^{2}\right)}{\left(n^{2}+2\right) \cdot\left(r \cdot\left(n b^{2}+2\right)-v \cdot\left(n b^{2}-1\right)\right)}
$$

where $r$ and $v$ are the specific refractivity $(\mathrm{ml} / \mathrm{g}$ ), and the partial specific volume $(\mathrm{ml} / \mathrm{g})$ of the pure substance (protein) deposited on the slide. If the adsorbed film is homogeneous, i.e. the refractive index is equal to the refractive index of the pure substance, the equation is simplified to:

$$
\Gamma=\frac{d \cdot\left(n^{2}-1\right)}{r \cdot\left(n^{2}+2\right)}
$$

The calculated mass is far less disturbed by experimental error than the $\mathrm{n}$ and $\mathrm{d}$ values calculated from $\psi$ and $\Delta$. Obviously, ellipsometry only determines the total adsorbed mass and does not discriminate between adsorption of different proteins.

The ellipsometer - An ellipsometer is an optical device designed to measure the change of polarization state upon reflection. The ellipsometer, schematically presented in Fig. 3, consists of a monochromatic light source with circular polarized light (e.g. a laser which produces light with $\lambda=632.8$ 
$\mathrm{nm}$ equipped with a circular polarizer). The light is plane polarized ( $\varepsilon=0$, $\theta=$ polarizer value) after passing a rotable polarizing prism (polarizer, $\mathrm{P}$ ). The light passes through a quarter wave plate (compensator) with its fast axis fixed at 45 degrees angle to the plane of incidence, and becomes elliptically polarized $\left(\theta=45^{\circ}\right)$. Rotation of the polarizer will change the phase difference $\Delta$ of parallel and senkrecht components of the incident beam (or ellipticity $\varepsilon, e . g$. for $\left.0^{\circ}<\mathrm{P}<90^{\circ} \rightarrow \varepsilon=\tan \left(\mathrm{P}-45^{\circ}\right)\right)$. The light is then reflected against a surface

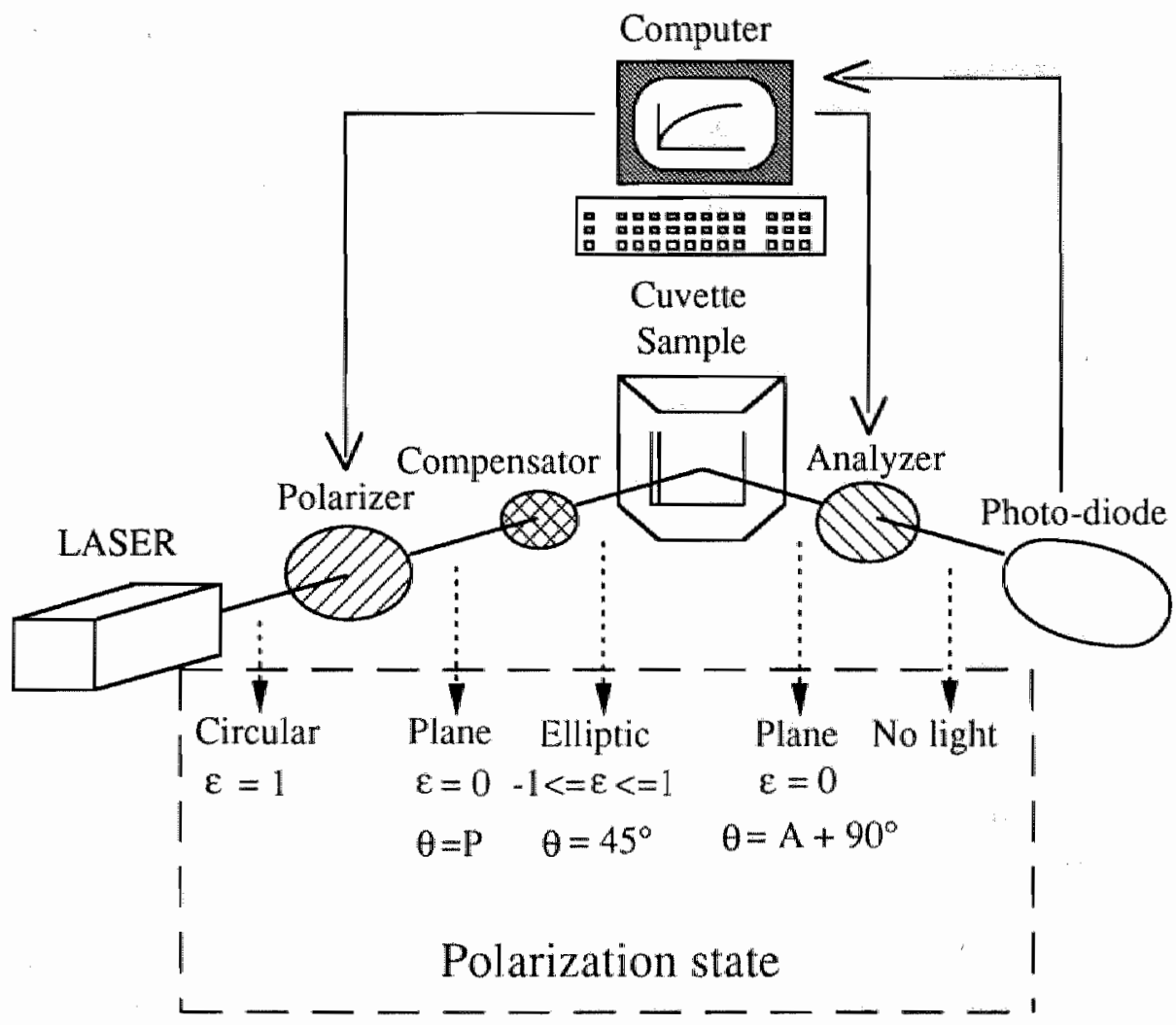

Fig. 3. The ellipsometer set-up used in our laboratory is presented schematically. The computer reads the photo-diode voltage and controls the angles of polarizer and analyzer. The sample is positioned in a quartz cuvette filled with buffer. The polarization state is given with polarizer and analyzer in null positions (See text). 
at an arbitrary chosen angle of incidence $\left(68^{\circ}\right)$, e.g. a silicon $(9,11,111,112)$ or chromium slide $(109,113)$. The polarizer is rotated such, that after reflection the phase difference is zero: The light is then plane polarized ( $\varepsilon=0$ ) and can be extinguished by rotation of the analyzer (A). The angle of the polarization of the reflected light is equal to $A+90^{\circ}$ and, $\tan \psi$ presents the ratio of amplitudes of $E_{p}$ and $E_{s}$. The intensity of the light after passing through the analyzer is measured with a photodiode and read into a computer. Polarizer and analyzer are rotated alternately by computer-controlled stepping motors to achieve minimal light intensity. This technique is called automated null ellipsometry.

Off-null ellipsometry - Accurate $\left(<1 \mathrm{ng} \cdot \mathrm{cm}^{-2}\right)$ and fast $(>10$ samples $\mathrm{s}^{-1}$ ) data acquisition is not easily achieved with a null ellipsometer equipped with stepping motors. In off-null ellipsometry the polarizer is placed several degrees out of minimum (off-null) and polarizer and analyzer positions are interpolated from light intensities. In Chapter 2 this technique is further explained.

\section{PROTEIN ADSORPTION AND FLOW}

Protein binding or conversions at macroscopic surfaces are often limited by the rate of protein transport towards the surface. The maximal transport rate of a protein to the surface is dependent on flow conditions and is proportional to the bulk protein concentration in solution. The initial adsorption rate is thus equal to a transport rate constant $(\Delta)$ corrected for the protein concentration. Very efficient stirring systems, as stirring rods (used in this Thesis) or a rotating disc (112) rotated at 2000 RPM, result in $\Delta=1-3 \mathrm{x}$ $10^{-3} \mathrm{~cm} / \mathrm{s}$. Thus for a protein concentration of $1 \mu \mathrm{g} / \mathrm{ml}, 1-3 \times 10^{-3} \mu \mathrm{g}$ protein per $\mathrm{cm}^{2}$ will adsorb in 1 second (Chapter 2). For example $0.035 \mu \mathrm{g} / \mathrm{ml}$ annexin $\mathrm{V}(1 \mathrm{nM})$ will take more than 45 minutes to reach maximal adsorption. These limitations do not only occur in adsorption experiments but also in enzymatic reactions on macroscopic surfaces. An extensive discussion of the influence of flow conditions and diffusion on protein transport is presented in Chapters 5 and 6 of ref. (112). 


\section{REFERENCES}

1. Jackson C.M., and Nemerson Y. (1980) Am. Rev. Biochem. 49, 765-811.

2. Davie E.W., Fujikawa K., and Kisiel W. (1991) Biochemistry 30, 10364-10370.

3. Nemerson Y. (1988) Blood 71, 1 18 .

4. Rosing J., Tans G., Govers-Riemslag J.W.P., Zwaal R.F.A., and Hemker H.C. (1980) J. Biol. Chem. 255, 274-283.

5. Mann K.G., Jenny R.J., and Krishnaswamy S. (1988) Ann. Rev. Biochem. 57, 915-956.

6. Tracy P.B., Eide L.L., Mann K.G. (1985) J. Biol, Chem. 260, $2119-2124$.

7. Friedberg R.C., Hagen P.-O, and Pizzo S.V. (1988) Blood 71, $1321-1328$.

8. Bevers E.M., Comfurius P., and Zwaal R.F.A. (1982) Eur. J. Blochem. 122, 81-85.

9. Giesen P.L.A. Willems, G.M., and Hermens W.Th. (1991) I. Biol. Chem. 266, 1379. 1382.

10. Krishnaswamy S., Jones K.C., Mann K.G. (1988) J. Biol. Chem. 263, 3823-3834.

11. Giesen P.L.A., Willems G.M., Hemker H.C., and Hermens W.T. (1991) J. Biol. Chem. 266, $18720-18725$.

12. Prydz H. (1983) Haemostasis 13, 156-160.

13. Nelsestuen G.L., and Broderius M. (1977) Biochemistry 16, 4172-4177.

14. Waart van de P., Hemker H.C., and Lindhout T. (1984) Biochemistry 23, 2838-2842.

15. Krishnaswamy S. (1990) d. Biol. Chem. 265, 3708-3718.

16. Abdilgaard U. (1968) Scand. J. Clin. Lab. Invest. 21, 89-91.

17. Carrell R.W., Christey P.B., and Boswell D.R. (1987) Thromb. and Haemost. State of the Art Book, 1-15.

18. Travis J., Salvesen G.S., (1984) Ann. Rev. of Biachem. 52, 665-709.

19. Walker F. (1980) J. Biol. Chem. 255, 5521-5524.

20. Esmon C.T. (1989) J. Bial. Chem. 264, 4743-4746.

21. Solymoss S., Tucker M.M.。 and Tracy P.B. (1988) J. Biol. Chem . 263, 14884-14890.

22. Sanders N.L., Bajaj S.P., Zivelin A., Rapaport S.I. (1985) Blood 66, $204-212$.

23. Govers-Riemslag J.W.P., Speijer H., Zwaal R.F.A., and Rosing J. (1985) Thromb. Res. 38, 375-388.

24. Carson S.D., and Ross S.E. (1988) Thromb. Res. 50, 679-685.

25. Gendreau M.A., Krishnaswamy S., and Mann K.G. (1989) J. Biol. Chem. 264, 6972. 6978.

26. Geisow M.J., Fritsche U., Hexham J.M., Dash B., and Johnson T (1986) Nature 320, 636-638.

27. Geisow M.J. (1986) FEBS. lett. 203, 99-103.

28. Südhof T.C., Slaughter C.A., Leznicki 1., Barjon P., and Raynolds G.A. (1988) Proc. Natl. Acad. Sci. USA 85, 664-668. 
29. Barton G.J, Newman R.H., Freemont P.S., and Crumpton M.J. (1991) Eur. J. Biochem. 198, 749-760.

30. Crumpton M.J, and Dedman J.R. (1990) Nature 345, 212.

31. Taylor W.R, and Geisow M.J. (1987) Protein Engineering 1, 183-187.

32. Huber R., Schneider M., Mayr I., Römisch J., and Pâques E.-P. (1990) FEBS. let. 275, 15-21.

33. Freemont P.S., Driessen H.P.C., Verbi W., and Crumpton M.J. (1990) J. Mol. Biol. $216,219-221$.

34. Gabriel B.L., Taylor K., Creutz C.E., and Kretsinger R.H. (1991) J. Structural Biology $107,29-37$.

35. Newman R., Tucker A., Ferguson C., Tsernoglou D., Leonard K., Crumpton M.J. (1989) J. Mol. Biol. 206, 213-219.

36. Mosser G., Ravanat C., Freyssinet J.-M., and Brisson A. (1991) J. Mol. Biol. 217, 241 245.

37. Newman R.H., Leonard K., and Crumpton M.J. (1991) FEBS. lett. 279, 21-24.

38. Schlaepfer D.D., Mehlman T., Burgess W.H., and Haigler H.T. (1987) Proc. Natl. Acad. Sci. USA 84, 6078-6082.

39. Creutz C.E., and Pollard H.B. (1982) Biophys. d. 37, 119-120.

40. Blackwood R.A., and Ernst J.D. (1990) Biochem. J. 266, 195-200.

41. Hirata F., Schiffmann E., Krishnamoorthy V., Salomon D. and Axelrod J. (1980) Proc. Natl. Acad. Sci. USA 77, 2533-2536.

42.Chap H., Comfurius P., Bevers E., Fauwel J., Vicendo P., Douste-Blazy L., and Zwaal R.F.A. (1987) Biochem. Biophys, Res. Com. 150, 972-978.

43. Tait J.F., Sakata M., McMullen B.A., Miao C.H., Funakoshi T., Hendrickson L.E., and Fujikawa K. (1988) Biochemistry 27, 6268-6276.

44. Miele L., Cordella-Miele E., Facchiano A., and Mukherjee A.B (1988) Nature 335, 726730.

45. Perreti M., Becherocci C., Mugridge K.G., Solito E., Silvestri S., and Parente L. (1991) Br. J. Pharmacol. 103, 1327-1332.

46. Brinsbergen van J., Slotboom A.J., and Has de G.H. (1989) FEBS. lett. 247, $293-297$.

47. Ahn N.G., Teller D.C., Bienkowski M.J., McMullen B.A., Lipkin E.W., and Haèn de C. (1988) d. Biol. Chem. 263, 18657-18663.

48. Gassama-Diagne A., Fauvel J., and Chap H. 1990) J. Biol. Chem. 265, 4309-4314.

49. Davidson F.F., Dennis E.A., Powell M., and Glenney J. (1987) J. Biol. Chem. 262, 1.698-1705.

50. Tsao F.H.C. (1990) Biochim. Biophys. Acta 1045, 29-39.

51. Creutz C.E., Pazoles C.J, and Pollard H.B. (1978) J. Biol Chem. 253, 2858-2866.

52. Hong K., Düzgünes N., Ekerd R., and Papahadjopoulos D. (1982) Proc. Narl. Acad. Sci. 


\section{USA 79, $4642-4644$.}

53. Nir S., Stutzin A., and Pollard H.B. (1987) Biochim. Biophys. Acta 903, 309-318.

54. Johnsson N., Vanderkerckhove J., Van Damme J., and Weber K. (1986) FEBS. Letr. $198,361-364$.

55. Drust D.S., and Creutz C.E. (1988) Nature 331, 88-91.

56. Ali S.M., Geisow M.J., and Burgoyne R.D. (1989) Nature 340, 313-315.

57. Ernst J.D., Hoye E., Blackwood R.A., and Mok T.L. (1991) J. Biol. Chem. 266, 66706673.

58. Meers P. (1990) Biochemistry 29, 3325-3330.

59. Ando Y., Imamura S., Hong Y.-M., Owada M.K., Takunaga T., and Kannagi R. (1989) J. Biol. Chem. 264, 6948-6955.

60. Jindal H.K., Chaney W.G., Anderson C.W., Davis R.G., and Vishwanatha J.K. (1991) J. Biol. Chem. 266, 5169-5176.

61. Pepinsky R.B., Sinclair L.K. (1986) Nature 321, 81-84.

62. Varticovski L., Chahwala S.B., Whitman M., Cantley L., Schindler D., Chow E.P., Sinclair L.K., and Pepinsky R.B. (1988) Biochemistry 27, 3682-3690.

63. Glenney J., and Zokas L. (1988) Biochemistry 27, 2069-2076.

64. Pfaffle M., Ruggeriro F., Hofmann H., Fernåndez M.P., Selmin O., Yamada Y., Garrone R., and Mark von der K. (1988) Embo. J. 7, 2335-2342.

65. Gerke V. (1989) FEBS lett. 258, 259-262.

66. Johnston P.A., Perin M.S., Reynolds G.A., Wasserman S.A. and Südhof T.C. (1990) J. Biol. Chem. 265, 11382-11388.

67. Gerke V. (1991) J. Biol. Chem. 166, 1697-1700.

68. Greenwood M., and Tsang A. (1991) Biochim. Biophys, Acta 1088, 429-432.

69. Smallwood M., Keen J.N., and Bowles D.J. (1990) Biochem. J. 270,157-161.

70. Römisch J., and Heimburger N. (1990) J. Biol. Chem. Hoppe-Seyler 371, 383-388.

71. Flaherty M.J., West S., Heimark R.L., Fujikawa K., and Tait J.F. (1990) J. Lab. Clin. Med. 115, 174-181.

72. Pepinsky R.B., Sinclair L.K., Browning J.L., Mattaliano R.J., Smart J.E;, Chow E.P., Falbel T., Ribolini A., Garwin J.L., Wallner B.P. (1986) J. Biol. Chem. 261, 4239. 4246.

73. Verhage H.G, Fazleabas A.T., and Donnelly K. (1988) Endocrinology 122, 1639-1645.

74. Christmas P., Callaway J., Fallon J., Jones J., and Haigler H.T. (1991) J. Biol. Chem. 266, 2499-2507.

75. Maurer-Fogy, I., Reutelingperger C.P.M., Pieters J., Bodo G., Stratowa C. Hauptmann R. (1988) Eur. J. Biochem. 174, 585-592.

76. Römisch J., Seiffge D., Reiner G., Pâques E.-P., Heimburger N. (1991) Thromb. Res. $61,93-104$. 
77. Schlaepfer D.D. and Haigler H.T. (1990) J. Cell Biology 111, 229-238.

78. Diaz-Munoz M., Hamilton S.L., Kaetzel M.A., Hazarika P., and Dedman J.R. (1990) J. Biol. Chem. 265, 15894-15899.

79. Burns A.L., Magendzo K., Shirwan A., Srivastava M, Rojas E., Alijani M., and Pollard H.B. (1989) Proc. Nail. Acad. Sci. USA 86, 3792-3802.

80. Rojas E., Pollard H.B., Haigler H.T., Parra C, and Burns A.L. (1990) J. Biol. Chem. $265,21207 \times 21215$.

81. Bohn H., Kraus W., and Winckler W. (1985) Arch. gynecol. 236, 225-233.

82. Tait J.F., Gibson D., and Fujikawa K. (1989) J. Biol. Chem. 264, 7944-7949.

83. Brisson A., Mosser G., and Huber R. (1991) J. Mol. Biol. 220, 199-203.

84. Glenney J.R., Tack B., Powell M.A. (1987) J. Cell Biol. 104, 503-511.

85. Massey D., Traverso V, and Maroux S. (1991) J. Biol. Chem. 266, 3125-3130.

86. Ando Y., Imamura S., Owada M.K., and Kannagi R. (1991) J. Biol. Chem. 266, 1101 1108 .

87. Martin F., Derancourt I., Capony J.-P., Watrin A., and Cavadore J.-C. (1988) Biochem. J. 251, 777-785.

88. Valentine-Braun K.A., Hollenberg M.D., Frase E., and Northup J.K. (1987) Arch. Biochem. Biophys. 259, 262-282.

89. Antonicelli F., Omri B., Breton M.F. Rothhut B., Russo-Marie F., Pavlovic-Hournac M., and Haye B. (1989) FEBS. lett. 258, 346-350.

90. Grundmann U., Abel K.-J., Bohn H., Löbermann H., Lottspeich F, and Küpper H. (1988) Proc. Natl. Acad. Sci. USA 85, 3708-37 12.

91. Reutelingsperger C.P.M., Hornstra G., Hemker H.C. (1985) Eur. J. Biochem. 151, 625629.

92. Iwasaki A., Suda M., Nakao H., Nagoya T. Sano Y., Arai K., Mizogushi T., Sato F., Yoshizaki H., Hirata M., Miyata T, Shidara $Y .$, Murata M., and Maki M. (1987) d. Biochem.102, 1261-1273.

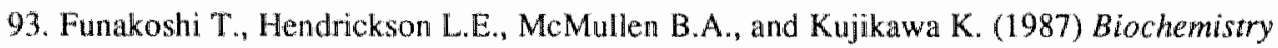
26, $8087+8092$.

94. Kaplan R., Jaye M., Burgess W.H., Schlaepfer D.D., and Haigler (1988) J. Biol. Chem. $263,8037-8043$.

95. Römisch J., Grote M., Weithmann K.U., Heimburger N., and Amann E. (1990) Biochem. J. 272, 223-229.

96. Lewitt-Bentley A., Doublié S., Fourme R., and Bodo G. (1989) J. Mol. Biol. 210, 875876.

97. Seaton B.A., Head J.F., Kaetzel M.A., and Dedman J. (1990) J. Biol. Chem. 265, 45674569 .

98. Huber R., Römisch J., and Pâques E.-P. (1990) Embo. J. 9, 3867-3874. 
99. Andree H.A.M., Reutelingsperger C.P.M., Hauptmann R., Henker H.C., Hermens W.T., and Willems Gi.M. (1990) J. Biol. Chem. 265, 4923-4928.

100. Thiagarajan P., and Tait J.F. (1990) J. Biol. Chem. 265, 17420-17423.

101. Römisch J., Schorlemmer U., Fickenscher K., Pâques E.-P. and Heimburger N. (1990) Thromb. Res. 60, 355-366.

102. Reutelingsperger C.P.M., Kop J.M.M., Hornstra G., and Hemker H.C. (1988) Eur. J. Biochem.173, 171-178.

103. Funakoshi T., Heimark R.L., Hendrickson L.E., McMullen B.A., and Fujikawa K. (1987) Biochemistry 26, 5572-5578.

104. Kondo S., Nogushi M., Funakoshi T., Fujikawa K., and Kisiel W. (1987) Thromb. Res. 48, 449-459.

105. Gramzinski R.A., Broze G.J., and Carson S.D. (1989) Blood 73, 983-989.

106. Boustead C.M., Walker J.H., and Geisow M.J. (1988) FEBS. Lett. 233, 233-238.

107. Azzam R.M.A., and Bashara N.M. (1977) Ellipsometry and polarized light, Elsewier North Holland inc, 52 Vanderbilt Avenue, New York, N.Y. 10017, ISBN 0-72040694-3.

108. McCrackin F.L., Passaglia E., Stromberg R.R., and Steinberg H.L. (1963) J. Res. Natl. Bur. Stand. 67, 363-377.

109. Cuypers P.A., Corsel J.W., Janssen M.P., Kop J.M.M., Hermens W.Th., and Hemker H.C. (1983) J. Biol. Chem. 258, 2426-2431.

110. Corsel J.W., Willems G.M., Kop J.M.M., Cuypers P.A., and Hermens W.Th. (1986) J. Coll. Interf. Sci. 111, 544-554.

111. Kop J.M.M., Willems G.M., and Hermens W.Th. (1989) J. Colloid Interface Sci. 133, 369-376.

112. Giesen P.L.A., Thesis, University of Limburg, Cardiovascular Research Institute Maastricht (1992) The Netherlands.

113. Kop J.M.M., Cuypers P.A., Lindhout T., Hemker H.C., Hermens W.T. (1984) J. Biol. Chem. 259, 13993-13998.

11.4. Wei G.J., Bloomfield V.A., Resnick R.M., and Nelsestuen G.L. (1982) Biochemistry 21, 1949-1959.

115. Dieijen van G., Tans G., Van Rijn J., Zwaal R.F.A., and Rosing J. (1981) Biochemistry 20, 7096-7101.

116. Waart van de P., Bruhls H., Hemker H.C., and Lindhout T. (1983) Biochemistry 22, 2427-2432.

117. Mayer L.D., Pusey M.L., Griep M.A., and Nelsestuen G.L. (1983) Biochemistry 22, 6226-6232.

118. Pusey M.L. Mayer L.D., Wei G.J., Bloomfield V.A., and Nelsestuen G.L. (1982) Biochemistry 21, 5262-5269. 
119. Wallner B.P., Mattaliano R.J., Hession C., Cate R.L., Tizard R., Sinclair L.K., Foeller C., Chow E.P., Browning J.L., Ramachandran K.L., Pepinsky R.B. (1986) Nature $320,78-81$.

120. Huang K.-S., Wallner B.P., Mattaliano R.J., Tizard R., Burne C., Frey A., Hession C., McGray P., Sinclair L.K., Chow E.E., Browning J.L., Ramachandran K.L., Tang J., Smart J.E., and Pepinsky R.B. (1986) Cell 46, 191-199.

121. Creutz C.E., Zaks W.J., Hamman H.C., Crane S., Martin W.H., Gould K.L., Oddie K.M., and Parsons S.J. (1987) J. Biol. Chem. 262, 1860-1868.

122. Tsao F.H.C., Hull W.M., Strickland M.S., Whitsett J.A., Foo T.K.F., Zografi G., and DeLuca P.M. (1991) Biochim. Biophys. Acta 1081, 141-150.

123. Kristensen T., Saris C.J.M., Hunter T., Kicks L.J., Noonan D.J., Glenney J.R., and Tack B.F. (1986) Biochemistry 25, 4497-4503.

124. Saris C.J.M., Tack B.T., Kristensen T., Glenney J.R., and Hunter T. (1986) Cell 46, 201-212.

125. Pepinsky R.B., Tizard R., Mattaliano J., Sinclair L.K., Miller G.T., Browning J.L., Chow E.P., Burne C., Huang K.-S., Pratt D., Wachter L., Hession C., Frey A.Z., and Wallner B.P. (1988) J. Biol. Chem. 263, 10799-10811.

126. Kaetzel. M.A., Hazarika $P_{\text {., }}$ and Dedman J.R. (1989) J. Biol. Chem. 264, 14463-14470.

127. Weber K., Johnsson N., Plessman U., Van N.P., Söling H.-D., Ampe C., and Vanderkerckhove J. (1987) Embo. J. 6, 1599-1604.

128. Iwasaki A., Suda M., Watanabe M., Nakao H., Hattori Y., Nagoya T., Saino Y., Shidara Y., and Maki M. (1989) J. Biochem. 106, 43-49.

129. Crompton M.R., Owens R.J., Totty N.F., Moss S.E., Waterfield M.D., Crumpton M.J. (1988) Embo. J. 7, 21-27.

130. Hauptmann R., Maurer-Fogy I., Krystek E., Bodo G., Andree H., and Reutelingsperger C.P.M. (1989) Eur. J. Biochem. 185, 63-71.

131. Hom Y.K., Südhof T.C., Lozano J.J., Haindl A.H., and Rocha V. (1988) J. Cell Phys. $135,435-442$.

132. Woolgar J.A., Boustead C.M., and Walker J.H. (1990) J. Neurochemistry 54, 62-71.

133. Lozano J.J., Haindl A.H., and Rocha V. (1989) J. Cell. Phys. 141, 318-324.

134. Berruti G. (1988) Exp. Cell. Res. 179, 374-384.

135. Comera C., Rothhut B., Russo-Marie F (1990) Eur. J. Biochem. 188, $139-146$.

136. Kobayashi R., Tashima Y. (1989) Biochem. Biophys. Res. Com. 162, 15-23.

137. Drust D.S., and Creutz C.E. (1991) J. Neurochemistry 56, 469-478.

138. Kobayashi R., Nakayama R., Ohta A., Sakai, F., Sakuragi S, and Tashima Y. (1990) Biochem. J. 266, 505-511.

139. Pula G., Bianchi R., Ceccarelli, Giambanco I., and Donato R. (1990) FEBS. lett. 277, $53-58$. 
140. Khanna N.C., Helwig E.D., Ikebuchi N.W., Fitzpatrick S., Bajwa R., and Waisman D.M. (1990) Biochemistry 29, 4852-4862.

141. Shadle P.J., Gerke V., and Weber K. (1985) J. Biol. Chem. 260, 16354-16360. 



\section{Testing Protein Adsorption Models by Off-null Ellipsometry:}

\section{Determination of Binding Constants from a Single Adsorption Curve}

Harry A. M. Andree, Wim Th. Hermens, and George M. Willems

\section{SUMMARY}

The kinetics of prothrombin adsorption on planar bilayers, prepared from $40 \%$ dioleoyl-phosphatidylserine (PS) and $60 \%$ dioleoylphosphatidylcholine (PC), are studied by off-null ellipsometry. A simple expression for the adsorption rate is derived from a model-free analysis. Interpretation of this expression in terms of transport processes shows that up to $\Gamma=1.8 \mathrm{pmol} / \mathrm{cm}^{2}$, i.e. $50 \%$ of the maximal surface coverage $\left(\Gamma_{\max }\right)$, the adsorption rate appears to be regulated by diffusion-limited transport of prothrombin, i.e. the adsorption rate is proportional to the concentration difference between bulk and the solution immediately adjacent to the surface. The latter concentration appears instantaneously in equilibrium with the surface excess, conforming to the classical Langmuir isotherm. The kinetics are thus described by a simple model containing the transport coefficient, the dissociation constant $K_{d}$ and the maximal surface coverage $\Gamma_{\max }$. With known $\Gamma_{\text {max }}$ this model allows estimation of $K_{d}$ from a single adsorption curve. However, for surface coverages exceeding $60 \%$ of maximal adsorption drastic deviations from this model are found. The intrinsic adsorption rate is substantially reduced, presumably by surface exclusion. 


\section{INTRODUCTION}

Prothrombin circulates in a concentration of $2 \mu \mathrm{M}$ in plasma as the precursor of the pivotal enzyme of blood coagulation, thrombin. Upon vascular damage and consequent activation of the blood coagulation system, prothrombin is converted to thrombin by the so-called prothrombinase complex. This consists of the activated coagulation factors $\mathrm{Xa}$ and $\mathrm{Va}$, forming a complex on the lipid surface, see ref. (1) for a review. Binding of prothrombin to the lipid membrane is essential for efficient conversion as the membrane surrounding the prothrombinase complex acts as a funnel, thereby greatly increasing the transport rate of prothrombin to the prothrombinase complex (2). Thus the adsorption kinetics of prothrombin to the lipid surface are important determinants of the thrombin production rate.

Traditionally blood coagulation reactions and prothrombin binding are studied with small unilamellar vesicles (SUV) providing the lipid membranes. In vivo, however, blood coagulation reactions are localized at macroscopic surfaces, e.g. damaged parts of the blood vessel wall, and are influenced by blood flow. In this situation the protein transport by convection and diffusion easily becomes rate limiting. This has spurred an interest in model systems using macroscopic, supported, lipid bilayers (2-6) for the study of lipidprotein interactions and lipid-bound reactions of blood coagulation.

Despite many experimental studies in the past decades, protein adsorption is still poorly understood $(7,8)$. Several reports showed deviations from the classical Langmuir model, which describes adsorption by mass action to independent binding sites (4,9-11). Also the incorporation of the diffusion limit has resulted in divergent models even for intrinsic adsorption kinetics conforming to the Langmuir model $(4,12)$. The aim of this study was to establish a model for the adsorption kinetics of prothrombin to lipid membranes. Simultaneous analysis of an array of adsorption curves, obtained at different protein concentrations, allows separation of net adsorption rate in total adsorption and desorption rates. Off-null ellipsometry (13) was used to obtain high quality adsorption curves of prothrombin to $40 \%$ PS / $60 \% \mathrm{PC}$ bilayers. By this technique the adsorbed protein mass can be measured at time intervals of $20 \mathrm{~ms}$, which is sufficiently fast to follow the rapid adsorptions in case of high protein concentrations. 
By the analysis of the experimental data a well-defined simple model for the adsorption kinetics could be identified for surface coverage below $50 \%$ of the maximal occupancy. The adsorption rate appears to be proportional to the solute concentration of prothrombin and is transport-limited, while the desorption rates depends only on the surface coverage. For higher surface coverages determination of the adsorption and, especially, desorption rate becomes progressively less accurate but the adsorption rate still can be estimated with sufficient accuracy to conclude that it decreases significantly below the diffusion limit.

\section{MATERIALS AND METHODS}

Protein - Bovine prothrombin was purified according to (14). The concentration of prothrombin after complete activation to thrombin was determined by active site titration with $\mathrm{p}$-nitrophenyl-p'-guanidinobenzoate (15).

Phospholipid bilayers - 1,2 dioleoyl-sn-glycero-3-phosphocholine (PC) and the corresponding phosphatidylserine (PS) were purchased from Sigma and Avanti Polar Lipids respectively. Phospholipid concentrations were determined by phosphate analysis (16). Suspensions of small unilamellar vesicles (SUV) were prepared by sonication of a $40 \%$ PS / $60 \%$ PC mixture (PS-PC) as described (17). A PS-PC ( $40 \%$ PS / 60\% PC) bilayer was deposited on silicon slides (Wacker Chemie, type $n$ ), made hydrophylic by treatment with chromic-sulphuric acid and extensive cleaning, by adsorption of vesicles as described (2). The lipid covered slide was flushed with buffer and was transferred to the ellipsometer cuvette avoiding exposure to air. Experiments were performed at room temperature $\left(20-22{ }^{\circ} \mathrm{C}\right)$ in buffer (50 $\mathrm{mM}$ TRIS/ $\mathrm{HCl}, \mathrm{pH}=7.5,100 \mathrm{mM} \mathrm{NaCl}, 3 \mathrm{mM} \mathrm{CaCl} 2$ and $0.5 \mathrm{~g} /$ litre bovine serum albumin (Sigma)).

Off-null ellipsometry - Adsorption of very thin films $(0.1-10 \mathrm{~nm})$ of phospholipid or protein on a reflecting surface such as silicon results in appreciable changes of the reflection coefficients of the surface (18). Such changes can be detected by ellipsometric measurement of the change of polarization of light after reflection and this is the basis of ellipsometric determination of protein adsorption as described earlier (Chapter 1,4,19). In 
our laboratory the ellipsometer is routinely operated as nulling ellipsometer in the so called polarizer-compensator-sample-analyzer (P-C-S-A) mode. Measurements consist of the adjustment of the angles $\mathrm{P}$ and $\mathrm{A}$ of the polarizer and analyzer by stepping motors under computer control. This adjustment is such that the light intensity leaving the analyzer becomes minimal. From the changes in $\mathrm{P}$ and $\mathrm{A}$ values due to the adsorption, the adsorbed protein mass is calculated using the Lorentz-Lorenz relation $(4,19)$. One measurement cycle, however, requires movement of $\mathrm{P}$ and $\mathrm{A}$ over several degrees each way and this takes 5-10 seconds, which is much too long for adequate sampling of adsorption curves with a duration of 10-120 seconds, as studied in this paper. Faster sampling of the light intensity passing through the analyzer, while keeping polarizer and analyzer at fixed angles, is easily accomplished. This light intensity signal can be converted to mass of adsorbed protein, because reflection at silicon near the Brewster angle has the property that protein adsorptions result in a change in the null-position $P$ of the polarizer proportional to the adsorbed protein mass, while the null position $A$ of the analyzer hardly is affected.

This last property allows a simplification of the expression for the detected light intensity, c.f. Formula 5.15 (18), for the situation that the polarizer is set at fixed position $\mathrm{P}_{0}$ (out of minimum) and the analyzer in the null position $A n(0)$ of the lipid covered silicon (13). The light intensity $I(t)$, a function of the time-dependent null-positions $\operatorname{Pn}(t)$ and $A n(t)$, is then given by the following linear relation between $I(t)$ and $\cos \left(2 \cdot\left(\mathrm{P}_{0}-\mathrm{Pn}_{\mathrm{n}}(\mathrm{t})\right)\right)$ :

$I(t)=0.5 \cdot K \cdot \| 1-\cos \left(2 \cdot\left(P_{0}-P_{n}(t)\right)\right)$.

Using values $\mathrm{Pn}(0)$ (at $t=0$ ) and $\mathrm{Pn}(\mathrm{t}$ ) of the null-position of the polarizer, determined by null-ellipsometry before the start and after completion of the adsorption, the value of $\cos \left(\left(\mathrm{P}_{0}-\operatorname{Pn}(t)\right)\right.$ at intermediate times can thus be calculated by linear interpolation. Application of the Lorentz-Lorenz relation (19) shows that at an angle of incidence of $68^{\circ}$ the mass of the adsorbed protein on silicon is in good approximation equal to $\Gamma(t)=0.085 \cdot(\operatorname{Pn}(t)$ $\mathrm{Pn}(0)$ ), with $\Gamma$ expressed in $\mu \mathrm{g} / \mathrm{cm}^{2}$ and $\mathrm{Pn}$ in degrees. 
Prothrombin adsorptions - The éxperiments were performed in a hydrophobic trapezoidal quartz cuvette, treated with Sigmacote (Sigma Chemical Co., SL-2). The solution was stirred with a Teflon-coated magnetic stirrer (length $10 \mathrm{~mm}$, diameter $3 \mathrm{~mm}$ ) rotating on the bottom of the cuvette at 1-2 $\mathrm{mm}$ distance from the adsorbing slide as described in (40). The adsorption was measured behind the centre of the stir. Prothrombin was preincubated in $1 \mathrm{ml}$ of the same buffer for at least 10 min prior to the experiment and the adsorption was started by addition of the prothrombin to the cuvette containing $4 \mathrm{ml}$ buffer.

Analy sis of data - The (net) adsorption rate $V_{0}$ for a given value $\Gamma_{0}$ was calculated from the measurements $\Gamma_{i}$ at time $t_{i}$ by a local least squares fit of a second order polynomial in time, $\mathrm{p}_{2}(\mathrm{t})$, to the $\Gamma_{\mathrm{i}}$ satisfying $\Gamma_{0}-0.1 \mathrm{pmol} / \mathrm{cm}^{2}$ $<\Gamma_{\mathrm{i}}<\Gamma_{0}+0.1 \mathrm{pmol} / \mathrm{cm}^{2}$. The time $\mathrm{t}_{0}$, with $\mathrm{p}_{2}\left(\mathrm{t}_{0}\right)=\Gamma_{0}$, was determined and $\mathrm{V}_{0}$ was calculated as the derivative of $\mathrm{p}_{2}(\mathrm{t})$ at $\mathrm{t}=\mathrm{t}_{0}$. The BMDP statistical software package was used for data analysis. Linear regression was performed with the program $1 R$ and the non-linear regression of the adsorption model, c.f. Formula 2, to experimental data with the program AR.

\section{RESULTS}

The short duration of adsorptions for high prothrombin concentrations necessitates some precautions in order to minimize transient effects, e.g. due to incomplete mixing. Therefore, protein was diluted in buffer at the same temperature as the cuvette to a relatively large volume $(1 \mathrm{ml})$ before addition to the cuvette containing $4 \mathrm{ml}$ buffer. With these precautions transient effects lasted less than $0.25 \mathrm{~s}$.

Fig. 1, left panel, shows adsorbed mass versus time for prothrombin adsorptions at a PS-PC bilayer. Adsorption experiments were performed at least in duplo for prothrombin concentrations $C=30,60,120,240$ and 360 $\mathrm{pmol} / \mathrm{cm}^{3}(\mathrm{nM})$, but for clarity only single experiments for $\mathrm{C}=30,60,120$ and $360 \mathrm{pmol} / \mathrm{cm}^{3}$ are displayed. Both initial adsorption rate and final adsorbed mass increase with the prothrombin concentration. Moreover it appears that the adsorption rate for a given prothrombin concentration decreases with increasing surface coverage. The dependence of the adsorption 

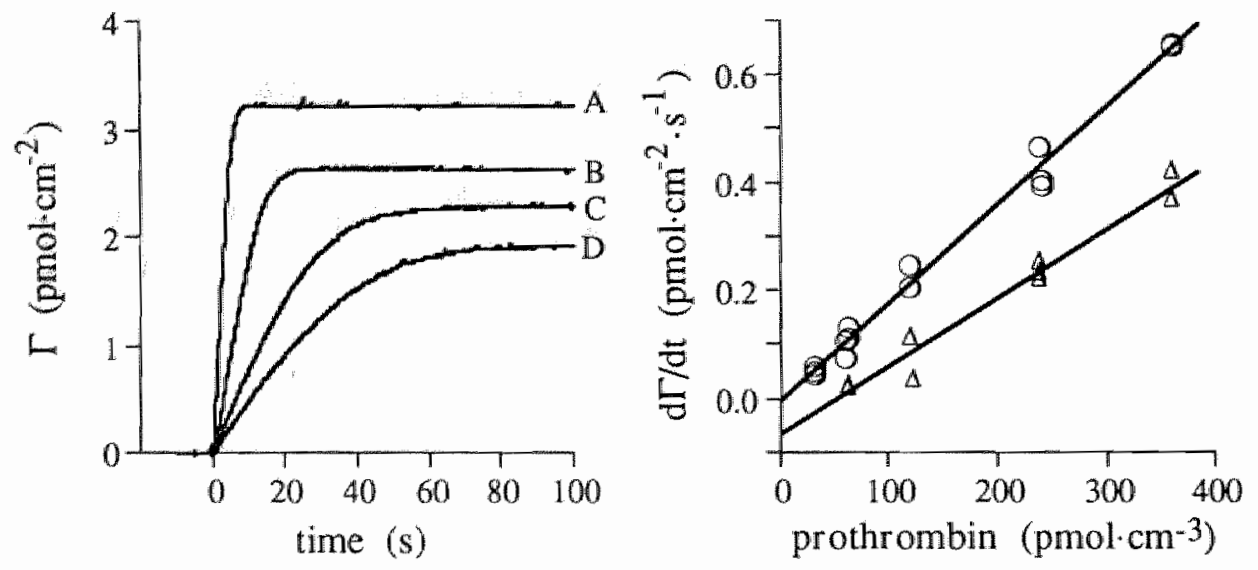

Fig. 1. Orfanull ellipsometry of prothrombin adsorptions. Adsorptions ( $\mathrm{pmol} / \mathrm{cm}^{2}$ ) of 30 (D), 60 (C), 120 (B), and 360 (A) pmol/ $\mathrm{cm}^{3}$ prothrombin at a $40 \%$ PS $/ 60 \%$ PC bilayer (left panel) are shown. The right panel shows net adsorption rates as function of the prothrombin bulk concentration of all individual adsorption curves for two values of the surface coverage, $\Gamma=0.5(O)$ and $2.5 \mathrm{pmol} / \mathrm{cm}^{2}(\Delta)$. Solid lines represent best fitting straight lines.
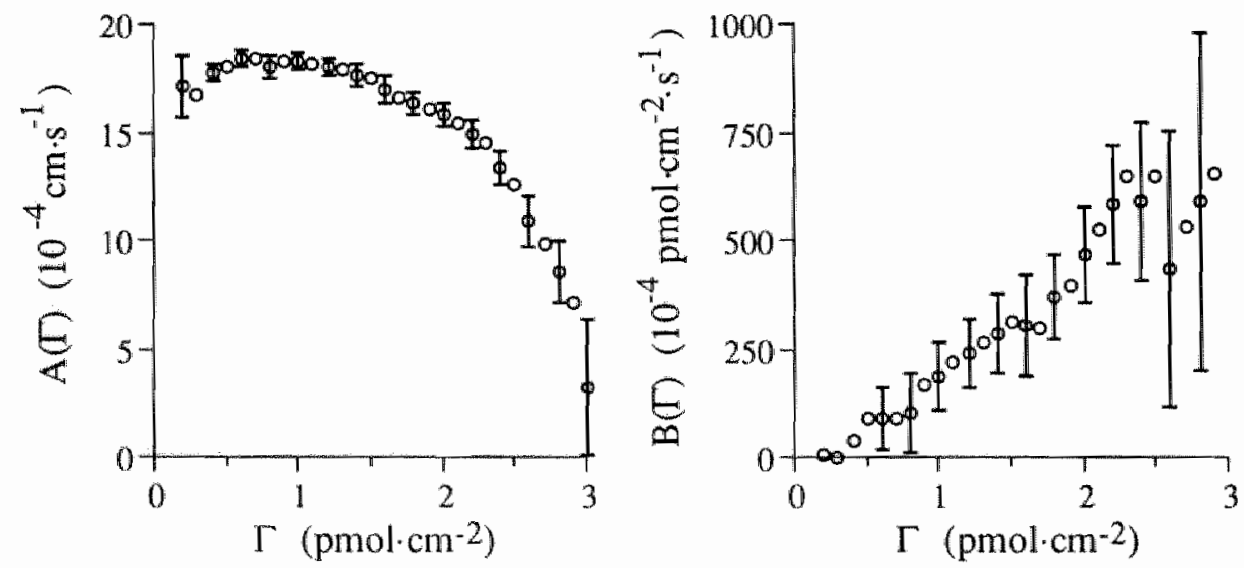

Fig. 2. Adsorption and desorption rate constants. The adsorption rate constant $A(\Gamma)$ (left panel) and the desorption rate B(r) (right panel), determined by the regression analysis in Fig. 1, are plotted versus $\Gamma$. Bars indicate standard error of the estimate (SEE). 
rate on the prothrombin concentration and surface coverage is further analyzed as indicated in the right panel of Fig. 1: For each individual adsorption curve the adsorption rate, $\mathrm{d} / \mathrm{dt} \Gamma$, was determined at a set of discrete values, $\Gamma=0.1,0.2, \ldots, 3.0 \mathrm{pmol} / \mathrm{cm}^{2}$, of surface coverage. The plot of the adsorption rate versus solution concentration $C$ is shown for $\Gamma=0.5$ and $2.5 \mathrm{pmol} / \mathrm{cm}^{2}$. Apparent is the close linear relation between the experimentally determined adsorption rate at a given surface coverage and the solution concentration $\mathrm{C}$. Consequently, adsorption kinetics can be described by

$\frac{\mathrm{d}}{\mathrm{dt}} \cdot \Gamma=\mathrm{A}(\Gamma) \cdot \mathrm{C}-\mathrm{B}(\Gamma)$

with $\mathrm{A}(\Gamma)$ the slope and $-\mathrm{B}(\Gamma)$ the offset of the regression line on the ordinate. This type of sorption kinetics can be simply interpreted. The first term on the right-hand side of this Formula, $\mathrm{A}(\Gamma) \cdot \mathrm{C}$, represents the total adsorption rate, while the second term $B(\Gamma)$ is the desorption rate. Also apparent from Fig. 1 is the increase of $\mathrm{B}(\Gamma)$ with increasing surface coverage while the slopes of the regression lines decrease for higher surface coverages.

In Fig. 2, left panel, the adsorption rate constant $A(\Gamma)$ is plotted as function of the surface coverage $\Gamma$. For surface coverages below $\Gamma<1.8$ $\mathrm{pmol} / \mathrm{cm}^{2}, \mathrm{~A}(\Gamma)$ is constant and equal to $17.8 \cdot 10^{-4} \mathrm{~cm} / \mathrm{s}$. At higher values of $\Gamma$ the adsorption rate constant $A(\Gamma)$ decreases strongly to $3.2 \cdot 10^{-4} \mathrm{~cm} / \mathrm{s}$ at $\Gamma=3.0 \mathrm{pmol} / \mathrm{cm}^{2}$, i.e. less than $20 \%$ of the value found for $\Gamma<1.8 \mathrm{pmol} / \mathrm{cm}^{2}$. The right panel of Fig. 2 shows the dependence of the desorption rate $B\left(\Gamma^{n}\right)$ upon the surface coverage. For the lower concentrations the final adsorptions remain below $\Gamma_{\max }$ and therefore successively more experiments will add no data to this range of $\Gamma$. This affects especially the estimation of the offset and causes the sharp increase in the error in the estimation of $B(\Gamma)$ for $\Gamma>2.6$ $\mathrm{pmol} / \mathrm{cm}^{2}$. Although the previous analysis results in a useful formal description of protein adsorption, the interpretation of the obtained data requires some elaboration.

For sufficiently high intrinsic adsorption and desorption rates there would exist local equilibrium between the protein concentration $\mathrm{C}_{0}$ in the solution immediately adjacent the adsorbing surface and the quantity $\Gamma$ of bound protein. If the equilibrium conforms to the Langmuir isotherm $\mathrm{C}_{0}$ is equal to $\mathrm{C}_{0}=\mathrm{K}_{\mathrm{d}} \cdot \Gamma /\left(\Gamma_{\max }-\Gamma\right)$. For a well stirred solution the depletion 
layer near the adsorbing surface is very thin $(3-10 \mu \mathrm{m})$ and diffusion and convection result in a nearly instantaneous formation of a quasi-steady state concentration profile during the protein adsorption. In this situation the transport from bulk solution to the surface is proportional to the concentration difference over the depletion layer, i.e. $\mathrm{d} / \mathrm{dt} \cdot \Gamma=\mathrm{A} \cdot\left(\mathrm{C}-\mathrm{C}_{0}\right)$, with $\mathrm{C}$ the bulk concentration and $\mathrm{A}$ a transport coefficient depending on the flow conditions and the diffusion constant of the protein $(4,20)$. Elimination of $\mathrm{C}_{0}$ results in the following expression for the adsorption rate:

$$
\frac{d}{d t} \cdot \Gamma=A \cdot\left(C-K_{d} \cdot \frac{\Gamma}{\Gamma \max -\Gamma}\right)
$$

The observation that $A(\Gamma)$ does not depend on $\Gamma$ in the range $0<\Gamma<1.8$ $\mathrm{pmol} / \mathrm{cm}^{2}$, indicates that $A(\Gamma)$ represents a rate limiting step unrelated to
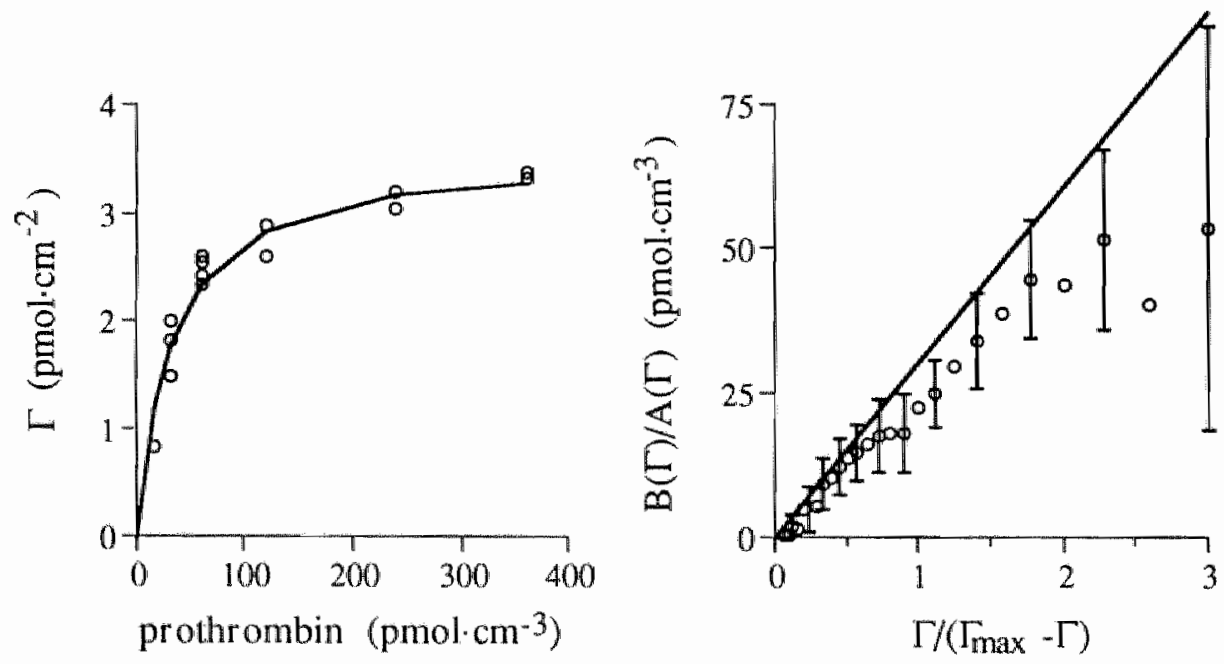

Fig. 3. Evaluation of binding constant. Left panel shows a plot of the final equilibrium adsorption $\Gamma_{\mathrm{eq}}$ as function of $\mathrm{C}$. The solid line indicates the best fitting Langmuir isotherm, with $\mathrm{K}_{\mathrm{d}}=31 \mathrm{pmol} / \mathrm{cm}^{3}(\mathrm{nM})$ and $\Gamma_{\max }=3.6 \mathrm{pmol} / \mathrm{cm}^{2}$. The right panel shows a plot of $B(\Gamma) / A(r)$ versus $\Gamma /\left(\Gamma_{\max } \cdot \Gamma\right)$. The straight line represent $K_{d} \cdot \Gamma /\left(\Gamma_{\max }-\Gamma\right)$, with $K_{d}=31$ pmol/cm ${ }^{3}$ as determined from equilibrium experiments. 
intrinsic adsorption kinetics, suggesting that $A(\Gamma)$ represents the diffusionlimit" This was confirmed by variation of the stirring rate. The value of $A(\Gamma)$ appeared to be proportional to the square root of the rotation rate of the stirrer (data not shown).

The validity of the adsorption model presented in Formula 2 was further checked in Fig. 3. Comparison of Formula 1 and 2 shows that for adsorption kinetics conforming to latter model the equality $B(\Gamma) / A(\Gamma)=$ $\mathrm{K}_{\mathrm{d}} \times \Gamma /\left(\Gamma_{\max }-\Gamma\right)$ must hold. The left panel of Fig. 3 shows the equilibrium
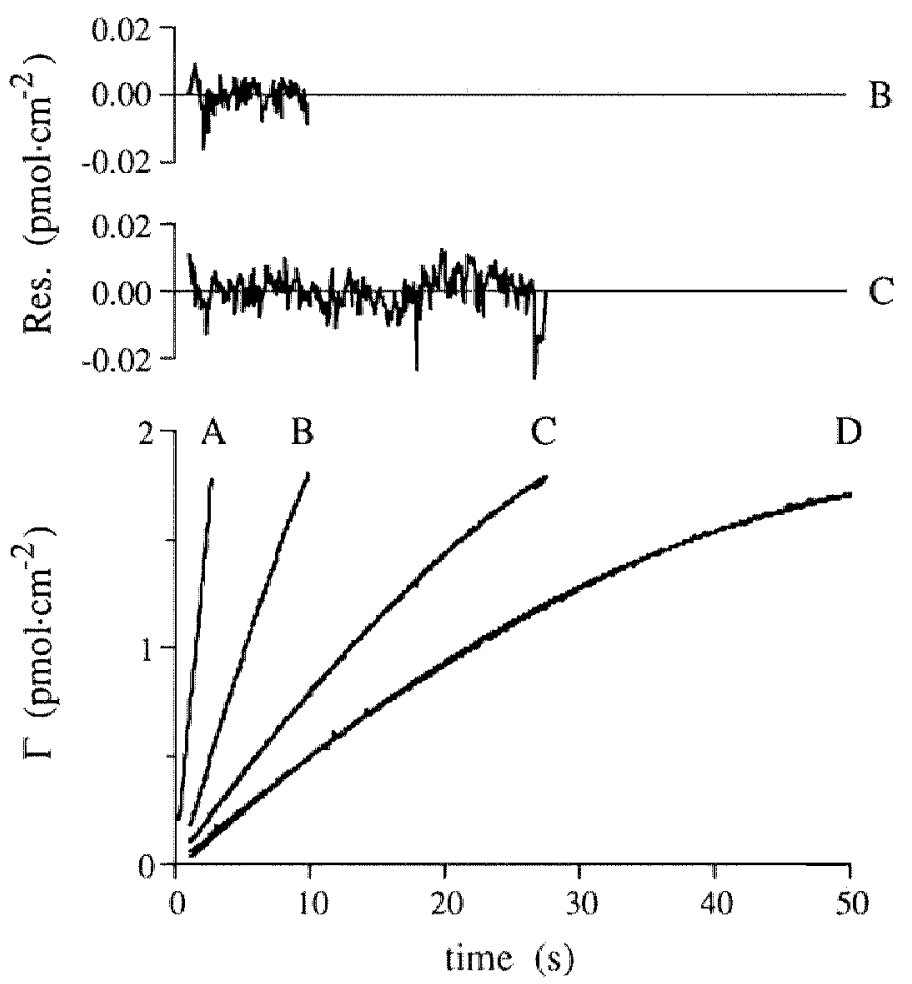

Fig. 4. Fits with adsorption model. Prothrombin adsorptions and best fitting model curves, according to Formula 2, are shown in the bottom panel for 30 (D), 60 (C), 120 (B), and $360(\mathrm{~A})$ pmol prothrombin $/ \mathrm{cm}^{3}$. The deviation (Res) between data and model are shown in the upper panels.

\footnotetext{
\# The derived variable $A$ appears equal to the fractional transport rate. This variable is termed $\Delta$ in the other Chapters of this thesis.
} 
adsorption as function of the prothrombin concentration $\mathrm{C}$. Non-linear least squares fit of the Langmuir isotherm, $\Gamma=\Gamma_{\max } \times C /\left(C+K_{d}\right)$, to these data results in a value $\mathrm{Kd}=31 \pm 4 \mathrm{pmol} / \mathrm{cm}^{3}$ for the dissociation constant and $\Gamma_{\max }$ $=3.6 \pm 0.1 \mathrm{pmol} / \mathrm{cm}^{2}$ for the maximal surface coverage. The right panel of Fig. 3 presents a replot of the data of Fig. 2 and shows a rather close linear relation between $B(\Gamma) / A(\Gamma)$ and $\Gamma /\left(\Gamma_{\max }-\Gamma\right)$ up to $\Gamma=1.8 \mathrm{pmol} / \mathrm{cm}^{2}$, with a slope of $26 \pm 1 \mathrm{pmol} / \mathrm{cm}^{3}$. No significant differences between these data and the theoretical line $K_{d} \times \Gamma /\left(\Gamma_{\max }-\Gamma\right)$ even up to surface coverages $\Gamma=2.3$ $\mathrm{pmol} / \mathrm{cm}^{2}\left(\Gamma /\left(\Gamma_{\max }-\Gamma\right)=1.8\right)$ are observed. Thus it is concluded that on the time scale of the adsorption (seconds) there exists instantaneous local equilibrium between lipid-bound and solute protein and that Formula 2 is valid up to surface coverages of $50 \%$ of $\Gamma_{\max }$.

This formalism offers the opportunity to estimate $K_{d}$ values from single adsorption curves and this was tested by performing a least squares fit, in $\mathrm{A}$ and $\mathrm{K}_{\mathrm{d}}$, of the (numerical) solution of Formula 2 to individual adsorption curves using the value $\Gamma_{\max }=3.6 \mathrm{pmol} / \mathrm{cm}^{2}$. The examples of this fit given in Fig. 4 show that the model allows accurate description of the measurements. The values $A$ and $K_{d}$ obtained from the non-linear regression analysis are given in Table 1. Apparent is the increasing error in the estimation of $\mathrm{K}_{\mathrm{d}}$ for higher prothrombin concentrations. Formula 2 shows that for higher prothrombin concentrations the model becomes less sensitive for the value of

Table I: Adsorption rate constants and dissociation constants determined from single adsorption experiments. SEE $=$ standard error of the estimate. $\mathrm{SD}=$ standard deviation [prothrombin]

A

$\left(\mathrm{pmol} / \mathrm{cm}^{3}\right)$

30

60

120

240

360

\section{$x 10^{-4}(\mathrm{~cm} / \mathrm{s})$}

$\$ 9.5$

1.1

18.7

0.6

19.1

1.7

18.8

1.7

18.6

1.1
SEE

0.05

0.04

0.16

0.16

0.07

0.01

0.11

0.02

0.10

0.03
$\mathrm{K}_{\mathrm{d}}$

SEE

$\begin{array}{lrr}\text { mean } & 18.6 & 0.10 \\ \mathrm{SD} & 1.1 & 0.03\end{array}$

$\left(\mathrm{pmol} / \mathrm{cm}^{3}\right)$

26.7

7.7

27.2

80

29.9

5.2

39.3

9.1

38.2

7.4
0.07

0.04

0.8

0.8

0.7

0.1

2.7

1.0

5.0

3.0 
$\mathrm{K}_{\mathrm{d}}$, which is reflected by the increased error in the estimation. Another complication for high concentrations is the sensitivity of the fit for the correct starting time of the adsorption. The values of $\mathrm{A}$ and $\mathrm{K}_{\mathrm{d}}$ so obtained, $c, f$. Table $I$, correspond closely to the values obtained by the analysis of Fig. 2 and 3 .

\section{DISCUSSION}

Binding parameters - The values $\mathrm{K}_{\mathrm{d}}=31 \mathrm{nM}$ and $\Gamma_{\max }=3.6 \mathrm{pmol} / \mathrm{cm}^{2}$ of the binding parameters presented in this paper agree well with earlier equilibrium measurements using null-ellipsometry (3), but deviate from results obtained from light scattering studies on prothrombin binding to SUV $(21,22)$. These studies reported an about tenfold higher value of $K_{d}=300 \mathrm{nM}$ and a maximal surface coverage $\Gamma_{\max }=14 \times 10^{-3} \mathrm{M} \cdot \mathrm{M}^{-1}$, which is about twofold higher than our value $\Gamma_{\max }=3.6 \mathrm{pmol} / \mathrm{cm}^{2}=6.0 \times 10^{-3} \mathrm{M} \cdot \mathrm{M}^{-1}$ if expressed as mole protein per mole of lipid for a mass of $0.47 \mu \mathrm{g} / \mathrm{cm}^{2}$ of the PS-PC bilayer. Differences with respect to prothrombin binding between highly curved vesicle surfaces and planar bilayers would present an obvious explanation for this discrepancy. In a recent comparison of prothrombin binding to SUV and planar bilayers, however, identical binding properties were found (13). Differences in experimental conditions, e.g. the use of eggyolk PC-brain PS $(21,22)$ instead of dioleoyl-phospholipids, execution of the experiments at $10^{\circ} \mathrm{C}(22)$ versus $22^{\circ} \mathrm{C}$, as well as experimental problems due to aggregation of vesicles with high $\mathrm{PS}$ content $(21,23)$ may contribute to the deviations.

Binding model - The data presented in Fig. 1 clearly establish the linear dependence of the adsorption rate on the prothrombin bulk concentration and the general applicability of the formalism of Formula 1. Moreover the analysis proposed in this paper allows a model-free estimation of the adsorption rate constant and desorption with a good, respectively moderate accuracy, at least for surface coverages up to $60 \%$. of $\Gamma_{\max }$. This allowed the derivation of a simple modlel, c.f. Formula 2, for the adsorption kinetics, which was based on instantaneous local equilibrium between bound prothrombin and prothrombin in solution immediately adjacent the surface. The existence of such instantaneous equilibrium is essentially equivalent to 
intrinsic adsorption kinetics being much more rapid than the transport limit, i.e. observed adsorption rates are diffusion-limited.

This conclusion is also corroborated by the observation that prothrombin adsorption to small unilamellar vesicles proceeds at about $20 \%$ of the diffusion limit with an association rate constant $k_{0}=1.7 \times 10^{7} \mathrm{M}^{-1} \cdot \mathrm{s}^{-1}$ expressed as mole prothrombin adsorption per mole prothrombin binding sites (per $\mathrm{M}$ prothrombin in solution per second) (22). For a planar bilayer with $\Gamma_{\max }=3.6 \mathrm{pmol} / \mathrm{cm}^{2}$ this intrinsic adsorption rate would imply an adsorption rate constant $A$ of $6.1 \times 10^{-2} \mathrm{~cm} / \mathrm{s}$ expressed in pmol prothrombin adsorption per $\mathrm{pmol} / \mathrm{cm}^{3}$ prothrombin in solution per second, i.e more than 30 fold higher than the adsorption rate observed in this study. However for surface coverages exceeding $2.5 \mathrm{pmol} / \mathrm{cm}^{2}$ the adsorption rate constant shows a rapid decrease, incompatible with an independent binding sites model with the cited adsorption rate constant. Such drastic effects of surface occupation on the adsorption rate have been reported earlier both for experimental studies and for model studies, incorporating size effects of the adsorbed protein molecules and the resulting surface exclusion $(4,11,24,25)$.

Conclusions - A method for the analysis of protein adsorption kinetics is presented, allowing the derivation of a simple model for the adsorption kinetics of prothrombin to phospholipid bilayers. This model can be used to estimate the dissociation constant from analysis of a single adsorption curve.

\section{ACKNOWLEDGEMENTS}

The authors thank M.P. Janssen for her expert technical assistance.

\section{REFERENCES}

1. Jackson C.M., and Nemerson Y. (1980) Am. Rev. Biochem. 49, 765-811.

2. Giesen P.L.A., Willems G.M., and Hermens W.Th. (1991) J. Bilol. Chem. 266, 13791382.

3. Kop J.M.M., Cuypers P.A., Lindhout T., Hemker H.C., and Hermens W.Th. (1984) J. Biol. Chem. 259, 13993-13998. 
4. Corsel J.W., Willems G.M., Kop J.M.M., Cuypers P.A., and Hermens W.T. (1986) J Colloid Interface Sci. 111, 544-554.

5. Gemmel C.H., Turitto V.T., and Nemerson Y. (1988) Blood 72, 1404-1406.

6. Schoen P., Lindhout T., Willems G.M., and Hemker H.C. (1990) Thromb. Heamostas. $64,542-547$.

7. Andrade J.D., and Hlady V. (1986) Adv. Polymer Sci. 79, 1.

8. Hermens W.Th., Kop J.M.M., and Willems G.M. (1988) in R.F.A. Zwaal, Coagulation and Lipids, CRC Press Inc, Boca Raton, pp. 73-97.

9. Tamm L.K., and Bartoldus I. (1988) Biochemistry 27, 7453.

10. Voegel J.C., Behr S., Mura M.J., Aptel J.D., Schmitt A., and Bres E.F. (1989) Colloids and Surfaces 40, 307.

11. Willems G.M., Hermens W.Th., and Hemker H.C. (1991) J. Biomater. Sci. Polymer. Edn. 2, 217.226.

12. Schaaf P., and Dejardin Ph. (1987) Colloids and Surfaces 24, 239.

13. Giesen P.L.A., Willems G.M., and Hermens W.Th., submitted.

14. Owen W.G., Esmon C.T., and Jackson C.M. (1974) J. Biol. Chem. 249, 594-605.

15. Chase $T_{\text {.y }}$ and Shaw E. (1969) Biochemistry 8, 2212.

16. Böttcher C.J.F., Van Gent C.M., and Pries C. (1962) Anal. Chim. Acta 24, 203-207.

17. De Kruijff B., Cullis P.R., and Radda G.K. (1975) Biochim. Biophys. Acta 406, 6-20.

18. Azzam R.M.A., and Bashara N.M. (1977) Ellipsometry and polarized light. NorthHolland Publ. Cy., Amsterdam.

19. Cuypers P.A., Corsel J.W., Janssen M.P., Kop J.M.M., Hermens W.Th. and Hemker H.C. (1983) J. Biol. Chem. 258, 2426-2431.

20. Levich V.G. (1962) Physicochemical hydrodynamics. Prentice-Hall Inc, Englewood Cliffs, N.J.

21. Nelsestuen G.L., and Broderius M. (1977) Biochemistry 16, 4172-4177.

22. Wei G.J., Bloomfield V.A., Resnick R.M., and Nelsestuen G.L. (1982) Biochemistry 21. 1949-1959.

23. Cutsforth G.A., Whitaker R.N., Hermans J., and Lentz B.R.(1989) Biochemistry 28 7453.

24. Feder J. (1980) Theor. Biol. 87, 237.

25. Schaaf P., and Talbot J. (1989) Physical Rev. Lett. 62, 175. 


\title{
Binding of Annexin V to Planar Phospholipid Bilayers
}

\author{
Harry A.M. Andree, Chris P.M. Reutelingsperger, Rudolf Hauptmann, \\ H. Coenraad Hemker, Wim Th. Hermens, and George M. Willems
}

\section{SUMMARY}

Annexin $\mathrm{V}$, previously termed Vascular anticoagulant $\alpha$ (VAC $\alpha$ ), is a member of the family of calcium and phospholipid binding proteins, the annexins. The binding properties of annexin $\mathrm{V}$ to phospholipid bilayers were studied by ellipsometry. Adsorption was calcium-dependent and completely reversible upon calcium depletion. Half-maximal adsorptions to phospholipid bilayers consisting of $100,20,5$ and $1 \%$ dioleoyl-phosphatidylserine (DOPS) supplemented with dioleoyl-phosphatidylcholine (DOPC) were reached at $\mathrm{Ca}^{2+}$ concentrations of $0.04,0.22,1.5$ and $8.6 \mathrm{mM}$. These surfaces all showed the same maximal adsorption of $0.22 \pm 0.01 \mu \mathrm{g}$ of annexin $\mathrm{V} / \mathrm{cm}^{2}$ (mean \pm S.D.). The adsorption to bilayers containing more than $10 \%$ DOPS was independent of annexin $\mathrm{V}$ concentrations in the range of $0.5-100 \mathrm{nM}$. Dissociation constants for annexin $\mathrm{V}$ binding to these surfaces were estimated to be below $2 \times 10^{-10} \mathrm{M}$. No adsorption was observed on pure DOPC bilayers at a $\mathrm{Ca}^{2}+$ concentration of $3 \mathrm{mM}$.

The ability to mediate Annexin V binding to 20\% DOPS / 80\% DOPC bilayers was highly specific for $\mathrm{Ca}^{2+}$. The use of other divalent cations resulted in decreased binding in the order $\mathrm{Cd}^{2+}>\mathrm{Zn}^{2+}>\mathrm{Mn}^{2+}>\mathrm{Co}^{2+}>\mathrm{Ba}^{2+}>\mathrm{Mg}^{2+}$. Zinc ions had a synergistic effect on $\mathrm{Ca}^{2}+$ dependent annexin $\mathrm{V}$ binding.

The $\mathrm{Ca}^{2+}$ concentration needed for half-maximal binding to cardiolipin, dioleoyl-phosphatidylglycerol, DOPS, phosphatidylinositol, phosphatic acid dioleoyl-phosphatidyl-ethanolamine and sphingomyelin increased in that order. Adsorption was independent of the overall surface charge of the phospholipid membrane. 


\section{INTRODUCTION}

Blood coagulation consists of a cascade of enzymatic reactions, resulting in the formation of thrombin, which cleaves fibrinogen into fibrin. Several procoagulant reactions, like the activation of prothrombin by factors $\mathrm{Xa}$ and $\mathrm{Va}$, are catalyzed by phospholipid surfaces to which the coagulation factors bind (1$3)$. Recently we have described the presence in vascular tissue of an anticoagulant protein VAC $\alpha$ (formerly VAC), which binds to phospholipids $(4,5)$. Protein and CDNA sequence information (6) showed $\mathrm{VAC} \alpha$ to be a member of the $\mathrm{Ca}^{2+}$ / phospholipid binding protein family including also $\mathrm{VACB}$ (7) lipocortin I $(8,9)$, calpactin I $(10,11)$, protein II (12), lipocortin III (13) and p67-calelectrin $(14,15)$. VAC $\alpha$ is identical to "inhibitor of blood coagulation" (IBC) (16), placental anticoagulant protein (PAP or PAP I) (17), placental protein 4 (PP4) (18), endonex in II (19) and lipocortin V (13). A consensus for a nomenclature of the $\mathrm{Ca}^{2+}$ /phospholipid binding proteins was recently reached: VAC $\alpha$ will be termed annexin $V$.

Proteins of this family, also termed annexins (20), show calcium dependent binding to phospholipids $(5,19,21-23)$. Consequently, these proteins interfere with phospholipid surface-dependent procoagulant reactions. For instance, Annexin $\mathrm{V}$ inhibits phospholipid dependent procoagulant reactions $(4,5,16,24,25)$ and phospholipase-A2 activity $(9,22)$. Despite these activities of the annexins demonstrated in vitro there is still no clear picture of their physiological roles. The binding to phospholipid membranes, however, is assumed to be a key feature.

This paper reports the phospholipid binding properties of recombinant annexin $V$ and shows that annexin $V$ has a high, calcium-dependent, affinity for various phospholipid surfaces. Three hypothetical binding mechanisms and the associated consequences for the physiological function are discussed. 


\section{MATERIALS AND METHODS}

Protein - Annexin $\mathrm{V}$ was prepared by cDNA recombinant techniques with plasmid pRH291, and purified as described before (6). The preparation was more than $99 \%$ pure. The only difference detected between recombinant and natural annexin $\mathrm{V}$ was an unblocked $\mathrm{N}$-terminal alanine in recombinant annexin $\mathrm{V}$, resulting in a slightly higher pI (4.9 versus 4.8 ).

Lipids - Dioleoyl-phosphatidylcholine (DOPC, no. P-1013) and dioleoylphosphatidylethanolamine (DOPE, no. P-0510) cardiolipin (CL, no. C-5646) dioleoyl-phosphatidylglycerol (DOPG, no. P-9664), phosphatidylinositol (PI, no. P-0639) dioleoyl-phosphatic acid (DOPA, no. P-2767) stearylamine (SA, S6755) and egg-yolk sphingomyelin (S-0756) were purchased from Sigma Chemical Co. Purity of DOPC and DOPE was confirmed by thin layer chromatography (26). Dioleoyl-phosphatidylserine (DOPS) was prepared by enzymatic conversion of DOPC (27). ${ }^{14} \mathrm{C}$-Labeled DOPS (specific activity = $100,000 \mathrm{dpm} \cdot \mu \mathrm{g}^{-1}$ ) was purchased from Amersham Corp.

Preparation of phospholipid bilayers on silicon slides - Phospholipid bilayers were stacked on silicon slides using a Langmuir film balance (Lauda type FW-1) as described by Corsel et al. (28). Hydrophylic silicon slides (Wacker Chemie) treated for $24 \mathrm{~h}$ with $30 \%$ chromic sulfuric acid and water were stored in $50 \%$ ethanol and water. They were thoroughly cleaned with detergent (Sparkleen) and water before use. The film balance was filled with deionized water (Millipore) and $50 \mu \mathrm{M} \mathrm{CaCl}_{2}$. A solution containing $2 \mathrm{~g} / \mathrm{l}$ phospholipid in chloroform was spread on this subphase. The DOPS fractions in stacked bilayers were checked with [1 ${ }^{4}$ C]DOPS in mixtures with DOPC. The stacked bilayers were removed from the silicon slide with a scintillation detergent (Du Pont Formula-989) and total radioactivity was measured in a Beckmann LS 3801 scintillation counter.

Stable billayers of pure DOPG, stearylamine and PI could not be obtained with the above-mentioned procedure.

Binding measurements by Ellipsometry - Adsorption of annexin V to phospholipid bilayers was studied using an automated ellipsometer $(28,29)$. Binding experiments were performed in a hydrophylic cuvette containing a final volume of $5 \mathrm{ml}$ of stirred buffer $(0.05 \mathrm{M}$ TRIS/HCl, $0.1 \mathrm{M} \mathrm{NaCl}, \mathrm{pH}=7.5, \mathrm{~T}=20$ ${ }^{\circ} \mathrm{C}$ ). Divalent cations were added step by step as chloride salts.

A continuous infusion of buffer, containing the indicated annexin $V$ 
concentration, was used in order to avoid annexin $V$ depletion of the buffer at concentrations of annexin $\mathrm{V}<0.1 \mu \mathrm{g} / \mathrm{ml}$.

The refractive index $\mathrm{n}$ and thickness $\mathrm{d}\left(10^{-8} \mathrm{~m}\right)$ of the adsorbed film were calculated from combined polarizer and analyzer readings (30). The mass $(\Gamma)$ of the adsorbed protein layer, expressed as micrograms/ $/ \mathrm{cm}^{2}$, was calculated from refractive index and thickness by a modified Lorentz-Lorenz equation (Equation 1) $(29,31)$ :

$$
\Gamma=\frac{3 d \cdot\left(n^{2}-n b^{2}\right)}{\left(n^{2}+2\right) \cdot\left(r \cdot\left(n b^{2}+2\right)-v \cdot\left(n b^{2}-1\right)\right)}
$$

where $\mathrm{n}_{\mathrm{b}}$ is the refractive index of the buffer. Values $\mathrm{r}=0.254 \mathrm{ml} / \mathrm{g}$ and $\mathrm{v}=$ $0.71 \mathrm{ml} / \mathrm{g}$ were used for the specific molar refractivity and the partial specific volume (29) of the protein.

Analysis of calcium titration curves - The maximal adsorption of annexin $V\left(\Gamma_{\max }\right)$ as shown in Table II was estimated from the $\Gamma$ intercept in the plot of $\Gamma$ versus $\left[\mathrm{Ca}^{2+}\right]^{-1}$. This value was used to calculate the calcium concentration resulting in half-maximal binding $\left[\mathrm{Ca}^{2+}\right]_{1 / 2}$. The $\mathrm{Ca}^{2+}$-dependent binding curves were analysed with a modified Hill plot of $\ln \left[\Gamma /\left(\Gamma_{\max }-\Gamma\right)\right]$ versus $\ln \left[\mathrm{Ca}^{2+}\right]$.

\section{RESULTS}

Stacking of bilayers - When a mixture of phospholipids is stacked the composition on the slide may differ from the surface composition on the trough, due to selective adherence. In order to check lipid composition on the silicon slide various mixtures of [ ${ }^{14}$ C]DOPS and DOPC were prepared, added to the film balance and subsequently stacked on the slides. The mass of the adsorbed phospholipids was measured by ellipsometry. The composition was determined after subsequent removal of the phospholipid with detergent by measuring the amount of ${ }^{14} \mathrm{C}$-label. The mass of the stacked bilayers was approximately 0.4 $\mu \mathrm{g} / \mathrm{cm}^{2}$, corresponding to $0.65 \mathrm{~nm}^{2}$ surface/molecule. Table I shows that the phospholipid composition on the silicon slide was in good agreement with the composition of the mixture spread on the Langmuir trough, which excludes a 
Table I: Evaluation of the composition of a phospholipid bilayer stacked an a silicon slide. The specific activity of $\left[{ }^{14} \mathrm{C}\right] \mathrm{DOPS}$ was $100,000 \mathrm{dpm} \mu \mathrm{g}^{-1}$. The area covered with phospholipid was $0.62 \mathrm{~cm}^{2}$.

\begin{tabular}{llcc}
\hline $\begin{array}{l}\left.{ }^{14} \mathrm{C}\right] \mathrm{DOPS} \\
\text { on film } \\
\text { balance }\end{array}$ & $\begin{array}{l}\text { Mass } \\
\text { phospholipid } \\
\text { ellipsometry }\end{array}$ & Activity & $\begin{array}{l}\text { DOPS } \\
\text { fraction } \\
\text { measured }\end{array}$ \\
\hline $\begin{array}{llc}\text { mol\% } \\
2\end{array}$ & $\begin{array}{l}\mu / \mathrm{cm}^{2} \\
5\end{array}$ & $d p m$ & $\%$ \\
5 & 0.396 & 450 & 1.9 \\
100 & 0.409 & 1130 & 4.5 \\
\hline
\end{tabular}

selective stacking behavior of DOPS.

Effect of divalent cations on the binding of annexin $V$ to phospholipids Annexin $\mathrm{V}$ bound calcium dependently to phospholipid membranes consisting of $20 \%$ DOPS / $80 \%$ DOPC. Addition of EDTA produced instantaneous and complete desorption (Fig. 1). The adsorption could be repeated several times by varying the free $\mathrm{Ca}^{2+}$ concentration without substantial changes in adsorbed

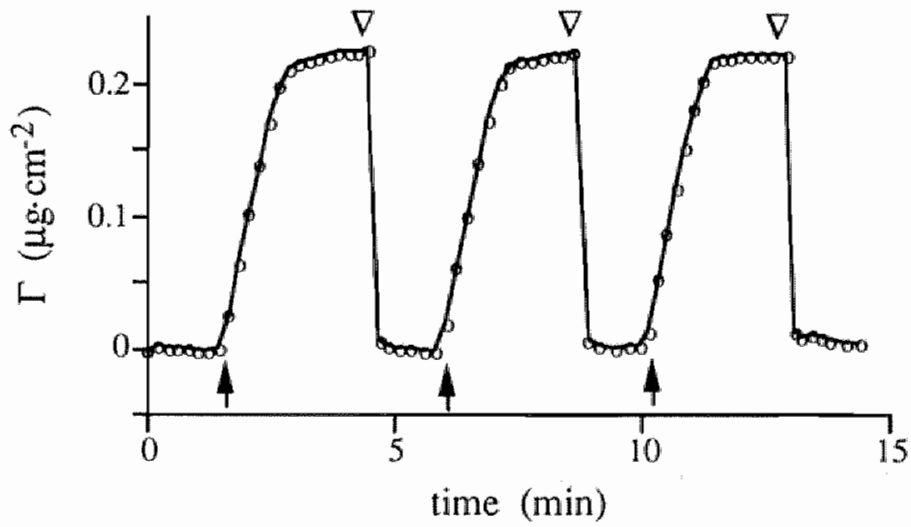

Fig. 1. Repeated adsorption and desorption of annexin V. Adsorption of annexin V (1 $\mu \mathrm{g} / \mathrm{ml})$ to a $20 \%$ DOPS $80 \%$ DOPC phospholipid bilayer. Addition of $\mathrm{Ca}^{2+}(3,4,6 \mathrm{mM})$ resulting in free $\mathrm{Ca}^{2+}$ concentrations of $3,3.5$, and $5 \mathrm{mM}$ and EDTA $(3.5,4.5,10 \mathrm{mM})$ is indicated by $\uparrow$ and $\nabla$, respectively. 
mass (S.D. $=0.001 \mu \mathrm{g} / \mathrm{cm}^{2}$ ) or adsorption rate $(\mathrm{C} . \mathrm{V} .=2 \%)$. The subsequent free $\mathrm{Ca}^{2+}$ concentrations in the experiment shown in Fig. 1 amounted to 3,3.5, and $5 \mathrm{mM}$. Similar repeated adsorptions were observed for a series of decreasing $\mathrm{Ca}^{2+}$ concentrations $3,2.5$ and $2 \mathrm{mM}$ (data not shown). This relative independence of annexin $\mathrm{V}$ adsorptions on the $\mathrm{Ca}^{2+}$ concentration in this range is consistent with data presented in Fig. 2. Irreversible changes in the annexin V molecule or the phospholipid bilayer due to the adsorption or desorption are thus unlikely. The binding of annexin $\mathrm{V}$ was also completely reversible if the cuvette was rinsed with $\mathrm{Ca}^{2+}$-free buffer.

Fig. 2 shows the effect of calcium and phospholipid composition on annexin $\mathrm{V}$ binding. These $\mathrm{Ca}^{2+}$ dose response curves are characterized by the $\mathrm{Ca}^{2+}$ concentration $\left(\left[\mathrm{Ca}^{2+}\right]_{1 / 2}\right)$ at which half-maximal annexin $\mathrm{V}$ adsorption was reached. For phospholipid bilayers consisting of $100,20,5$ and $1 \%$ DOPS, $\left[\mathrm{Ca}^{2+4}\right] 1 / 2$ values of $36 \mu \mathrm{M}, 220 \mu \mathrm{M}, 1.5 \mathrm{mM}$ and $8.6 \mathrm{mM}$ respectively, were measured (Table II). This is in good agreement with the $\left[\mathrm{Ca}^{2+}\right]_{1 / 2}$ of $53 \mu \mathrm{M}$ measured for endonexin II ( = annexin V) binding to an equimolar mixture of PS/PC vesicles (19). The maximal adsorbed mass $\left(\Gamma_{\max }\right)$ in Table II was determined by extrapolation of the calcium titration curve and was independent

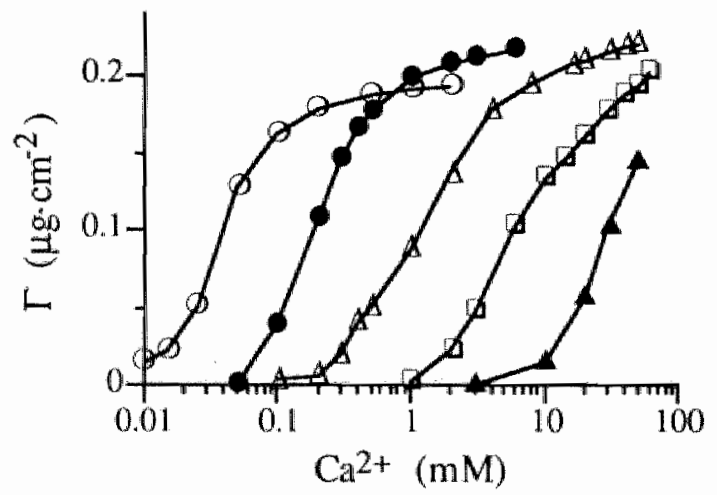

Fig 2. The influence of phospholipid composition and $\mathrm{Ca}^{2+}$ concentration on the adsorption of anmexin V. O $100 \%$ DOPS; $20 \%$ DOPS; $\triangle 5 \%$ DOPS; $91 \%$ DOPS; $100 \%$ DOPC; All mixtures were supplemented with DOPC. [Annexin $\mathrm{V}]=1 \mu \mathrm{g} / \mathrm{ml}$. 
of the DOPS fraction in the membrane and amounted to $0.22 \pm 0.01 \mu \mathrm{g} / \mathrm{cm}^{2}$ (mean \pm S.D.). The shape of the curves (an offset followed by a linear increase in $\Gamma$ with increasing $\left[\mathrm{Ca}^{2+}\right]$ ) suggests co-operativity. Analysis according to Hill, however, showed curves with decreasing slope for increasing calcium concentrations. The binding curves were very similar in shape except for a shift in horizontal direction for various phospholipids. The slope at $\left[\mathrm{Ca}^{2+}\right]_{1 / 2}$ was 1.6 \pm 0.5 (mean \pm S.D.) which is strikingly different from values reported by Schlaepfer et al. (19) for endonexin II (=annexin V).

The cation requirement was highly specific for $\mathrm{Ca}^{2}+$ (Fig. 3). Binding was only marginally promoted by $\mathrm{Cd}^{2+}, \mathrm{Zn}^{2+}, \mathrm{Mn}^{2+}$ and $\mathrm{Co}^{2+}$ and not by $\mathrm{Ba}^{2+}$ and $\mathrm{Mg}^{2+}$. The binding promoting capacity of the cation was slightly stronger if the ionic radius resembled the radius of the calcium ion $(0.99 \AA)$. This trend did not apply for zinc ions which have a relatively small ionic radius $(0.74 \AA)$. The addition of zinc resulted in comparatively large adsorption.

Table II: Maximal adsorption and calcium requirement for the binding of annexin $V$ to various phospholipid surfaces. Maximal binding $\left(\Gamma_{\max }\right)$ of Annexin $\mathrm{V}$ to the indicated phospholipid surface together with the calcium concentration that results in half maximal binding $\left[\mathrm{Ca}^{2+}\right]_{1 / 2}$ were calculated from calcium titration curves as described in "methods". Mean values $\pm S$.D. of at least 3 separate experiments are presented. ND, not determined.

\begin{tabular}{|c|c|c|c|}
\hline Lipid & $\Gamma_{\max }$ & \multicolumn{2}{|c|}{$\left[\mathrm{Ca}^{2+}\right] 1 / 2$} \\
\hline$(\mathrm{mol} / \mathrm{mol} \%)$ & $\left(\mu \mathrm{g} / \mathrm{cm}^{2}\right)$ & $m M$ & \\
\hline DOPS (100) & $0.195 \pm 0.025$ & 0.036 & \pm 0.013 \\
\hline DOPS / DOPC (20/80) & $0.222 \pm 0.014$ & 0.22 & \pm 0.06 \\
\hline DOPS / DOPC (5/95) & $0.229 \pm 0.004$ & 1.5 & \pm 0.5 \\
\hline DOPS / DOPC (1/99) & $0.234 \pm 0.007$ & 8.6 & \pm 2.5 \\
\hline Cardiolipin / DOPC (20/80) & $0.209 \pm 0.011$ & 0.039 & \pm 0.022 \\
\hline DOPG / DOPC (20/80) & $0.212 \pm 0.003$ & 0.155 & \pm 0.027 \\
\hline PI / DOPC (20/80) & $0.221 \pm 0.005$ & 0.47 & \pm 0.05 \\
\hline DOPA / DOPC (20/80) & $0.207 \pm 0.006$ & 0.75 & \pm 0.26 \\
\hline DOPE / DOPC (20/80) & $0.213 \pm 0.003$ & 0.86 & \pm 0.21 \\
\hline Sphingomyelin / DOPC (20/80) & $0.225 \pm 0.014$ & 7 & \pm 3 \\
\hline DOPC $(100)$ & ND & $>30$ & \\
\hline
\end{tabular}




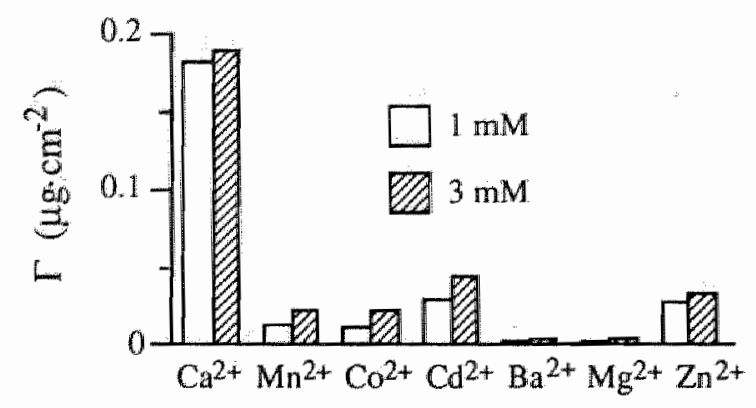

Fig.3. Effect of divalent ions on the adsorption of annexin $V$. Annexin $V$ adsorption to $20 \%$ DOPS and $80 \%$ DOPC bilayers. [Annexin $\mathrm{V}$ ] $=1 \mu \mathrm{g} / \mathrm{ml}$.

Zinc synergism - High concentrations of zinc ions $(1 \mathrm{mM})$ promote only little annexin $\mathrm{V}$ adsorption (Fig. 3), and a concentration of $50 \mu \mathrm{M}$ did not result in any adsorption. This concentration, however, strongly affected the binding in the presence of $\mathrm{Ca}^{2+}$. The value of $\left[\mathrm{Ca}^{2+}\right]_{1 / 2}$ dropped from 8.6 to $2.7 \mathrm{mM}$ for bilayers with 1\% DOPS (Fig. 4). Analysis of the calcium titration curves by the modified method of Hill resulted in similar curves as obtained in the absence of zinc ions. The slope at $\left[\mathrm{Ca}^{2+}\right]_{1 / 2}$ of $1.6 \pm 0.25$ (mean \pm S.D.) was not different from the slope in the absence of $\mathrm{Zn}^{2+}$.

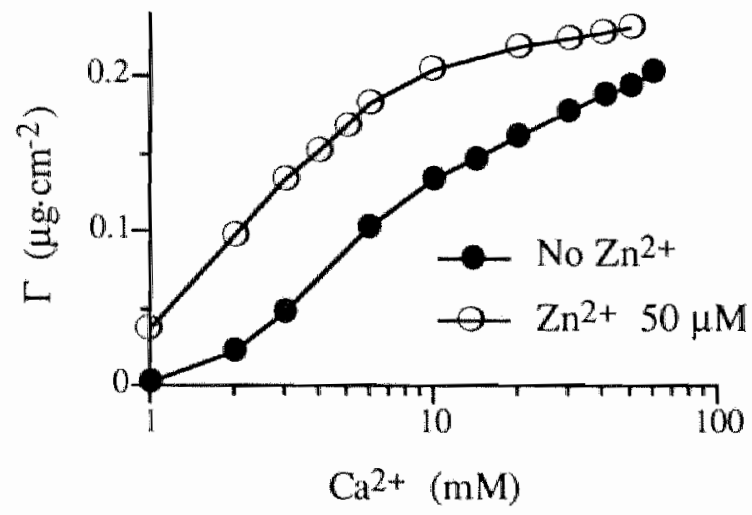

Fig 4. Synergistic effect of $\mathrm{Zn}^{2+}$ on the $\mathrm{Ca}^{2+}$ dependent adsorption of annexin $\mathrm{V}$. Adsorption of annexin $\mathrm{V}$ as a function of the $\mathrm{Ca}^{2+}$ concentration to $1 \%$ DOPS / $99 \%$ DOPC

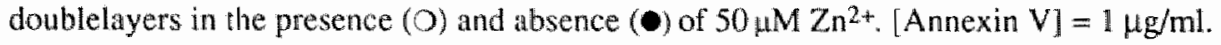




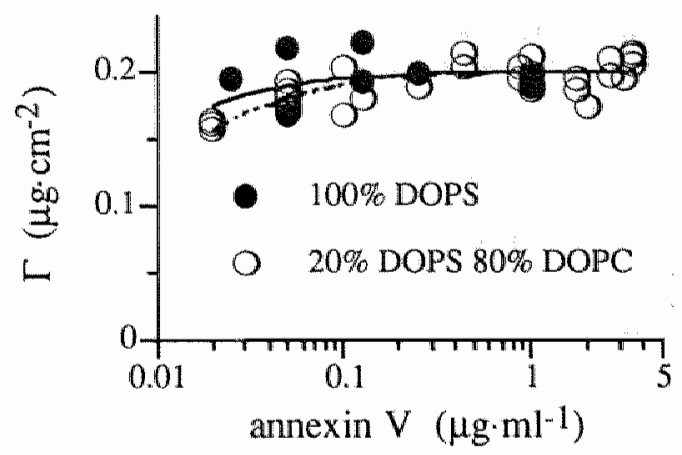

Fig. 5. Binding isotherms of annexin V. Binding of various annexin $V$ concentrations to bilayers of $100 \%$ DOPS $(\bullet)$ and $20 \%$ DOPS / $80 \%$ DOPC (O). Simulated binding isotherms for $K_{d}=1 \times 10^{-10} \mathrm{M}(\longrightarrow)$ or $K_{d}=2 \times 10^{-10} \mathrm{M}(\cdots)$ and $\Gamma_{\max }=0.20 \mu \mathrm{g} / \mathrm{cm}^{2}$ are plotted. $\left[\mathrm{Ca}^{2+}\right]=3 \mathrm{mM}$.

High affinity of annexin $V$ for phospholipids - Binding of annexin $V$ to a $20 \%$ DOPS / $80 \%$ DOPC and 100\% DOPS surfaces were measured at various annexin $\mathrm{V}$ concentrations in the presence of $3 \mathrm{mM} \mathrm{CaCl}_{2}$. As is shown in Fig. 5 the quantity of annexin $\mathrm{V}$ bound exceeded $80 \%$ of maximal $\Gamma$ at the lowest concentration tested $(0.02 \mu \mathrm{g}$ Annexin $\mathrm{V} / \mathrm{ml})$, indicating a $\mathrm{K}_{\mathrm{d}}$ value lower than $5 \times 10^{-10} \mathrm{M}$. Further lowering of annexin $\mathrm{V}$ concentrations produced practical problems since adsorption times were excessively prolonged. An estimation of the $\mathrm{K}_{\mathrm{d}}$ by extrapolation of the binding isotherms indicated a $\mathrm{K}_{\mathrm{d}}$ of approximately $10^{-10} \mathrm{M}$.

The binding of annexin $\mathrm{V}$ to a phospholipid surface was governed by the transport rate limit as revealed by analysis of binding kinetics (not shown). The rate of adsorption, therefore, was directly proportional to annexin $\mathrm{V}$ concentration. Remarkably, this turned out to be the case until a surface coverage of $90 \%$ of the maximal $\Gamma$ was reached. This binding behavior clearly contrasts with the kinetics observed for e.g. prothrombin, albumin and fibrinogen, which already show a decreased adsorption rate when about $30 \%$ of maximal surface coverage (28) is reached. This lack of effect of surface coverage on the rate of adsorption indicates high affinity of annexin $\mathrm{V}$ for phospholipids. 


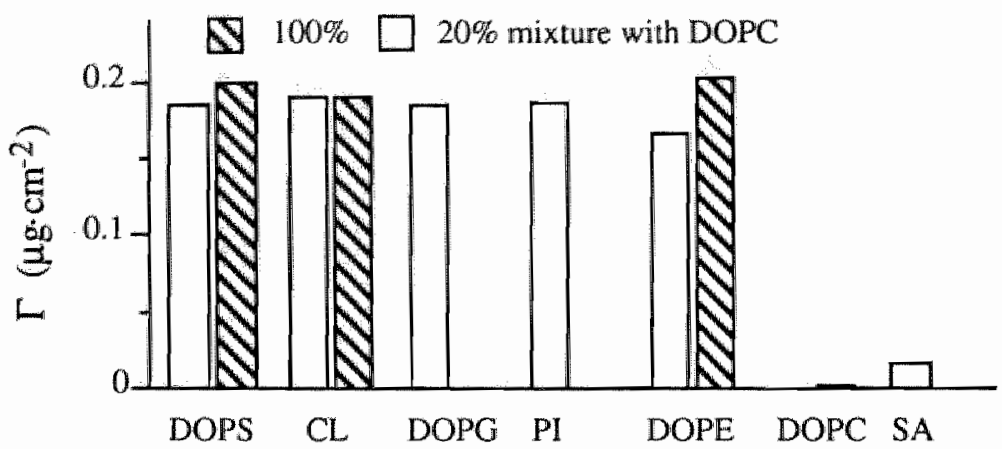

Fig 6. Adsorption of annexin $V$ to phospholipid bilayers of various composition. Annexin $V$ adsorption to DOPS, cardiolipin (CL), DOPE, DOPG, PI, and SA mixed with $80 \%$ DOPC. $[$ Annexin $V]=1 \mu \mathrm{g} / \mathrm{ml} \cdot\left[\mathrm{Ca}^{2+}\right]=3 \mathrm{mM}$.

Maximal binding of annexin $V$ - The maximal bound mass $\left(\Gamma_{\max }\right)$ of annexin $V$ was $0.22 \mu \mathrm{g} / \mathrm{cm}^{2}$ (Fig. 5). One adsorbed molecule of annexin $V$ occupies $27.4 \mathrm{~nm}^{2}$ and covers 42 molecules of phospholipid. If the molecules are spherical and are adsorbed as a closed monolayer of protein a mean molecular radius of $2.6 \mathrm{~nm}$ in the plane of adsorption can be calculated.

Effect of phospholipid composition on the binding of annexin $V$ Although the binding of annexin $\mathrm{V}$ is stimulated by the presence of DOPS (Fig. 2 ), the annexin $V$ binding is not specific for this phospholipid. Fig. 6 presents the binding of annexin $\mathrm{V}$ to Cardiolipin, DOPG, PI, DOPE, DOPC and SA at 3 $\mathrm{mM} \mathrm{Ca}{ }^{2+}$. Table II shows that $\left[\mathrm{Ca}^{2+}\right] 1 / 2$ is lipid dependent and increases if cardiolipin, DOPG, DOPS, PI, DOPA, DOPE or sphingomyelin are used. Schlaepfer et al. (19) found half-maximal binding of endonex in II (=annexin V) at calcium concentrations of $40 \mu \mathrm{M}, 53 \mu \mathrm{M}$ and $300 \mu \mathrm{M}$ for mixtures of $50 \%$ $\mathrm{PE}, 50 \% \mathrm{PS}$ and $50 \% \mathrm{PI}$ supplemented with $50 \% \mathrm{PC}$, respectively. We found half-maximal binding to $50 \%$ DOPE $/ 50 \%$ DOPC at $\left[\mathrm{Ca}^{2+}\right]_{1 / 2}=500 \mu \mathrm{M}$ (data not shown) which does not correspond to their findings. This could be due to differences in the acyl side chain of the phospholipid.

The difference in binding to DOPC and DOPE is striking. At physiological plasma calcium concentrations no binding of annexin $\mathrm{V}$ to pure DOPC was observed. DOPE is neutral or partially negatively charged at $\mathrm{pH}=7.5$ 


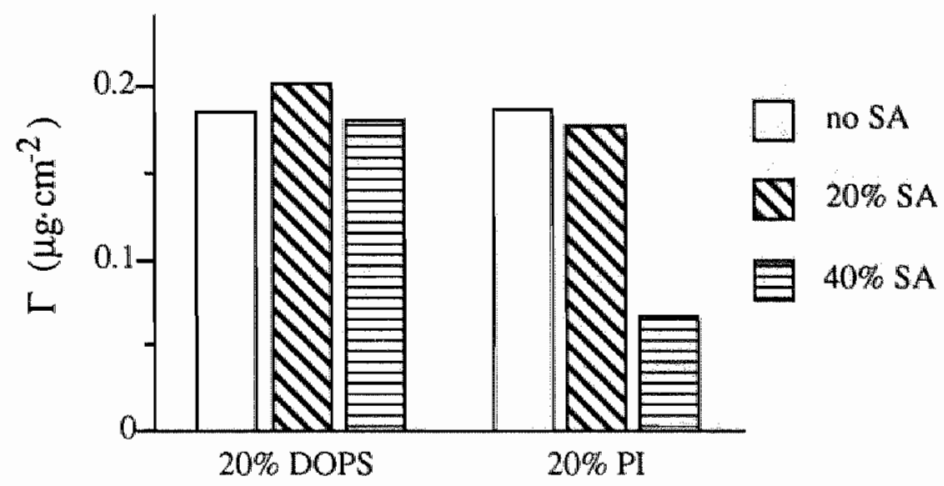

Fig. 7. Effect of the net charge of a phospholipid surface. Annexin $V$ adsorption to bilayers of $20 \%$ DOPS or $20 \%$ PI without stearylamine (SA) or mixed with $20 \%$ or $40 \%$ SA supplemented with DOPC. $[$ Annexin $\mathrm{V}]=1 \mu \mathrm{g} / \mathrm{ml}$. $\left[\mathrm{Ca}^{2+}\right]=3 \mathrm{mM}$.

and differs from DOPC in that the amine group of DOPE is not methylated. DOPE, however, showed annexin $\mathrm{V}$ binding comparable to the charged lipids, e.g. DOPA. The DOPE used in our experiments was $99 \%$ pure and not contaminated with negatively charged phospholipids (TLC).

The importance of the electrical charge of the surface was further investigated by addition of stearylamine (SA) to the phospholipid mixture. Only little adsorption to the positively charged lipid SA was observed (Fig. 6). Rosing et al. (32) showed that SA is distributed homogeneously in vesicles and can neutralize the negative charge of the surface. The procoagulant activities of these surfaces were not changed (32). As can be seen in Fig. 7 annexin $V$ binds with unchanged $\Gamma_{\max }$ to layers with a positive net charge containing $20 \%$ DOPS and $40 \%$ SA, and to uncharged layers with $20 \%$ PI and $20 \%$ SA. Onlly partial inhibition was observed when PI was mixed with a twofold molar excess of SA.

\section{DISCUSSION}

The amino acid sequence of Annexin $\mathrm{V}$ determines it as a member of the protein family of annexins (6). These proteins have closely related structures and they all show a 4-fold, or in the case of annexin VI $(14,15), 8$-fold amino acid sequence repetition in the core, which is preceded by a variable $\mathrm{N}$-terminal 
tail. Calpactin I exists as a tetramer of two heavy chains (amnexin II) and two light chains (p11) $(33,34)$. These proteins are very well preserved in various species, indicating a tight structure / function relation. A common feature is the $\mathrm{Ca}^{2+} /$ phospholipid binding ability. Although some in vitro activities of annexins are found, their true physiological functions are not yet known, but they are probably related to membrane-associated processes.

Possibility of intracellular, $\mathrm{Ca}{ }^{2+}$-dependent, binding of annexin $\mathrm{V}$ to phospholipids - If phospholipid binding is important to the intracellular function of Annexin V, binding has to occur with calcium concentrations ranging from 0.1 to $10 \mu \mathrm{M}$. In contrast to e.g. lipocortin $1(21)$ and calpactin $1(22,35)$ we found no phospholipid binding of annexin $V$ in this range even to membranes consisting of $100 \%$ DOPS. With $\left[\mathrm{Ca}^{2+}\right]_{1 / 2}$ as an indicator for the affinity of annexin $\mathrm{V}$ binding, cardiolipin shows the strongest binding. Cardiolipin is an important compound of the mitochondrial inner membrane, but the calcium concentration required for binding to $20 \%$ cardiolipin still exceeds normal intracellular levels.

These data do not prove that intracellular annexin $\mathrm{V}$ binding does not occur. Binding of other annexins can be modulated in various ways. Phosphorylation of the Tyr-21 residue of annexin I (lipocortin I) by epidermal growth factor (EGF) receptor associated kinase reduces $\mathrm{Ca}^{2}+$ requirement from $22 \mu \mathrm{M}$ to $4 \mu \mathrm{M}$ and may thus play a part in the regulation of the intracellular function of this protein (21). Monoclonal antibodies directed against the $\mathrm{N}$ terminal tail of annexin I interfere with the binding properties of the core (36). Interaction of annexin II with $\mathrm{p} 11$ increases its affinity towards PS, whereas phosphorylation of annexin II results in the opposite effect (35). Limited proteolysis of annexin I $(21,37)$ and II $(34)$ indicate that the core is important for $\mathrm{Ca}^{2+}$ and phospholipid binding but that the $\mathrm{N}$-terminal tail also affects the $\mathrm{Ca}^{2+}$ requirement.

It is unknown whether one of these modulating mechanisms exists for the annexin $\mathrm{V}$ molecule. Phosphorylation of the $\mathrm{N}$-terminal tail of annexin $\mathrm{V}$ has not yet been found. Purified antibodies against the $\mathrm{N}$-terminal tail could not be obtained nor could limited proteolysis of annexin $V$. It is as yet unknown whether there exist a protein that associates with annexin $V$. The binding of annexin $\mathrm{V}$ could, however, be influenced by the addition of small amounts of zinc. Since the zinc concentrations used in this study are within the range of normal serum concentrations (38) this synergistic effect may have physiological 
significance.

Extracellular binding of Annexin V to phospholipid surfaces - Pepinsky et al. (13) demonstrated the extracellular appearance of annexin $V$ (lipocortin V) and Grundmann et al. (18) reported the presence of Annexin $V$ (PP4) in peripheral blood. Since Annexin V lacks the classical signal sequence required for secretion it is not known whether the extracellular localization is caused by cell death or by a secretion process. The latter possibility would implicate a novel mechanism of secretion, as is believed to be true for certain growth factors (39).

Phospholipids which promote Annexin $\mathrm{V}$ binding most strongly are located in the intracellular leaflet of the plasma membrane (40). Activation of platelets or endothelial cells, or cell damage, will expose these phospholipids to the coagulation factors in plasma. These factors may be activated and thus start the coagulation cascade. The present study shows that annex in $\mathrm{V}$ concentrations exceeding $10^{-10} \mathrm{M}$ could cover these structures at the prevailing $\mathrm{Ca}^{2}+$ concentrations and thus prevent this activation. In good agreement with this finding, annexin $\mathrm{V}$ inhibits the in vitro procoagulant activity of platelets by binding to the platelet membrane (Chapter 5).

High affinity of Annexin $V$ for phospholipid surfaces - Displacement of coagulation factors at the phospholipid surface by Annexin V will occur if the $K_{d}$ values of annex in $V$ are considerably lower than the $K_{d}$ 's of the coagulation factors. For prothrombin a $\mathrm{K}_{\mathrm{d}}$ of $1.7 \times 10^{-7} \mathrm{M}$ was reported to $20 \%$ DOPS / $80 \%$ DOPC (31). This $\mathrm{K}_{\mathrm{d}}$ is at least three orders of magnitude higher than the $\mathrm{K}_{\mathrm{d}}$ of annexin $\mathrm{V}$. The $\mathrm{K}_{\mathrm{d}}$ of coagulation factor $\mathrm{Va}$ is estimated ranging from $10^{-7}$ to $10^{-11} \mathrm{M}(41,42)$. The latter value is possibly in the range of the $\mathrm{K}_{\mathrm{d}}$ of annexin V. Chapter 4 deals with the displacement of phospholipid-bound factor $\mathrm{Va}$ by annexin $\mathrm{V}$. The displacement of factors $\mathrm{Xa}$ and II on large volume vesicles by bovine annexin $\mathrm{V}$ was already shown (5). The $\mathrm{K}_{\mathrm{d}}$ of factor $\mathrm{Xa}$ is strongly dependent upon the presence of factor $\mathrm{Va}(1,43)$. Therefore the displacement of factor $\mathrm{Xa}$ will probably be related to factor $\mathrm{Va}$ binding.

For bovine annexin $V$ we earlier reported a $K_{d}$ of $6 \times 10^{-9} \mathrm{M}(5)$. This $K_{d}$ is at least one order of magnitude higher than found in the present study for human arnexin $\mathrm{V}$ obtained by recombinant DNA technique, possibly reflecting a species differences.

Models - For the annexins I, II, and IV a phospholipid binding model has been proposed (44), based on the amino acid sequence and a comparison with 
crystallographic data on calmodulin, which does not belong to the family of annexins. In this model the phosphate group of the phospholipid mollecule binds via calcium to negatively charged amino acids in a cleft in the annexin molecule. The amine group, present in e.g. PS and PE, could support this binding by interaction with other negatively charged amino acids. When this model was applied to annexin $\mathrm{V}$, it turned out that annexin $\mathrm{V}$ binding is not specific for the head of the phospholipid. Taylor and Geisow (44) already noticed that the hydrophylic head of the PI molecule is too large to fit in the cleft. The phosphate group of the phospholipid is best available if the size of the head is small. If the half-maximal calcium concentration is a good indicator of Annexin $\mathrm{V}$ binding, this concentration is expected to increase with the increasing size of the head of the phospholipids like in e.g. DOPA, DOPG and PI. In contrast to this hypothesis, however, annexin $\mathrm{V}$ needed the lowest $\mathrm{Ca}^{2+}$ concentration to bind to DOPG, then to PI and finally to DOPA. The theory of the $\mathrm{Ca}^{2+}$ binding cleft, on the other hand, could explain the specificity of the binding for $\mathrm{Ca}^{2+}$ if the size of the cleft determines the size of the binding divalent ion.

The binding of annexin $\mathrm{V}$ as function of the calcium concentration showed dependence on the lipid used only with regard to the calcium concentration needed for half-maximal occupation. The curves were similar apart from a shift along the $\log \left(\mathrm{Ca}^{2+}\right)$ axis. The curves in this study when analyzed according to Hill were non-linear, which contrasts with findings of Schlaepfer et al. (19). This difference could be caused by the large excess of protein binding sites present in the latter study, which limits the influence of protein-protein interactions on the total binding measurements. A comparable effect of protein surface coverage on the binding affinity and kinetics of prothrombin was shown earlier (28). The slope of the calcium titration curve in the presence of zinc was similar to the slope in the absence of zinc. This indicates that zinc does not occupy a calcium binding site. Treatement of annexin $\mathrm{V}$ with $\mathrm{N}$-ethyl-malamide, which metylates its cystein, abolishes the $\mathrm{Zn}^{2}+$ effect. The synergism also disappeared in an annex in $\mathrm{V}$ preparation with cys -315 replaced by a serine. This indicates that cys-315 is the $\mathrm{Zn}^{2+}$ binding site of annexin $\mathrm{V}$.

One molecule of annexin $\mathrm{V}$ occupies $27.4 \mathrm{~nm}^{2}$ surface. More than 2 molecules annexin $\mathrm{V}$ adsorb to each molecule DOPS in bilayers with only $1 \%$ DOPS. Selective stacking was ruled out with $\left[{ }^{14} \mathrm{C}\right] \mathrm{DOPS}$ (Table I) and one may 
propose three possible mechanisms to explain this observation.

Firstly, annexin V molecules may bind to PS and then interact with new annexin $V$ molecules. Such polymerization must occur in the plane of adsorption, otherwise it would not stop when the surface is covered with a monolayer annexin $\mathrm{V}$. High affinity of annexin $\mathrm{V}$ to phospholipids is explained in this model because the annexin $\mathrm{V}$-annexin $\mathrm{V}$ complex has multiple binding sites to the phospholipid surface. Polymerization other than intermolecular disulfide dimerization, has never been reported for annexin V. Near the surface, however, high protein concentrations and favorable orientation may occur, or the annexin $V$ conformation may change due to adsorption. Chapter 5 confirms the occurrence of annexin V clusters on surfaces with low curvature.

Secondly, annexin V molecules may bind to PS and then be transferred to $\mathrm{PC}$, i.e. PS could catalyze the binding to $\mathrm{PC}$. Binding to $\mathrm{PC}$ is still calcium dependent and completely reversible upon EDTA addition. No irreversible hydrophobic interaction between annexin $\mathrm{V}$ and the phospholipid layer is required.

Another possibility is that annexin $\mathrm{V}$ binds directly to $\mathrm{PC}$. This would explain the observed binding to layers of pure PC (Fig. 6). Binding to $\mathrm{PC}$ has not been described in the literature yet. It could be an artifact caused by some small contamination with acid phospholipids or hydrolysis of PC giving lysoPC and oleic acid.

During preparation of this manuscript Tait et al. (45) reported a $\mathrm{K}_{\mathrm{d}}$ of $<1$ $\times 10^{-10} \mathrm{M}$ for PAP-I to vesicles with $20 \% \mathrm{PS}$ and $80 \% \mathrm{PC}$ at ionic strength of $0.15 \mathrm{M}$. This value obtained by using fluorescence quenching measurements is consistent with our findings. However, they report a maximal binding ratio of 1 molecule PAP-I to 550 mollecules phospholipid at $0.5 \mathrm{M} \mathrm{NaCl}$. This difference in maximal binding could be a result of differences between planar phospholipid bilayers and sharply curved sonicated vesicles (See Chapter 5). The results of Tait et al. (45) support the postulated anticoagulant mechanism of annexin $\mathrm{V}(5)$.

General conclusions - The data of the present study make binding of annexin $\mathrm{V}$ unlikely under intracellular conditions. However, exposition of the phospholipids located in the intracellular membrane leaflet to extracellular conditions, also important for inducing procoagullant activity, results in annexin $\mathrm{V}$ binding under physiological conditions. If polymerization occurs, the proteinprotein-phospholipid complex will cover the surface effectively and thus 
prevent membrane associated processes of other proteins (e.g. blood coagulation). More research is needed to prove this hypothesis.

\section{REFERENCES}

1. Nesheim M. E., Taswell J. B., and Mann K. G. (1979) J.Biol.Chem. 254, 10952-10962.

2. Rosing J., Tans G., Govers-Riemslag J. W. P., Zwaal R. F. A., and Hernker H. C. (1980) J. Biol. Chem. 255, 274-283.

3. Jackson C. M., and Nemerson Y. (1980) Ann. Rev. Biochem. 49, 765-81].

4. Reutelingsperger C. P. M., Hornstra G., and Hemker H. C. (1985) Eur. J. Biochem. 151, 625-629.

5. Reutelingsperger C. P. M., Kop J. M. M., Hornstra G., and Hemker H. C. (1988) Eur. J. Biochem. 173, 171-178.

6. Maurer-Fogy I., Reutelingsperger C. P. M., Pieters J., Bodo G., Stratowa C., and Hauptmann R. (1988) Eur.J Biochem. 174, 585-592.

7. Hauptmann R., Maurer-Fogy I., Krystek E., Bodo G., Andree H. A. M., and Reutelingsperger C. P. M. (1989) Eur.J.Biochem. 185, 63-71.

8. Huang K. S., Wallner B. P., Mattaliano R. J., Tizard R., Burne C., Frey A., Hession C., McGray P., Sinclair L. K., Chow E. P., Browning J. L., Ramachandran K. L., Tang J., Smart J. E., and Pepinsky R. B. (1986) Cell 46, 191-199.

9. Wallner B. P., Mattaliano R. J., Hession C., Cate R. L., Tizard R., Sinclair L. K., Foeller C., Chow E. P., Browning J. L., Ramachandran K. L., and Pepinsky, R. B. (1986) Nature 320,77-81.

10. Saris C. J. M., Tack B. F., Kristensen T., Glenney J. R., and Hunter T. (1986) Cell 46, $201 \times 212$.

11. Kristensen T., Saris C. J. M., Hunter T., Hicks L. J., Noonan D. J., Glenney J. R., and Tack B. F. (1986) Biochemistry 21, 4497-4503.

12. Weber K., Johnsson N., Plessmann U., Van P. N., Söling H. - D., Ampe C., and VandeKerckhove J. (1987) EMBO J. 6, 1599-1604.

13. Pepinsky R.B., Tizard R., Mattaliano R.J., Sinclair L.K., Miller G.T., Browning J.L., Chow E.P., Burne C., Huang K.-S., Pratt D., Wachter L., Hession C., Frey A.Z., and Wallner B.P. (1988) J.Biol.Chem. 263, 10799-10811.

14. Südhof T.C., Slaughter C.A., Leznicky I., Barjon P., and Reynolds G.A. (1988) Proc. Narl Acad. Sci USA 85, 664-668.

15. Crompton M.R., Owens R.J., Totty N.F., Moss S.E., Waterfield M.D., and Crumpton M.J. (1988) EMBO.J. 7, 21-27. 
16. Iwasaki A., Suda M., Nakao H., Nagoya T., Samo Y., Arai K., Mizoguchi T., Sato F. Yoshizaki H., Hirata M., Miyata T., Shidara Y., Murata M., and Maki M. (1987) J.Biochem. (Tokyo) 102, 1261-1273.

17. Funakoshi T., Hendrickson L.E., McMullen, B.A., and Fujikawa K. (1987) Biochemistry 26, 8087-8092.

18. Grundmann U., Abel K.-J., Bohn H., Löbermann H., Lottspeich F., and Küper H. (1988) Proc. Natl. Acad. Sci. USA 85, 3708-3712.

19. Schlaepfer D.D., Mehlman T., Burgess W.H., and Haigler H.T. (1987) Proc. Natl. Acad. Sci. USA 84, 6078-6082.

20. Geisow M.J. (1986) FEBS. lett. 203, 99-103.

21. Schlaepfer D.D., and Haigler H.T. (1987) J.Biol.Chem 262, 6931-6937.

22. Davidson F.F., Dennis E.A., Powell M., and Glenney J.R. (1987) J Biol.Chem. 262, 1698-1705.

23. Tait J.F., Sakata M., McMullen B.A., Mao C.H., Funakoshi T., Hendrickson L.E., and Fujikawa K. (1988) Biochemistry 27, 6268-6276.

24. Funakoshi T, Heimark R.L., Hendrickson L.E., McMullen B.A., and Fujikawa K. (1987) Biochemistry 26, 5572-5578.

25. Kondo S., Noguchi M., Funakoshi T., Fujikawa K., and Kisiel W. (1987) Thromb. Res. 48, 449-459.

26. Renkonen O., and Luukkonen A. (1976) Lipid chromatographic analysis, vol 1 .

27. Comfurius P., and Zwaal R.F.A. (1977) Biochim. Biophys. Acta 488, 36-42.

28. Corsel J.W., Willems G.M., Kop J.M.M., Cuypers P.A., and Hermens W.Th. (1986) J. Colloid Interface Sci. 111, 544-554.

29. Cuypers P.A., Corsel J.W., Janssen M.P., Kop J.M.M., Hermens W.Th., and Hemker, H.C. (1983) J. Biol. Chem. 258, 2426-2431.

30. McCrackin F.L., Passaglia E., Stromberg R.R., and Steinberg H.L. (1963) J. Res. Nat. Bur. Srand. Sect. A 67, 3-7.

31. Kop J.M.M., Cuypers P.A., Lindhout Th., Hemker H.C., and Hermens W.Th. (1984) J. Bial. Chem. 259, 13993-13998.

32. Rosing J., Speijer H., and Zwaal R.F.A. (1988) Biochemistry 27, 8-11.

33. Gerke V., and Weber K. (1984) EMBO.d. 3, 227-233.

34. Glenney J. (1986) J Biol.Chem. 261, 7247-7252.

35. Powell M.A., and Glenney J.R. (1987) Biochem. J. 247, 321-328.

36. Glenney I., and Zokas L. (1988) Biochemistry 27, 2069-2076.

37. Huang K.-S., McGray P., Mattaliano R.J., Burne C., Chow E.P., Sinclair L.K., and Pepinsky R.B. (1987) J.Biol.Chem. 262, 7639-7645.

38. Braunwald E. „Isselbacher K.J., Petersdorf R.G., Wilson J.D., Martin J.B., and Fauci A.S. (1987) Harrison's principles of internal medicine, 11 th ed.,pp. 419-420 and A3, 
McGraw-Hill Book Co., New York.

39. Burgess T.L. and Kelly R.B. (1987) Ann. Rev. Cell Biol. 3, 243-293.

40. Op den Kamp J.A.F. (1979) Ann.Rev.Biochem. 48, 47-71.

41. Bloom J.N., Nesheim M.E., and Mann K.G. (1979) Biochemistry 18, 4419-4425.

42. Pusey M.L., Mayer L.D., Wei G.J., Bloomfield V.A., and Nelsestuen G.L. (1982)

Biochemistry 21, 5262-5269.

43. Waart van de $P_{.}$Bruls H., Hemker H.C., and Lindhout Th. (1983) Biochemistry 22, 2427-2432.

44. Taylor W.R., and Geisow M.J. (1987) Protein Engineering 1, 183-187.

45. Tait J.F., Gibson D., and Fujikawa K. (1989) J. Biol. Chem. 264, 7944-7949. 




\section{Displacement of Factor Va by Annexin $V$}

Harry A.M. Andree, Wim Th. Hermens, H. Coenraad Hemker, and George M. Willems

\section{SUMMARY}

Annexin $V$, a protein present in large quantities in endothelial cells, inhibits prothrombinase activity by high affinity binding to phospholipid surfaces. However, one of the constituents of the prothrombinase complex, blood coagulation factor $\mathrm{Va}$, has a similarly high affinity for such surfaces. Ellipsometry was used to address the question whether annexin $\mathrm{V}$ was able to displace factor Va from a $20 \%$ phosphatidylserine $/ 80 \%$ phosphatidylcholine (PS/PC) surface. Annexin V, in contrast to factor Va, desorbes from this surface if the calcium concentration is decreased below $50 \mu \mathrm{M}$. This difference was used to estimate the displacement of factor $\mathrm{Va}$ by annexin $\mathrm{V}$. Displacement was virtually complete $(>97 \%)$, and independent of the annexin $\mathrm{V}$ concentration (5-1000 $\mathrm{nM}$ ). The displacement kinetics were studied with off-null ellipsometry. It appears that the initial annexin $\mathrm{V}$ adsorption rate to a bilayer with $30-40 \%$ of maximal surface coverage preadsorbed factor $\mathrm{Va}$ proceeds unhindered until a normalized surface coverage, expressed as $\sigma=$ $\left(\Gamma / \Gamma_{\max }\right)_{\text {annexin }} \mathrm{v}+\left(\Gamma / \Gamma_{\max }\right)$ factor $\mathrm{Va}_{\mathrm{a}}$, exceeds 0.75 . The desorption rate of factor $\mathrm{Va}$ at the final part of the desorption curve $\left(\Gamma_{\text {factor }} \mathrm{Va}<0.03 \mu \mathrm{g} / \mathrm{cm}^{2}\right)$ proved independent of the annexin $\mathrm{V}$ concentration. This allowed estimation of the intrinsic desorption rate constant $\left(k_{\text {off }}\right)$ of factor $V a: k_{\text {off }}=0.023 \mathrm{~s}^{-1}$. Combining this result with the measured apparent adsorption and desorption rates of factor $\mathrm{Va}$, the dissociation constant $\left(\mathrm{K}_{d}=0.1 \mathrm{nM}\right)$ and the intrinsic adsorption rate constant $\left(k_{o n}=10^{9} \mathrm{M}^{-1} \cdot \mathrm{s}^{-1}\right)$ were obtained. 


\section{INTRODUCTION}

Factor $V a$ plays a pivotal role in effective prothrombin conversion. Once bound to phospholipid, it provides a high affinity binding site $\left(\mathrm{K}_{\mathrm{d}}=1-50\right.$ $\left.x \cdot 10^{-12} \mathrm{M}\right)$ to factor $X a$, the prothrombin converting enzyme (1-3). Binding of factor $X a$ to factor Va results in a large increase (2000 times) in the prothrombin conversion rate by factor $\mathrm{Xa}\left(\mathrm{k}_{\mathrm{cat}}=4000 \mathrm{~min}^{-1}\right)(4,5)$. Factor $\mathrm{Va}$ also protects the prothrombinase activity of factor $\mathrm{Xa}$ against inhibition by the phospholipid binding prothrombin activation peptides, fragments 1 , and 1$2(6)$.

Annexin $\mathrm{V}$, formerly called vascular anticoagulant alpha (VAC $\alpha$ ), is a $36 \mathrm{kDa}$ protein discovered in vascular tissue as a potent inhibitor of phospholipid dependent reactions in blood coagulation $(7,8)$. Various names (VAC $\alpha$, PAP-I, PP4, endonex in II, IBC, calphobindin I) were employed for this protein (9). In plasma both the extrinsic and intrinsic pathway of blood clotting are inhibited by annexin $V(7,10)$. In purified systems thrombin formation by prothrombinase (phospholipid, factor $\mathrm{Va}$, factor $\mathrm{Xa}, \mathrm{Ca}^{2+}$ ) and by phospholipid-bound factor $\mathrm{Xa}$, but not by factor $\mathrm{Xa}$ in the absence of phospholipids, is inhibited by annexin V. Annexin V, however, does not interfere with thrombin mediated conversion of fibrinogen and does not prolong clotting time in thrombin activated plasma. No interaction (binding) between annexin $\mathrm{V}$ and factor $\mathrm{Xa}$ could be demonstrated (10) and no proteolytic activity of annexin $\mathrm{V}$ is involved (7). Thus, the anticoagulant mechanism of annexin $\mathrm{V}$ differs from the other known regulators of blood coagulation, the SERPINS (e.g. antithrombin III) and activated protein C, that attack the activated clotting factors directly, $c f$. (11) for a review. These observations indicate that the anticoagulant action of annexin $\mathrm{V}$ resides in its interference with the phospholipid binding of clotting factors, as was postulated in the first report on this protein (7).

This mode of inhibition fits well with the known high affinity $\left(\mathrm{K}_{\mathrm{d}}<\right.$ $10-10 \mathrm{M}$ ) of annexin $\mathrm{V}$ to $20 \%$ phosphatidylserine / $80 \%$ phosphatidylcholine at $3 \mathrm{mM} \mathrm{Ca}^{2+}(12-14)$. In comparable circumstances, the binding affinity of clotting factors $\mathrm{II}$ (prothrombin) and $\mathrm{Xa}$ to phospholipids is several orders lower $\left(K_{d}=10^{-7} \mathrm{M}\right), c f$. (15) for a review. Thus it can be anticipated that annexin $\mathrm{V}$ displaces these clotting factors from the lipid, as was indeed 
demonstrated $(8,16)$. For factor $V a$ and factor $V$, however, a similarly high affinity binding, with $\mathrm{K}_{\mathrm{d}}=1-5 \times 10^{-11} \mathrm{M}(17,18)$ is reported.

This study therefore investigated whether annexin $\mathrm{V}$ is able to displace factor $\mathrm{Va}$ from the PS/PC membrane. We demonstrate that annexin $\mathrm{V}$ indeed displaces $>97 \%$ of factor $\mathrm{Va}$ from phospholipid membranes. The rapid displacement kinetics as function of the annexin $V$ concentration were studied by off-null ellipsometry. Initial adsorption kinetics of annexin $V$ were identical to observed kinetics on bare PS/PC bilayers, with a diffusion limited adsorption rate proportional to the annexin $\mathrm{V}$ bulk concentration. The factor $\mathrm{Va}$ desorption rates could be estimated from the terminal mono-exponential part of the displacement curve, which appeared to be independent of the annexin $\mathrm{V}$ concentration and thus corresponds to the intrinsic desorption rate of factor $\mathrm{Va}$.

\section{MATERIALS AND METHODS}

Materials - 1,2-dioleoyl-3-sn-glycero-phosphatidylcholine (PC) (P1013) was purchased from Sigma Chemical (St. Louis) and the corresponding phosphatidylserine (PS) from Avanti Polar Lipids (Alabama).

Buffer - All experiments were performed in buffer: $50 \mathrm{mM}$ TRIS/HCl, $\mathrm{pH}=7.5,100 \mathrm{mM} \mathrm{NaCl}, 3 \mathrm{mM} \mathrm{CaCl}_{2}$, and $0.5 \mathrm{~g} / \mathrm{l}$ bovine serum albumin (Sigma A-7030) at $20^{\circ} \mathrm{C}$, unless stated otherwise.

Preparation of phospholipid vesicles and bilayers - All experiments were performed with mixtures of $20 \%$ PS and $80 \%$ PC. Small unilamellar vesicle solutions were prepared as described (19). Silicon slides (Wacker Chemie) were made hydrophylic (14) and phospholipid bilayers were adsorbed on the slides by dipping them in a stirred vesicle solution (20).

Proteins - Recombinant annexin V was purified from E. coli HB 101 transformed with plasmid pRH291, containing the complete coding region of human annexin $\mathrm{V}$, as described in ref. (12). Clotting factor $\mathrm{V}$ was prepared from bovine blood as described by Lindhout (2). Factor Va was obtained by activation of factor $\mathrm{V}$ with thrombin and the concentration was determined by assessment of prothrombinase activity with an excess factor $\mathrm{Xa}$, prothrombin and phospholipid (2). 
Ellipsometric determination of protein adsorption - Binding experiments were performed at $20^{\circ} \mathrm{C}$ in a trapezoidal quartz cuvette, treated with Sigmacote (SL-2, Sigma Chemical Co.) in order to avoid protein depletion (21). The solution was stirred with a Teflon-coated magnetic stirrer (length $0.8 \mathrm{~cm}$, diameter $2 \mathrm{~mm}$ ) at 1800 rotations per minute. The quantity of protein adsorbed at the phospholipid bilayer on the silicon slide was measured every $7.10 \mathrm{~s}$ with an automated null-ellipsometer as described earlier $(21,22)$ (Fig. 1 and 2). Off-null ellipsometry (Chapter 2) was used for the accurate assessment of adsorption and displacement kinetics. Briefly: The change in reflected light intensity, due to adsorption is measured (every $20 \mathrm{~ms}$ ). Polarizer values were interpolated from measurements of light intensity and converted into adsorbed mass.

\section{RESULTS}

Comparison of adsorptions of annexin $V$ and factor Va-Adsorptions of annexin $\mathrm{V}$ and factor $\mathrm{Va}$ to a PS/PC bilayer were compared with nullellipsometry. Fig. 1 left panel shows the binding of annexin $V(30 \mathrm{nM})$ to a PS/PC bilayer. The adsorption stabilized at the maximal surface coverage $\left(\Gamma_{\max }\right)$ of $0.21 \mu \mathrm{g} / \mathrm{cm}^{2}, c f$. ref (14). Flushing the cuvette with buffer had virtually no effect on the adsorbed mass. Addition of excess EDTA, however, resulted in nearly instantaneous and virtually complete desorption of annex in $V$. The final adsorbed mass after addition of EDTA was $0.006 \pm 0.006 \mu \mathrm{g} / \mathrm{cm}^{2}$ (mean \pm S.D., $n=9$ ) below the mass of the original billayer. Fig. 1 right panel shows the adsorption of factor $2.5 \mathrm{nM}$ Va to a PS/PC bilayer. The $\Gamma_{\max }$ of factor Va to PS/PC (20/80) was $0.40 \mu \mathrm{g} / \mathrm{cm}^{2}$, equal to $2.5 \mathrm{pmol} / \mathrm{cm}^{2}$, or 4.7 $\mathrm{mmol} \mathrm{Va} / \mathrm{mol}$ phospholipid (data not shown). Flushing the cuvette with buffer produced a slow desorption $\left(\mathrm{t}_{1} / 2=1.5\right.$ hours). Addition of EDTA induced a negligible extra desorption, probably caused by dissociation of the heavy and light chain of factor Va. 

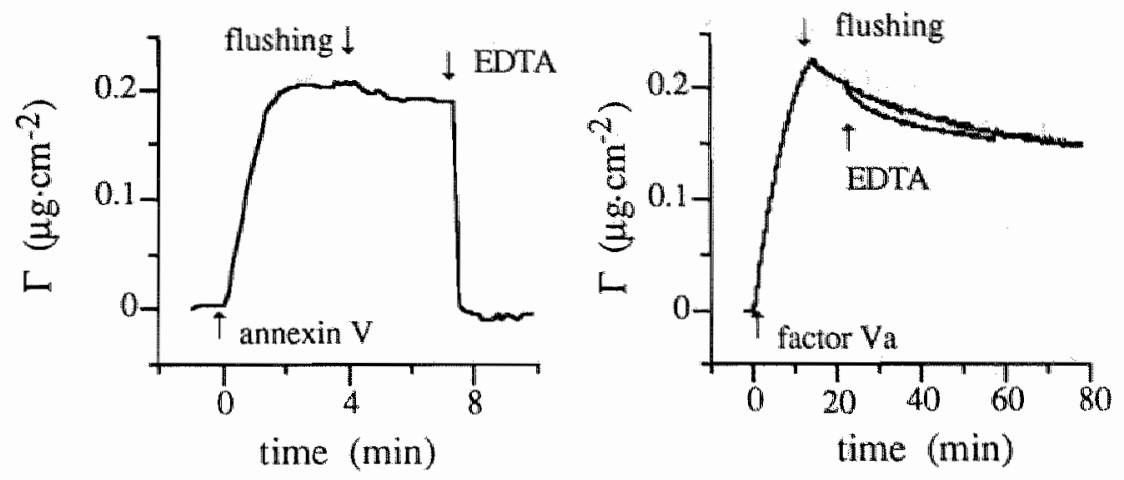

Fig. 1. Comparison of annexin $\mathrm{V}$ and factor $\mathrm{Va}$ adsorptions. Left panel: Adsorption of annexin V to a PS/PC bilayer. Adsorption was started by addition of $30 \mathrm{nM}$ annexin $\mathrm{V}$, after 8 min annexin $V$ was removed from the cuvette by flushing and after 11 min EDTA was added to a final concentration of $6 \mathrm{mM}$. Right panel: Adsorption of factor Va to a PS/PC bilayer. Adsorption was started by addition of $2.5 \mathrm{nM}$ factor Va. After $13 \mathrm{~min}$ factor Va was removed by flushing. In an additional experiment $6 \mathrm{mM}$ EDTA was added after $22 \mathrm{~min}$.
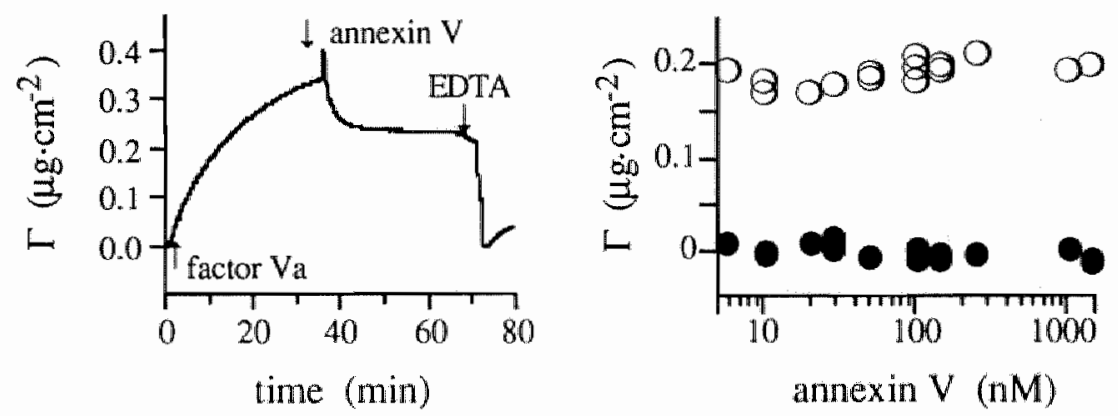

Fig. 2. Factor Va displacement. Left panel: Factor Va adsorption was started by addition of $2.5 \mathrm{nM}$ factor $V$ a to the cuvente. After $35 \mathrm{~min} 50 \mathrm{nM}$ annexin $V$ was added. followed by $6 \mathrm{mM}$ EDTA after $73 \mathrm{~min}$. Right panel: The adsorbed mass of experiments as presented in the left panel just before (O) and after $(\bullet)$ addition of EDTA are plotted as function of the annexin $V$ concentration.

Displacement of factor $V a$ by annexin $V$ - The different effects of EDTA on the desorption of annexin $\mathrm{V}$ and factor $\mathrm{Va}$, shown in Fig. 1, were used to estimate the amount of factor $V$ a that could be displaced by Annexin V. In Fig. 2 left panel, first factor $\mathrm{Va}(2.5 \mathrm{nM})$ was adsorbed to the bilayer. After 35 minutes annexin $V$ was added $(50 \mathrm{nM})$. This resulted in a transient 
extra adsorption of annexin $V$ followed by a spontaneous decrease in total mass. The final adsorbed mass of $0.20 \pm 0.02 \mu \mathrm{g}$ protein $/ \mathrm{cm}^{2}$ is identical to the $\Gamma_{\text {max }}$ of annexin $V$, and is independent of the factor $V a$ concentration $(0.25$ $2.5 \mathrm{nM}$, data not shown) and annexin $\mathrm{V}$ concentration (Fig. 2 right panel). This suggests that the final adsorbed protein consists predominantly of annexin $V$, as was confirmed by addition of EDTA after equilibration. The elimination of calcium by EDTA causes complete desorption of annexin $\mathrm{V}$ followed by a slow readsorption of factor $\mathrm{Va}$ and/or factor $\mathrm{Va}$ light chain (Fig. 2 left panel).

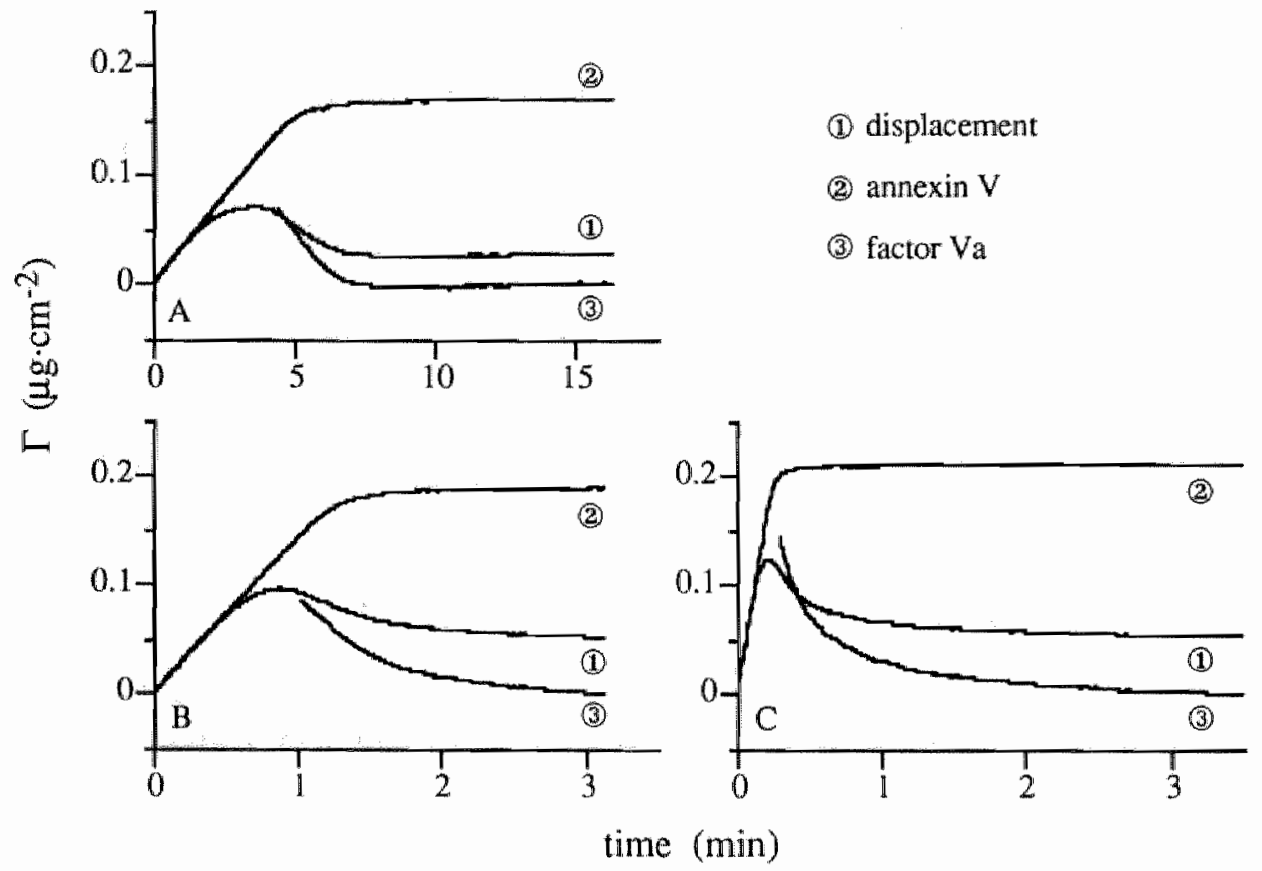

Fig. 3. Factor Va desorption curves. Total adsorption curves ( $\left.\Gamma_{\text {factor }} \mathrm{Va}+\Gamma_{\text {annexin }} v\right)$ measured with off-null ellipsometry with displacement peak (1). The zero level of these adsorptions represents $0.14-0.17 \mu \mathrm{g} \cdot \mathrm{cm}^{-2}$ preadsorbed factor $\mathrm{Va}$. The corresponding annexin $V$ adsorptions to a bare phospholipid surface are also shown. The final part of the factor $\mathrm{Va}$ (3) desorption curves was calculated as the difference curve (See text). A, upper panel: $10 \mathrm{nM}$ annexin V; B, lower left panel: $50 \mathrm{nM}$ annexin V; C lower right panel: $250 \mathrm{nM}$ annexin V. (Note the different time scale for the upper panel). 
Desorption of annexin $\mathrm{V}$ was nearly instantaneous and the minimum in adsorbed mass was attained within 15 seconds after addition of EDTA. This minimum in adsorbed mass was used as estimation of the retained mass at the surface, which within experimental error was equal to the mass of the original PS/PC bilayer $\left(-0.008 \pm 0.007 \mu \mathrm{g} / \mathrm{cm}^{2}\right)$ (Fig. 2 right panel). With an estimated experimental accuracy of $0.01 \mu \mathrm{g} / \mathrm{cm}^{2}$, these observations demonstrate that annexin $\mathrm{V}$ displaces at least $97 \%$ of adsorbed factor $\mathrm{Va}$.

Sorption kinetics of transient displacement peaks - The transient adsorption kinetics were studied further by off-null ellipsometry. First factor $\mathrm{Va}$ was adsorbed to a surface coverage of $0.8-1 \mathrm{pmol} / \mathrm{cm}^{2}$, whereupon the adsorption was stopped by flushing the cuvette with $20 \mathrm{ml}$ buffer. Fig. 3 shows "displacement peaks" as presented in Fig. 2, i.e. the mass of preadsorbed factor Va was subtracted from total adsorbed protein mass after addition of annexin $\mathrm{V}$. The rapid initial adsorption of annexin $\mathrm{V}$ is apparent. Fig. 4 shows that the initial adsorption rate of annexin $V$ to preadsorbed factor $V$ a equals the transport-limited adsorption rate $(\Delta)$ of annexin $V$ to the slide. Apparently, annexin $V$ adsorption is initially not affected by preadsorbed factor $\mathrm{Va}$ and no substantial desorption of factor $\mathrm{Va}$ occurs in this initial phase.

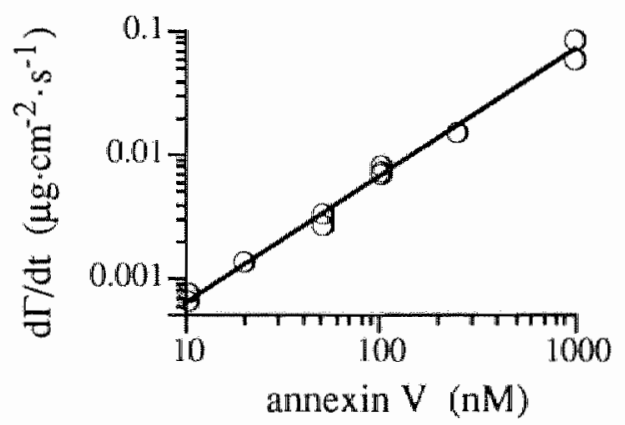

Fig. 4. Transport limited adsorption of annexin $V$ to preadsorbed factor $\mathrm{Va}$. The transport rate limit, determined for annexin $\mathrm{V}$ adsorptions to bare phospholipid surfaces, was $\Delta=23.9 \pm 1.1 \mathrm{~cm} \cdot \mathrm{s}^{-1}$ (mean \pm S.D.) and is indicated by the solid line. Symbols indicate the initial adsorption rate of annexin $V$ to a surface covered with $0.8-1 \mathrm{pmol} \cdot \mathrm{cm}^{-2}$ of factor $V$ a. 

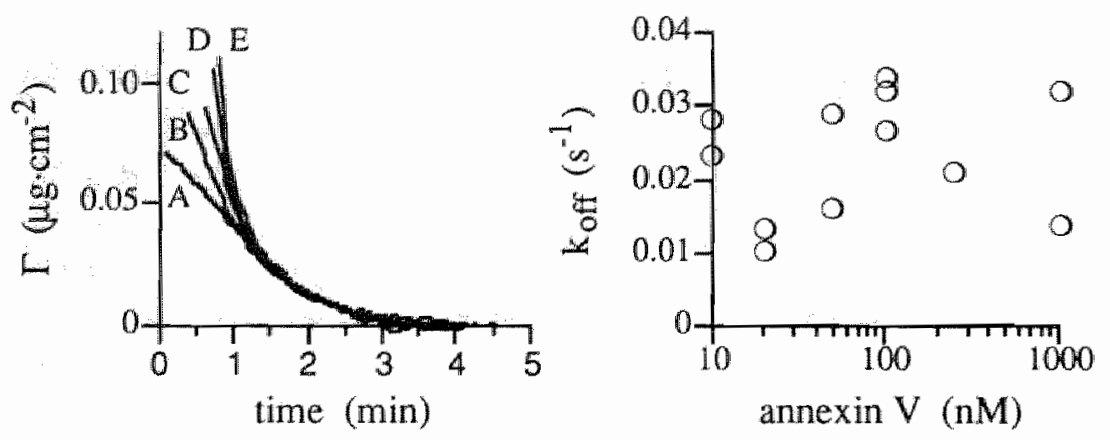

Fig. 5. Intrinsic desorption rate of factor Va. Left panel: Factor Va desorption curves, calculated as described in the text for values of $\left(\Gamma_{\max }\right)_{\text {annexin }} \mathrm{V}=0.2 \mu \mathrm{g} / \mathrm{cm}^{2}$ and $\left(\Gamma_{\text {max }}\right.$ ) factor $\mathrm{Va}=0.4 \mu \mathrm{g} / \mathrm{cm}^{2}$, for $10(\mathrm{~A}), 20(\mathrm{~B}), 50(\mathrm{C}), 100$ (D) and 250 (E) $\mathrm{nM}$ annexin $\mathrm{V}$ are shown. Right panel: Desorption rates were determined from the final part of the displacement curves of factor $\mathrm{Va}\left(\Gamma<0.03 \mu \mathrm{g} \cdot \mathrm{cm}^{-2}\right)$. The intrinsic desorption rate constant $\mathrm{k}_{\mathrm{off}}$ is plotted as function of the annexin $V$ concentration.

The desorption rate of factor $\mathrm{Va}$ - The estimated final desorption rates of factor $\mathrm{Va}$ in Fig. 3 proved independent of the annexin $\mathrm{V}$ concentration. This strongly suggests a steady-state exchange process with the lipid surface completely covered by annexin $\mathrm{V}$ and factor $\mathrm{Va}$, such that additional annexin $\mathrm{V}$ adsorption is only possible on the area left unoccupied by desorption of factor $\mathrm{Va}$. For a factor $\mathrm{Va}$ surface concentration of $\Gamma_{\text {factor }} \mathrm{Va}$, the fraction of the lipid surface occupied by factor $\mathrm{Va}$ is $\left(\Gamma / \Gamma_{\max }\right)$ factor $\mathrm{Va}$. If this amount of factor $\mathrm{Va}$ desorbs and is replaced by annexin $\mathrm{V}$, the extra adsorption of annex in $V$ will be equal to $\left(\Gamma_{\max }\right)_{\text {annexin }} \mathrm{V} \cdot\left(\Gamma / \Gamma_{\max }\right)$ factor $\mathrm{V}$. This must result in complete coverage of the surface with annexin $\mathrm{V}$ and therefore the equality $\left(\Gamma_{\max }\right)_{\text {annexin }} \mathrm{V} \cdot\left(\Gamma / \Gamma_{\max }\right)$ factor $\mathrm{Va}_{\mathrm{a}}=\left(\Gamma_{\max }-\Gamma\right)$ annexin $\mathrm{v}$ holds. This can be simplified to $\sigma=\left(\Gamma / \Gamma_{\max }\right)_{\text {annexin }} \mathrm{V}+\left(\Gamma / \Gamma_{\max }\right)$ factor $\mathrm{Va}=1$, when $\sigma$ represents the normalized surface coverage. Using the condition $\sigma=1$, the $\Gamma_{\text {factor }} V$ a can be be deduced from total adsorption: $\Gamma_{\text {factor }} \mathrm{Va}_{a}=\Gamma_{\max } \mathrm{Va}_{\mathrm{a}}\left(\Gamma_{\text {total }}-\Gamma_{\max }\right.$ annexin $v) /\left(\Gamma_{\max }\right.$ factor $v_{a}-\Gamma_{\max }$ annexin $\left.v\right)$, and the results are shown in Fig. 5 (left panel) for various annexin $V$ concentrations (10-250 nM). As can be observed, desorption rates at surface concentrations of factor $\mathrm{Va}>0.03 \mu \mathrm{g} / \mathrm{cm}^{2}$ are correlated to the annexin $\mathrm{V}$ concentrations, but below this surface concentration the desorption becomes independent of the annexin $V$ concentration. This indicates that at this part of the curve the desorption is 
controlled by the intrinsic desorption rate of factor $\mathrm{Va}$. In the right panel of Fig. 5 the desorption rate constant ( $\mathrm{k}_{\text {off }}$ ) calculated for surface concentrations below $0.03 \mu \mathrm{g} / \mathrm{cm}^{2}$, is shown as function of the annexin $\mathrm{V}$ concentration. A mean value $k_{\text {off }}=0.023 \pm 0.007 \mathrm{~s}^{-1}$ for the intrinsic dissociation constant was obtained by this procedure.

\section{DISCUSSION}

Factor Va displacement by annexin $V$ from the PS/PC membrane Annexin $V$ was shown to possess a high affinity for phospholipid surfaces. The $\mathrm{K}_{\mathrm{d}}$ value could not be determined accurately but an upper limit of $0.1 \mathrm{nM}$ was estimated (12-14). Factors $\mathrm{Va}$ and $\mathrm{V}$, however, were also reported to bind extremely tight to anionic phospholipid surfaces $(17,18)$ although lower binding affinities were also reported $(24,25)$. According to the Langmuir binding model, two proteins with equal binding affinity adsorb to the ratio of their concentrations in solution. Thus, equal affinity would imply that for concentrations of $1 \mathrm{nM}$ factor $\mathrm{Va}$ and $5 \mathrm{nM}$ annexin $\mathrm{V}$ at least $20 \%$ of the preadsorbed factor $\mathrm{Va}$ remains bound, which contrasts to the virtually complete displacement found in the present study. This implies either a much stronger binding of annexin $\mathrm{V}$ compared to factor $\mathrm{Va}$ or the invalidity of the independent binding site model. Two-dimensional clustering of annexin $\mathrm{V}$ on the membrane is shown in the next Chapter and indeed indicates a deviation from the classical Langmuir model.

Complete reversibility of factor $V a$ binding - The nearly complete displacement of factor $\mathrm{Va}$ by annexin $\mathrm{V}$ observed in this study demonstrates reversible binding of factor $\mathrm{Va}$. This is in agreement with the complete desorption of the majority of factor $\mathrm{Va}$ after addition of prothrombin fragment 1-2 (26). Similar desorption is observed for increased ionic strength or high calcium concentrations ( $>20 \mathrm{mM}$ ) (data not shown). It is interesting to note that factor $\mathrm{Va}$ as well as annexin $\mathrm{V}$ show reversible binding to phospholipids although for both proteins penetration of the lipid bilayer has been reported $(27,28)$.

Inhomogeneity of the factor Va preparation - Factor Va desorption was dependent on the annexin $V$ concentration for surface coverage exceeding 0.03 $\mu \mathrm{g} / \mathrm{cm}^{2}$. The $k_{\text {off }}$ determined for high surface coverages was $0.1-0.2 \mathrm{~s}^{-1}$ for 
displacement by $1 \mu \mathrm{M}$ annexin $\mathrm{V}$, similar to an earlier report (26), but 10 times higher than found at low surface coverage $\left(<0.03 \mu \mathrm{g} / \mathrm{cm}^{2}\right)$. The existence of an inhomogeneous mixture of factor $V a$ with fractions with low $\left(\mathrm{K}_{\mathrm{d}}=1-2 \mathrm{nM}\right)$ and high $\left(\mathrm{K}_{\mathrm{d}}=0.05-0.1 \mathrm{nM}\right)$ affinity for PS/PC would provide a plausible explanation for these data. Selective purification of the fraction with either the lower or higher $\mathrm{K}_{\mathrm{d}}$ would also explain the differences in $\mathrm{K}_{\mathrm{d}}$ values published before.

Factor Va sorption kinetics and binding affinity to PS/PC bilayers - The desorption rate constant for factor $\mathrm{Va}$ obtained in the displacement experiments with annexin $V$ for surface coverage below $0.03 \mu \mathrm{g} / \mathrm{cm}^{2}, \mathrm{k}_{\text {off }}=$ $2.3 \cdot 10^{-2} \mathrm{~s}^{-1}$, was independent of annexin $\mathrm{V}$ concentration. Our interpretation that the observed desorption rate represents the intrinsic desorption rate constant is in apparent contradiction to the about thousand fold lower desorption rate constant $\left(k_{\text {off }} \mathrm{fpp}^{\mathrm{a} p}=(0.3-1) \times 10^{-4} \mathrm{~s}^{-1}\right)$ observed in the present study for factor $\mathrm{Va}$ desorption in the absence of annexin $\mathrm{V}$. This latter desorption rate, however, is only apparent because, due to the very high intrinsic adsorption rates $(17,26)$, a desorbed molecule has a much higher chance to readsorb than to escape to the solution, and the observed net desorption rate will be much lower than the intrinsic desorption rate. This situation can be analyzed with the model:

$$
\frac{\mathrm{d} \Gamma}{\mathrm{dt}}=\Delta \cdot \mathrm{C}_{\mathrm{bulk}}-\Delta \cdot \mathrm{K}_{\mathrm{d}} \frac{\Gamma}{\Gamma \max -\Gamma}
$$

presented in Chapter 2 of this thesis. After flushing $C_{b u l k}=0$ and $\mathrm{d} \Gamma / \mathrm{dt}$ becomes equal to $\mathrm{k}_{\mathrm{off}} \mathrm{app}$. $\Gamma$. Using a value $\Delta=1 \cdot 10^{-3} \mathrm{~cm} / \mathrm{s}$ for the transport coefficient and $\Gamma_{\max }=2.5 \mathrm{pmol} / \mathrm{cm}^{2}$ for the maximal surface coverage, the observed desorption rate $\left(\mathrm{d} \Gamma / \mathrm{dt}\right.$ ), at a surface concentration of $1.5 \mathrm{pmol} / \mathrm{cm}^{2}$, corresponds to a value of the dissociation constant equal to $\mathrm{K}_{\mathrm{d}}=$ $\left(\mathrm{k}_{\text {off }} \mathrm{app} / \Delta\right) \cdot\left(\Gamma_{\max }-\Gamma\right)=(0.3-1) \times 10^{-4} / 1 \cdot 10^{-3} \cdot 1 \times 10^{-12} \mathrm{~mol} / \mathrm{cm}^{3}=30-100$ $\mathrm{pM}$. This value is somewhat higher than reported by Kop et al. for factor $\mathrm{V}$. This difference may be due to differences between factor $\mathrm{V}$ and $\mathrm{Va}$, or just to differences in the preparations (See inhomogeneity). The $K_{d}$ agrees very well with the value of $90 \mathrm{pM}$ reported by Pusey et al. for factor $\mathrm{V}$ and $\mathrm{Va}$ binding to $\mathrm{PS} / \mathrm{PC}$ at $20^{\circ} \mathrm{C}(17)$, but is much lower than the value $\mathrm{K}_{\mathrm{d}}=3 \mathrm{nM}$ reported in a recent study (26). The latter study used stopped-flow light scattering to 
measure the association and the dissociation rates, after addition of prothrombin fragment 1. A discrepantly high maximal binding of $22.9 \mathrm{mmol}$ factor $\mathrm{Va} / \mathrm{mol}$ PS/PC was reported, 4-6 times higher than the $\Gamma_{\max }$ of 4-5 mmol factor $\mathrm{Va} / \mathrm{mol} \mathrm{PS} / \mathrm{PC}$ found in this study and ref. (17). Even for a closed packed protein layer, this $\Gamma_{\max }$ would imply a thickness of $14 \mathrm{~nm}$ for the adsorbed protein layer, i.e. about 3 times the hydrodynamic radius of factor $\mathrm{Va}$, strongly suggesting an over-estimation of the adsorbed mass. Such over-estimation could be explained by a minor degree of vesicle aggregation (Refs. Chapter 2). Vesicle aggregation may also offer an explanation for the dissociation rate constant ( $k_{\text {off }}=0.17 \mathrm{~s}^{-1}$ ) reported being $7-10$ fold higher (26), than found by Pusey et al. $\left(k_{\text {off }}=0.013 \mathrm{~s}^{-1}\right)(17)$ and in the present study $\left(k_{\text {off }}=0.023 \mathrm{~s}^{-1}\right)$. Accepting the low value of $K_{d}=30-100 p M$ a value of $k_{\text {on }}$ $=\mathrm{k}_{\mathrm{off}} / \mathrm{K}_{\mathrm{d}}=0.2-0.7 \times 10^{-9} \cdot \mathrm{M}^{-1} \cdot \mathrm{s}^{-1}$ is calculated for the intrinsic adsorption rate constant.

Relevance to hemostasis - Displacement of $>97 \%$ of factor Va by annexin $\mathrm{V}$ from the phospholipid surface, as shown in this study, would present an attractive model for the anticoagulant action of annexin V. In vivo, however, one of the rate limiting factors for thrombin generation at the blood vessel wall is the transport of prothrombin toward the damaged vessel wall. The diffusion limited transport rate depends on the shear rate of blood flow and on the size of the lesion involved (15). It was estimated that in a representative blood vessel wall, with a shear rate of $400 \mathrm{~s}^{-1}$, the maximal capacity of prothrombin transport to a lesion of $0.1 \mathrm{~cm}$ length amounts to about $60 \mathrm{pmol} \cdot \mathrm{cm}^{-2} \cdot \mathrm{min}^{-1}$. This implies that no more than $1 \%$ of the $\Gamma_{\max }$ of factor $\mathrm{Va}$ is needed to support maximal prothrombinase activity. The amount of factor $\mathrm{Va}$ displaced in this study may therefore not be relevant for prothrombinase activity. In the next Chapter (Clustering .... Andree et al, submitted) we study factor $\mathrm{Va}$ displacement by annexin $\mathrm{V}$ for very low surface coverage of factor $\mathrm{Va}\left(2 \mathrm{fmol} / \mathrm{cm}^{2}\right)$ and demonstrate that in this range most of the preadsorbed factor $\mathrm{Va}$ remains bound to the lipid after incubation with annexin $\mathrm{V}$.

\section{ACKNOWLEDGEMENTS}

We thank M.P. Janssen for her expert technical assistance. 


\section{REFERENCES}

1. Nesheim M.E, and Mann K.G. (1981) J. Biol. Chem. 256, 9874-9882.

2. Lindhout Th., Govers-Rlemslag J.W.P., Waart van de P., Hemker H.C., and Rosing J. (1982) Biochemistry 21,5494-5502.

3. Giesen P.L.A, Willems G.M., Hemker H.C., and Hermens W.Th. (1991) J. Biol. Chem. 266, $18720-18725$.

4. Neshein M.E., Taswell J.B., and Mann K.G. (1979) J. Biol. Chem. 254, 10952-10962.

5. Rosing J., Tans G., Govers-Riemslag J.W.P., Zwaal R.F.A., and Hemker H.C. (1980) J. Biol. Chem. 255, 274-283.

6. Govers-Riemslag J.W.P., Speijer H., Zwaal R.F.A., Rosing J. (1985) Thromb. Res. 38, 375-388.

7. Reutelingsperger C.P.M., Hormstra G., and Hemker H.C. (1985) Eur. J. Biochem. 151, $625-629$.

8. Reutelingsperger C.P.M., Kop J.M.M., Hornstra G., and Hemker H.C. (1988) Eur. J. Biochem. 173, 17 1-178.

9. Crumpton M.J, and Dedman J.R. (1990) Nature 345, 212

10. Funakoshi T., Heimark R.L., Hendrickson L.E., McMullen B.A., and Fujikawa K. (1987) Biochemistry 26, 5572-5578.

11. Rosenberg R.D., and Rosen berg J.S. (1984) J. Clin. Invest. 74, 1-6.

12. Maurer-Fogy I., Reutelingsperger C.P.M., Pieters J., Bodo G., Stratowa Ch., and Hauptmann R. (1988) Eur. J. Biochem 174, 585-592.

13. Tait J.F., Gibson D., and Fujikawa K. (1989) J. Biol. Chem. 264, 7944-7949.

14. Andree H.A.M., Reutelingperger C.P.M., Hauptmann R., Hemker H.C., Hermens W.T., and Willems G.M. (1990) J. Biol. Chem. 265, 4923-4928.

15. Hermens W.T., Kop J.M.M., and Willems G.M. (1988) Coagulation and lipids (Zwaal ed.) CRC Press Inc., Boca Raton.

16. Thiagarajan P., and Tait J.F. (1990) J. Biol. Chem. 265, 17420-17423.

17. Pusey M.L., Mayer L.D., Wei G.J., Bloomfield V.A., and Nelsestuen G.L. (1982) Btochemistry 21, 5262-5269.

18. Kop J.M.M., Willems G.M., and Hermens W.Th. (1989) I. Colloid Interface Sci. 133, 369.376.

19. Kruijff de B., Cullis P.R., and Radda G.K. (1975) Biochim. Biophys. Acra 406, 6-20.

20. Giesen P.L.A., Willems G.M., and Hermens W.Th. (1991) J. Biol. Chem. 266, 1379 1382.

21. Corsel J.W., Willems G.M., Kop J.M.M., Cuypers P.A., and Hermens W.Th. (1986) J. Colloid Interface Sci. 111, 544-554.

22. Cuypers P.A., Corsel J.W., Janssen M.P., Kop J.M.M., Hermens W.Th., and Hemker H.C. (1983) J. Bioi. Chem. 258, 2426-2431.

23. Giesen P.L.A. (1992) Thesis, CARIM, University of Limburg.

24. Bloon J.N., Nesheim M.E., and Mann K.G. (1979) Biochemistry 18, 4419-4425.

25. Waart van de P., Bruhls H., Henker H.C., and Lindhout T. (1983) Biochemistry 22, 2427-2432.

26. Krishnaswamy S., Jones K.C., and Mann K.G. (1988) J. Biol. Chem. 263, 3823-3834. 
27. Lecompte M.F., Krishnaswamy S., Mann K.G., Nesheim M.E., Gitler C. (1987) J. Biol. Chem. 262, 1935-1937.

28. Rojas E., Polard H.B., Haigler H.T., Parra C., and Burns A.L. (1990) J. Biol. Chem. $265,21207-21215$. 



\title{
Clustering of Lipid-bound Annexin V explains its Anticoagulant Effect
}

\author{
Harry A.M. Andree, Marc C.A. Stuart, Wim Th. Hermens, \\ Chris P.M. Reutelingsperger, H. Coenraad Hemker, \\ Peter M. Frederik, and George M. Willems
}

\section{SUMMARY}

In 1985 we isolated a new vascular anticoagulant protein VAC $\alpha$, now called annexin $V$, with a high binding affinity $\left(K_{d}<10^{-10} \mathrm{M}\right)$ for phospholipids. Its anticoagulant effect was attributed to displacement of coagulation factors from the phospholipid membrane. The present study demonstrates that the inhibition of prothrombinase activity by annexin $\mathrm{V}$ strongly depends on the curvature of the membrane surface and on the calcium concentration. For $20 \%$ phosphatidylserine and $80 \%$ phosphatidylcholine, half-maximal inhibition requires $3.5 \mathrm{mM}$ calcium with small vesicles against $0.7 \mathrm{mM}$ with large vesicles, and $0.2 \mathrm{mM}$ with planar bilayers. Using a new ellipsometric technique, identical effects of curvature and calcium are demonstrated on the lipid-binding of annexin $V$. This seemingly confirms the displacement model. At low surface concentration the displacement of coagulation factors proved to be incomplete, with residual surface concentrations of factors $\mathrm{Xa}, \mathrm{Va}$ and prothrombin sufficient for effective production of thrombin. Cryo-electron microscopy revealed that annexin $\mathrm{V}$ binding to large vesicles caused the development of planar facets, indicating the formation of large sheets of clustered annexin V. Apparently, the formation of these two-dimensional arrays is promoted by calcium and hampered by high surface curvature. It is speculated that the complete inhibition ( $>99 \%$ ) of prothrombinase aclivity by annex in $\mathrm{V}$ unprecedented by other phospholipid binding proteins is caused by the reduced lateral mobility of prothrombin and factor $\mathrm{Xa}$ in this rigid sheets of annexin $\mathrm{V}$ covering the membrane. 


\section{INTRODUCTION}

Several steps in the complicated process of blood coagulation, for instance the activation of factor $\mathrm{X}$ by the factor IXa/factor VIIla complex or the conversion of prothrombin (factor II) to thrombin (factor IIa) by the factor $\mathrm{Xa}$ /factor $\mathrm{Va}$ (prothrombinase) complex, are greatly stimulated by the adsorption of an enzyme/cofactor complex and the substrate to phospholipid membranes. For instance, the thrombin generating capacity of factor $\mathrm{Xa}$ is enhanced by $4-6$ orders of magnitude after its assembly with factor $\mathrm{Va}$ on a lipid surface (see ref. 1 for a review).

Annexin V (formerly called Vascular Anticoagulant $\alpha(2)$ ) has a high, calcium-dependent, binding affinity for negatively charged phospholipids (35 ) and blood platelets (6). The protein was discovered by its anticoagulant effect (2). Since then it has been demonstrated to inhibit several phospholipiddependent reactions, such as lipid degradation by phospholipase $A_{2}(7,8)$, production of thrombin by the prothrombinase complex $(2,9-11)$ and activation of factor $X$ by the tissue factor/factor VIIa complex (12-15). Annexin $\mathrm{V}$ does not inhibit factor $\mathrm{Xa}$ activity in the absence of phospholipids, and does not bind to factor $\mathrm{Xa}$ (11). It neither has a proteolytic activity (2). Therefore, it is generally assumed that annexin $\mathrm{V}$ inhibits blood coagulation by displacement of blood coagulation factors from the procoagulant phospholipid surface.

In the present study it is observed that, for low ( $3 \mathrm{mM}$ ) calcium concentrations, the inhibition of prothrombinase activity by annexin $\mathrm{V}$ is considerably less for small vesicles (SUV) than for large vesicles (LV), platelets or planar bilayers. Using a new technique for ellipsometric measurement of the concentrations of unbound protein in vesicle suspensions, it is verified that indeed less annexin V binds to SUV than to planar bilayers. These findings seem to confirm the displacement concept, but a separate series of experiments demonstrates that displacement of coagulation factors from the phospholipid surface by annexin $\mathrm{V}$ is completely. The remaining surface concentrations of factor $\mathrm{Xa}$, factor $\mathrm{Va}$ and prothrombin are sufficient for effective production of thrombin. Annexin $V$ thus seems to interfere with the conversion process itself. Using cryo-electron microscopy it was found that adsorption of annexin $\mathrm{V}$ on large phospholipid vesicles, with a low surface curvature, results in the formation of facets on the vesicles. Apparently, sheets 
of clustered annexin $\mathrm{V}$ molecules are formed on the surface, with sufficient rigidity to deform the bilayer.

\section{MATERIALS AND METHODS}

Phospholipids - 1,2-dioleoyl-sn-glycero-3-phosphatidylcholine (PC) and 1,2-dioleoyl-sn-glycero-3-phosphatidylglycerol (PG) were purchased from Sigma Chemical Co. 1,2-dioleoyl-sn-glycero-3-phosphatidylserine (PS) was bought from Avanti Polar Lipids. Unless stated otherwise a mixture of $20 \%$ PS / $80 \%$ PC (PS/PC) was used. Some experiments were performed with $20 \%$ PG / 80\% PC. Small unilamellar vesicles $(\varnothing 20-30 \mathrm{~nm}$, SUV) were prepared by sonication of a nitrogen-dried phospholipid mixture in buffer (16). Large vesicles $(\varnothing 70-200 \mathrm{~nm}, \mathrm{LV})$ were obtained by lipid extrusion through a 200 $\mathrm{nm}$ polycarbonate filter under moderate nitrogen pressure (17). Planar phospholipid bilayers were stacked on hydrophylic sillicon slides (Wacker Chemie) by dipping the slides in a stirred vesicles solution as described (18).

Buffers - All experiments were performed at room temperature (20-22 ${ }^{\circ} \mathrm{C}$ ) in a TRIS/HCl buffer $\mathrm{pH} 7.5$ unless platelets were used. The TRIS/HCl buffer contained $3 \mathrm{mM} \mathrm{Ca}{ }^{2+}$, unless stated otherwise, $100 \mathrm{mM} \mathrm{NaCl}$, and 0.5 $\mathrm{g} / \mathrm{l}$ fatty acid free bovine serum albumin (Sigma Chemical Co., A-7030) in order to prevent protein depletion by adsorption to cuvette walls, stir etc. Experiments with platelets were performed in Hepes buffer $\mathrm{pH}=7.4$, containing $3 \mathrm{mM} \mathrm{Ca}{ }^{2+}, 137 \mathrm{mM} \mathrm{NaCl}, 2.7 \mathrm{mM} \mathrm{KCl}, 1.7 \mathrm{mM} \mathrm{MgCl}, 10 \mathrm{mM}$ Hepes, $25 \mathrm{mM}$ Glucose and $0.5 \mathrm{~g} / \mathrm{l}$ bovine serum albumin.

Proteins - Human recombinant annexin V, prepared as described in ref. (13), was a kind gift of Boehringer Ingelheim. Coagulation factors II, X, and $\mathrm{V}$ were purified from bovine plasma according to Lindhout (19). Factors $X$ and V were activated with Russels Viper Venom-X (Sigma Chemical Co.) (20) and thrombin (19), respectively. Concentrations of factor Xa preparations were determined by active site titration with p-nitrophenyl-p"guanidinebenzoate hydrochloride (ICN Nutritional Biochemicals). Low factor $\mathrm{Xa}$ concentrations were determined with a prothrombinase assay with excess factor Va $(1 \mathrm{nM}), 20 \%$ PS / 80\% PC vesicles $(50 \mu \mathrm{M})$ and prothrombin (1 $\mu \mathrm{M})$. Standard curves from 0.1 to $1 \mathrm{pM}$ factor $\mathrm{Xa}$ yielded $\mathrm{k}_{\text {cat }}$ values of 3850 \pm 350 min $^{-1}$ (mean \pm S.D.) at $37^{\circ} \mathrm{C}$. Prothrombin concentrations were 
determined after activation with Echis Carinata venom (Sigma). Factor Va concentrations were determined by assessment of prothrombinase activity with excess factor $\mathrm{Xa}(100 \mathrm{pM})$, vesicles $(50 \mu \mathrm{M})$ and prothrombin $(1 \mu \mathrm{M})$ at 37 ${ }^{\circ} \mathrm{C}$. Thrombin concentrations were determined with the chromogenic substrate S-2238 (AB Kabi Diagnostica), from the kinetics of absorbance at $405 \mathrm{~nm}$, using a Cobas Bio spectrophotometer (Hoffmann-La Roche) (18).

Measurement of protein adsorption on planar bilayers - Binding of proteins to planar phospholipid bilayers was measured by ellipsometry $(5,21)$. Experiments were performed in a quartz cuvette, filled with $5 \mathrm{ml}$ of buffer and rendered hydrophobic by pretreatment with Sigmacote (Sigma Chemical Co. SL-2). The solution was stirred with Teflon-coated magnetic stir (length 8 $\mathrm{mm}$, diameter $2 \mathrm{~mm}$ ), rotating at $1800 \mathrm{RPM}$ and separated $1-2 \mathrm{~mm}$ from the site of measurement on the slide.

Measurement of the adsorption of annexin $V$ on vesicles - The initial adsorption rate of annexin $\mathrm{V}$ on planar $\mathrm{PS} / \mathrm{PC}$ bilayers is transport-limited and satisfies the relation: $\mathrm{d} \Gamma / \mathrm{dt}=\mathrm{C}_{\text {bulk }} \cdot \Delta$, with $\Gamma$ the surface concentration of

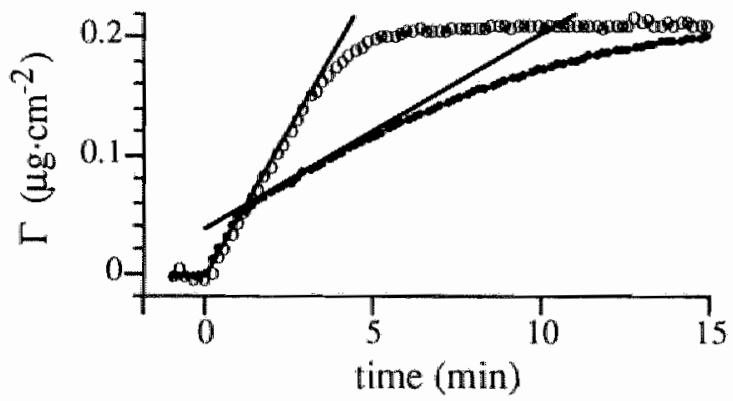

Fig 1. Ellipsometric measurement of annexin $V$ binding to vesicles. $A t t=0$ annexin $V(15 \mathrm{nM})$ was added to the cuvette (O) and the annexin $\mathrm{V}$ adsorption to a PS/PC bilayer was measured. After I min PS/PC SUV ( $₫ \mu \mathrm{M})$ was added (๑) and this resulted within $15 \mathrm{~s}$ after addition in a decrease of the adsorption rate from $8.5 \cdot 10^{-4} \mu \mathrm{g} \cdot \mathrm{cm}^{-2} \mathrm{~s}^{-1}$ before vesicle addition to $2.8 \cdot 10^{-4} \mu \mathrm{g} \cdot \mathrm{cm}^{-2} \cdot \mathrm{s}^{-1}$ Straight lines represent the best fitting regression line to the annexin adsorption up to $1 \mathrm{~min}$ and the annexin adsorption 1 min after addition of the vesicles. The experiment was performed at room temperature $\left(20-22^{\circ} \mathrm{C}\right)$ in TRIS/HCl buffer $(\mathrm{pH}=7.5,50$ mM TRIS, $100 \mathrm{mM} \mathrm{NaCl}, 10 \mathrm{mM} \mathrm{CaCl}$, and $0.5 \mathrm{~g} /$ bovine senum albumin). 
protein $\left(\mu \mathrm{g} \cdot \mathrm{cm}^{-2}\right), C_{\text {bulk }}$ the bulk concentration of protein $\left(\mu \mathrm{g} \cdot \mathrm{cm}^{-3}\right)$, and $\Delta$ the mass transfer constant $\left(\mathrm{cm} \cdot \mathrm{s}^{-1}\right)$, which depends on stirring conditions, the buffer viscosity and the diffusion coefficient of the protein $(22,5)$. Experimentally this was verified for annexin $V$ concentrations from 3-100 $\mathrm{nM}$. These observations are used to estimate the annexin $\mathrm{V}$ binding to PS/PC vesicles through measurement of the reduction of the free annexin $V$ concentration caused by binding to the lipid vesicles. This is illustrated in Fig. 1: without addition of lipid vesicles the adsorption rate is constant up to $75 \%$ of maximal surface coverage $\left(\Gamma_{\max }\right)$. Addition of $1 \mu \mathrm{M}$ PS/PC vesicles 1 min after the start of the adsorption results in a rapid decrease of the adsorption rate to about $30 \%$ of the initial adsorption rate. For an annexin concentration of $15 \mathrm{nM}$ and $1 \mu \mathrm{M}$ PS/PC SUV the transient is completed within $10-15 \mathrm{~s}$. Thereafter, a new, lower, steady state adsorption rate is established, corresponding to the new free annexin V concentration. Addition of an excess lipid vesicles $(10 \mu \mathrm{MPS} / \mathrm{PC})$ to $15 \mathrm{nM}$ annexin $\mathrm{V}$ at $3 \mathrm{mM}$ completely stops the adsorption. From these data it is concluded that the steady-state free annexin $\mathrm{V}$ concentration is rapidly established and that the quasi steady-state adsorption rate observed after addition of vesicles is proportional to the free annexin $\mathrm{V}$ concentration. It is unaffected by lipid vesicles per se or by lipid bound annexin $\mathrm{V}$, see Discussion. In the binding experiments presented in Fig. 3 the vesicles were added to the cuvette prior to the adsorption by addition of annexin $\mathrm{V}$ and the free annexin $\mathrm{V}$ concentration was determined using the calibration line mentioned before. Best accuracy is attained if binding to vesicles causes a reduction of the free annexin $V$ concentration exceeding $25 \%$. For experiments with $15 \mathrm{nM}$ annexin $\mathrm{V}$ this required $1 \mu \mathrm{M}$ SUV and $2 \mu \mathrm{M} \mathrm{LV}$. Experiments with $100 \mathrm{nM}$ annexin $V$ were performed with $5 \mu \mathrm{M}$ SUV.

Measurement of prothrombinase activity in vesicle suspensions - A sample of $50 \mu \mathrm{l}$ annexin $V$ was added to $100 \mu \mathrm{l}$ of buffer containing a final concentration of $0.1 \mu \mathrm{M}$ phospholipid vesicles, $10 \mathrm{pM}$ factor $\mathrm{Va}, 100 \mathrm{pM}$ factor $\mathrm{Xa}(100 \mu \mathrm{mol}$ of prothrombinase per mol of phospholipid) and calcium as indicated. This mixture was incubated for 5 minutes. Prothrombin $(4 \mu \mathrm{M})$ was preincubated with $3 \mathrm{mM}$ calcium for at least 10 minutes. Thrombin generation was started by addition of $50 \mu \mathrm{l}$ of $4 \mu \mathrm{M}$ prothrombin, to a final concentration of $1 \mu \mathrm{M}$. Serially drawn samples were added to buffer with 20 mM EDTA and $0.1 \mathrm{~g} \cdot$ litre $^{-1}$ soybean trypsin inhibitor (Sigma), and stored on 
ice until thrombin was determined.

Measurement of prothrombinase activity on planar bilayers - Planar phospholipid bilayers of $0.6 \mathrm{~cm}^{2}$ surface area were used. In $5 \mathrm{ml}$ of buffer this corresponds to about $0.06 \mu \mathrm{M}$ phospholipid (22). Factor $\mathrm{Va}(10 \mathrm{pM})$ and factor Xa (50 pM) were allowed to adsorb for 7 minutes. From the transportlimited adsorption rates of these proteins, at such low concentrations, the resulting surface coverage with prothrombinase can be estimated (18) at about $2 \mathrm{fmol}$ per $\mathrm{cm}^{2}$, corresponding to $4 \mathrm{nmol}$ prothrombinase per mol of phospholipid. The cuvette was flushed and prothrombin was added to a final concentration of $1 \mu \mathrm{M}$. This concentration is sufficiently high to prevent transport-limitation in the production of thrombin (18). Thrombin production was estimated in serial samples as described.

Measurement of prothrombinase activity on blood platelets - Washed platelets were prepared as described (23). Stirred platelets $\left(1.2 \times 10^{6}\right.$ platelets per $\mathrm{ml} \approx 0.1 \mu \mathrm{M}$ phospholipid) were activated by incubation with $10 \mu \mathrm{M}$ calcium ionophore A-23187 (Sigma) for $10 \mathrm{~min}$. Since platelets contain factor $V$, prothrombinase activity was not measured factor Va-limited, but factor Xa-limited. Factor Va $(1 \mathrm{nM})$ and factor Xa $(10 \mathrm{pM})$ were allowed to bind for 5 minutes. Annexin $V$ was added and after 2 min the reaction was started by addition of $1 \mu \mathrm{M}$ prothrombin.

Visualization of vesicles - Vesicles were visualized with the use of cryoelectron microscopy (24). No stains were used. A 700 mesh grid of $3.5 \mu \mathrm{m}$ thickness was dipped into the vesicle suspension (PS/PC concentration $5 \mathrm{mM}$ ). The adhering film was vitrified by rapid plunging into liquid ethane. Films were stored in liquid nitrogen and observed in a Gatan 626 cryo-holder at $-170^{\circ} \mathrm{C}$ with a Philips CM12 microscope. Electron micrographs were taken at $100 \mathrm{kV}$ under low dose conditions, and $1-2 \mu \mathrm{m}$ defocus was used to improve contrast.

\section{RESULTS}

Fig. 2 presents the inhibition of prothrombinase activity on small unilamellar vesicles $(0.1 \mu \mathrm{M})$, large vesicles $(0.1 \mu \mathrm{M})$, planar bilayers $(0.6$ $\mathrm{cm}^{2}$ in $\left.5 \mathrm{ml} \sim 0.06 \mu \mathrm{M}\right)$ and on platelets $\left(1.2 \cdot 10^{6} \mathrm{ml}^{-1} \sim 0.1 \mu \mathrm{M}\right)$ at a calcium concentration of $3 \mathrm{mM}$ as function of the annexin $\mathrm{V}$ concentration. Without 
addition of annexin the prothrombinase activity, expressed as mol thrombin produced per mol factor Va (Xa for platelets) per min was 1900, on SUV, 1400 on $\mathbb{L V}, 2200$ on planar bilayers and 1200 on platelets. Complete inhibition, with a half-maximal annexin $V$ concentration of $4-5 \mathrm{nM}$, is observed for platelets and planar bilayers. On SUV inhibition is incomplete with a maximal inhibition of only $40 \%$ on SUV an for LV an intermediate extent of inhibition of $90 \%$ is observed. Depletion of annexin V, due to lipid binding, plays only a minor role because $0.1 \mu \mathrm{M}$ vesicles or planar bilayers could maximally bind $1.2 \mathrm{nM}$ annexin $\mathrm{V}$, see below. The horizontal axis in Fig. 2 therefore represents, apart for this minor correction, the free annexin $\mathrm{V}$ concentration.

The disparity between prothrombinase inhibition on low curvature (planar bilayers and platelets) and high curvature (SUV) lipid is investigated further in Fig. 3 by comparison of prothrombinase inhibition by annexin $\mathrm{V}$

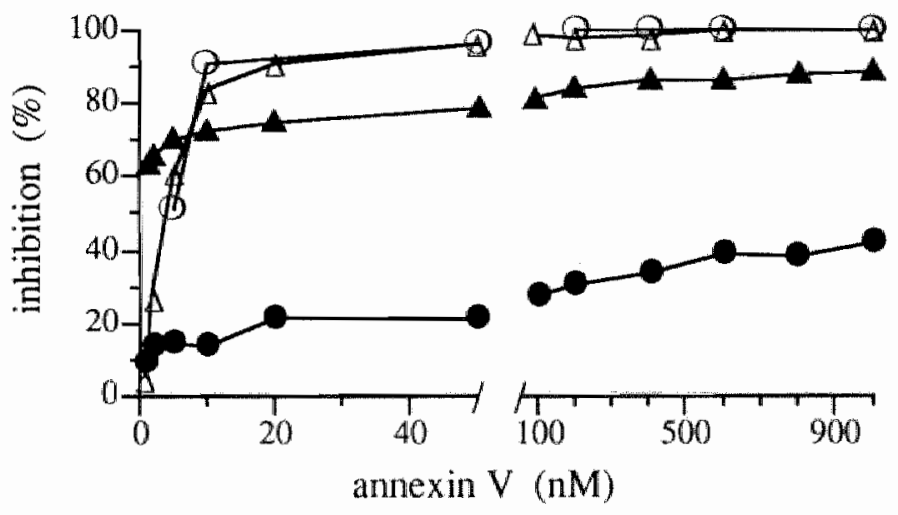

Fig. 2. Inhibition of prothrombinase. Inhibition of prothrombinase activity on planar bilayers $(O)$, on $1.2 \cdot 10^{6}$ calcium ionophore activated platelets per ml $(\Delta)$ and on $0.1 \mu \mathrm{M}$ small $(\bullet)$ and large vesicles $(\boldsymbol{\Lambda})$. Prothrombinase assembled as follows. Vesicles were incubated during 5 min with $10 \mathrm{pM}$ factor $\mathrm{Va}$ and $100 \mathrm{pM}$ factor Xa. After activation with ionophore A23187 platelets were incubated during $5 \mathrm{~min}$ with $10 \mathrm{pM}$ factor $\mathrm{Xa}$ and $1 \mathrm{nM}$ factor $\mathrm{Va}$. On planar billayers $2 \mathrm{fmol} / \mathrm{cm}^{2}$ prothrombinase was first assembled by adsorption of $10 \mathrm{pM} \mathrm{Va}$ and an excess of $50 \mathrm{pM}$ factor $X$ a during $7 \mathrm{~min}$. The assembly was stopped by replacement of the buffer. After assembly of prothrombinase anmexin $\mathrm{V}$ was added to the final concentration indicated on the horizontal axis and after 5-10 minutes prothrombin was added to start thrombin production. Calcium concentration was $3 \mathrm{mM}$ and the experiments were performed at room temperature. 

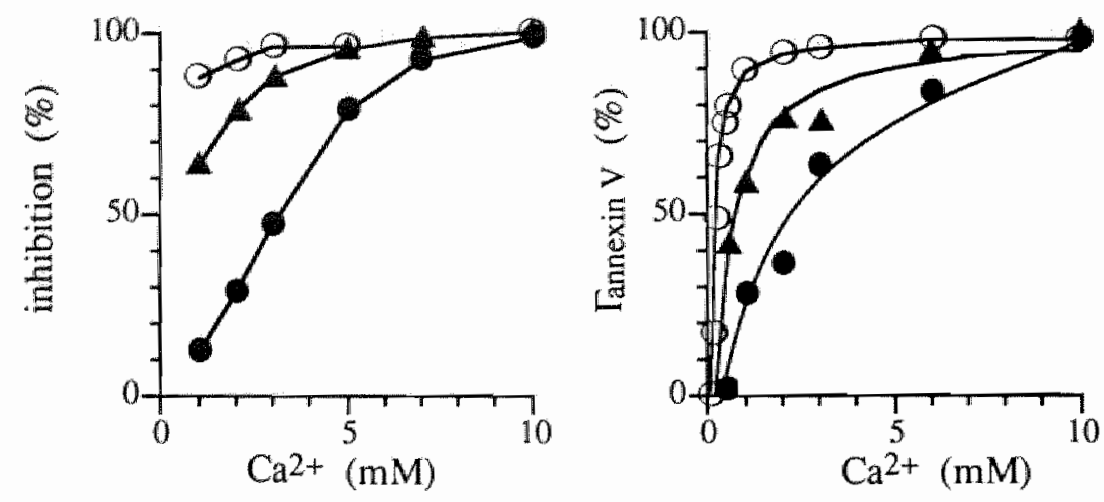

Fig. 3. Effect of calcium on inhibition of prothrombinase activity by annexin $V$. and on binding of annexin $V$ to PS/PC membranes. Left panel shows the extent of inhibition of prothrombinase on planar bilayers (O), $0.1 \mu \mathrm{M}$ SUV $(\bullet)$ and $0.1 \mu \mathrm{M} \mathrm{LV}(\boldsymbol{\Lambda})$ by $1 \mu \mathrm{M}$ annexin $\mathrm{V}$ as function of the calcium concentration. Experiments were performed as described in Fig. 2. Right panel shows the PS/PC binding of $100 \mathrm{nM}$ annexin $\mathrm{V}$ to planar bilayers (O) and of $15 \mathrm{nM}$ annexin V to I $\mu \mathrm{M}$ SUV (๑) and $2 \mu \mathrm{M} \mathrm{LV} \mathrm{(4).}$

and lipid-binding of annexin $\mathrm{V}$ as function of the calcium concentration. The left panel shows that prothrombinase inhibition increases with increasing $\mathrm{Ca}^{2+}$ concentration and decreases with surface curvature. Ultimately, at $10 \mathrm{mM}$ calcium, even for SUV complete inhibition of prothrombinase is observed. Measurement of prothrombinase activity was restricted to calcium concentrations above $1 \mathrm{mM}$ as the prothrombinase complex tends to dissociate below this concentration. The right panel of Fig. 3 shows the parallel effect of calcium on lipid-binding of annexin $V$. The half-maximal calcium concentration for inhibition as well as binding was 3-4 $\mathrm{mM}$ on SUV and 0.7 $\mathrm{mM}$ on LV. At $1 \mathrm{mM}$ calcium prothrombinase inhibition on planar bilayers is still nearly complete $(87 \%)$ and half-maximal binding on planar bilayers required only $0.2 \mathrm{mM}$ calcium. A second series of binding experiments with higher $(5 \mu \mathrm{M}) \mathrm{PS} / \mathrm{PC}$ and $(100 \mathrm{nM})$ annexin $\mathrm{V}$ concentrations versus $1 \mu \mathrm{M}$ $\mathrm{PS} / \mathrm{PC}$ and $15 \mathrm{nM}$ annexin $\mathrm{V}$ (for the experiments shown), was performed for SUV in order to verify whether the decreased binding of annexin $\mathrm{V}$ is caused by a decreased binding affinity or a decreased number of binding sites. The increased concentrations resulted in an about 8-fold increased free annexin $V$ concentration at half-maximal binding: $70 \mathrm{nM}(5 \mu \mathrm{MPS} / \mathrm{PC})$ versus $9 \mathrm{nM}(1$ 
$\mu \mathrm{M} \mathrm{PS} / \mathrm{PC}$ ). These experiments did not show a shift of the half-maximal calcium concentration for binding. Only $20 \%$ higher annexin $\mathrm{V}$ binding 11.9 vs. $9.9 \mathrm{mmol}$ annexin V/mol PS/PC was observed and it was thus concluded that decreased binding of annexin $V$ reflects reduction of binding sites. Frequent lipid inclusions as observed for $L V$ in Fig. 7. caused a lower annexin $\mathrm{V}$ binding at $10 \mathrm{mM} \mathrm{Ca}{ }^{2+}(5.5-6.3 \mathrm{mmol} /$ annexin $\mathrm{V} / \mathrm{mol} \mathrm{PS} / \mathrm{PC})$. Therefore, titrations were performed with $2 \mu \mathrm{M} \mathrm{LV}$ in stead of $1 \mu \mathrm{M}$ SUV.

Fig. 4 demonstrates that annexin $V$ is unable to completely displace factor $\mathrm{Va}$ from the phospholipid surface. In the control situation, with 2 fmol. $\mathrm{cm}^{-2}$ factor $\mathrm{Va}$ adsorbed on the surface and $50 \mathrm{pM}$ factor Xa in solution with $1 \mu \mathrm{M}$ prothrombin added to the buffer, resulted in a thrombin production of $4.4 \pm 0.7 \mathrm{pmol} \cdot \mathrm{cm}^{-2} \cdot \mathrm{min}^{-1}(\bullet)$. If $100 \mathrm{nM}$ annexin $V$ was added, followed by flushing the cuvette with buffer containing $3 \mathrm{mM}$ calcium, annexin $\mathrm{V}$ and factor $\mathrm{Va}$ are removed from the buffer but remain adsorbed on the surface. Reintroduction of factor $\mathrm{Xa}$ and prothrombin now produced only $6 \%$ of the original conversion rate $(\Delta)$. Apparently, surface-bound annexin $V$ interferes

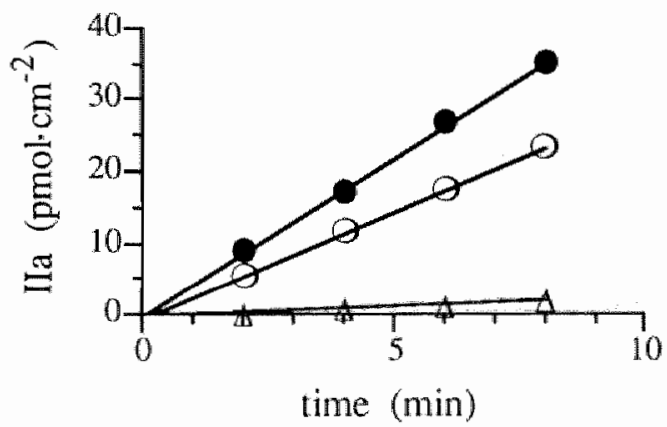

Fig. 4. Incomplete displacement of factor $V a$ from the PS/PC membrane. Prothrombinase was assembled on the PS/PC bilayer by adsorption of $10 \mathrm{pM}$ factor $\mathrm{Va}$ and 50 pM factor Xa during 7 min. Assembly was stopped by flushing the cuvette with buffer, $1 \mu \mathrm{M}$ prothrombin was added and thrombin generation was determined from serial samples (-). Incubation of the prothrombinase assembled on the PS/PC surface with 100 nM annexin $V$ during 5 min and subsequent removal of unbound annexin $V$ from solution prior to addition of prothrombin results in a drastic reduction of the thrombin production ( $\Delta$ ). Also shown is the thrombin production observed after removal (by flushing the cuvette with buffer with $50 \mu \mathrm{M}$ $\mathrm{Ca}^{2+}$ ) of the annexin $\mathrm{V}$ from the PS/PC bilayer in the previous experiment and reconstitution of prothrombinase by addition of $3 \mathrm{mM}$ calcium and $50 \mathrm{pM}$ factor $\mathrm{Xa} 7 \mathrm{~min}$ prior to addition of prothrombin (O). 


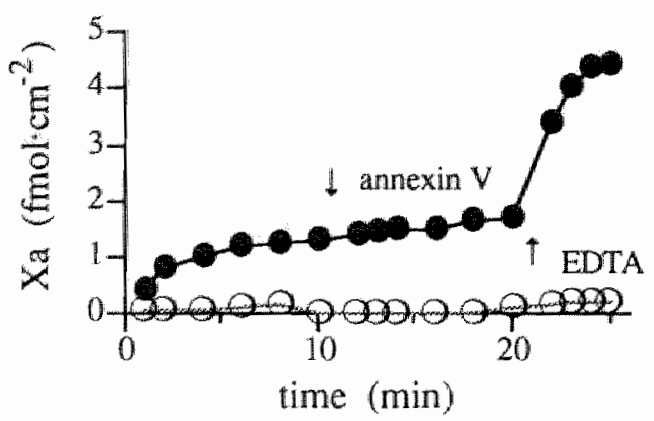

Fig. 5. Incomplete displacement of factor Xa from the PS/PC membrane. About $20 \mathrm{fmol} / \mathrm{cm}^{2}$ of factor Xa was adsorbed to a planar PS/PC bilayer by incubation during $14 \mathrm{~min}$ of $50 \mathrm{pM}$ factor $\mathrm{Xa}$. Thereafter the cuvette was flushed with buffer and allowed to equilibrate for 7 min. A mask, preventing exposure to air, was placed on the lipid membrane and the slide was transferred to a clean cuvette. The release of factor $\mathrm{Xa}$ from the bilayer was measured by determination of the factor $X$ a concentration in serial samples from the buffer. After measurement of spontaneous release of factor Xa during $10 \mathrm{~min} 100 \mathrm{nM}$ annexin $V$ was added and factor Xa release was followed for another $10 \mathrm{~min}$. Finally $3.5 \mathrm{mM}$ EDTA was added in order to quantify the remaining membrane bound factor Xa. Experiments on PS/PC (•) and pure $\mathrm{PC}(\mathrm{O})$ bilayers are shown.

with the conversion process. Hereafter, annexin $\mathrm{V}$ was removed from the surface by flushing the cuvette with buffer containing $50 \mu \mathrm{M}$ calcium (5). Reintroduction of factor $\mathrm{Xa}$ and prothrombin now demonstrated that about $70 \%$ of the original factor $\mathrm{Va}$ concentration remained on the surface $(O)$. The maximal thrombin conversion capacity was determined separately with excess prothrombinase on the surface and $1 \mu \mathrm{M}$ prothrombin in buffer, and amounted to $30 \mathrm{pmol} \cdot \mathrm{cm}^{-2} \cdot \mathrm{min}^{-1}$. Thus, the thrombin productions shown in Fig. 4 were not transport-limited.

Fig. 5 shows that annexin $\mathrm{V}$ does not completely displace Factor $\mathrm{Xa}$ from the surface. About $20 \mathrm{fmol} \cdot \mathrm{cm}^{-2}$ of factor Xa was adsorbed on a planar bilayer during incubation with $50 \mathrm{pM}$ factor $\mathrm{Xa}$ for $14 \mathrm{~min}$. The cuvette was flushed to remove free factor $\mathrm{Xa}$ and allowed to equilibrate for 7 minutes. During this period part of the factor Xa desorbs from the lipid surface. Regrettably accuracy of ellipsometry is insufficient to monitor these minute adsorbed quantities $\left(\sim 1 \mathrm{ng} / \mathrm{cm}^{2}\right)$, but for a higher surface coverage of 0.044 $\mu \mathrm{g} / \mathrm{cm}^{2}\left(<10 \%\right.$ of $\left.\Gamma_{\max }\right)$ a value for the desorption rate constant, $\mathrm{k}_{\text {off }}=0.15$ 0.3 min $^{-1}$ is observed. A mask was placed over the phospholipid membrane, 
preventing exposure to air, and the slide was transferred to a clean cuvette with buffer. This precaution is needed to prevent non specific release of factor $\mathrm{Xa}$ from the cuvette walls. As shown in Fig. 5, some factor Xa slowly desorbs spontaneously from the surface. Annexin $\mathrm{V}$ was added but hardly stimulated factor Xa release. Addition of EDTA, however, released $2.7 \mathrm{fmol} . \mathrm{cm}^{-2}$ of factor Xa from the bilayer, and this quantity exceeds the surface concentration of factor $\mathrm{Va}$ used in the previous experiments. Thus the total release after transfer to the clean cuvette amounts only $4.7 \mathrm{fmol} / \mathrm{cm}^{2}$, i.e. $20-25 \%$ of the 20 fmol $/ \mathrm{cm}^{2}$ initially adsorbed. This discrepancy is, however, only apparent due to the neglecting of the factor $\mathrm{Xa}$ desorption during the $7 \mathrm{~min}$. equilibration, which amounts $60-80 \%$ of the initially adsorbed quantity. A phospholipid bilayer of $100 \% \mathrm{PC}$ did not show factor Xa release, excluding non specific effects.

Binding of prothrombin to a phospholipid membrane fully covered with annexin $\mathrm{V}$ is demonstrated in Fig. 6. Annexin $\mathrm{V}$ was adsorbed to its maximal coverage of $200 \mathrm{ng} \cdot \mathrm{cm}^{-2}\left(=5.7 \mathrm{pmol} \cdot \mathrm{cm}^{-2}\right)$ and prothrombin was added to a final concentration of $1 \mu \mathrm{M}$. After 2 minutes, the extra adsorption of prothrombin was $29 \pm 3.2 \mathrm{ng} \cdot \mathrm{cm}^{-2}\left(=0.4 \mathrm{pmol} \cdot \mathrm{cm}^{-2}\right)$. As discussed below, this surface concentration largely exceeds the concentration required for efficient thrombin production. For buffer concentrations in the micromolar range,

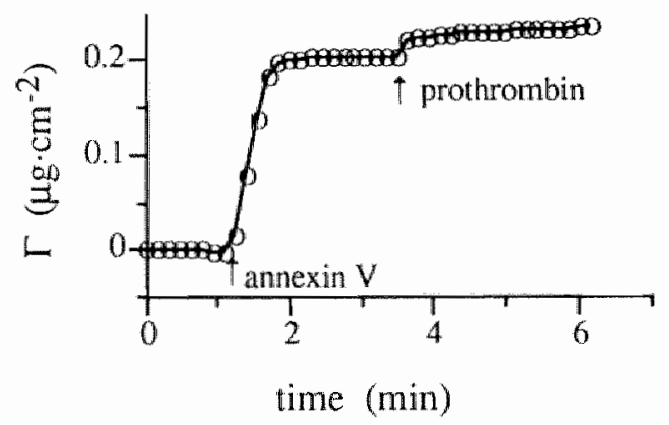

Fig. 6. Prothrombin adsorption to a PS/PC bilayer covered with annexin $V$. Adsorption of annexin $V(100 \mathrm{nM})$ to a PS/PC bilayer was allowed to proceed until $\Gamma_{\max }$ was attained. About $1.5 \mathrm{~min}$ thereafter $1 \mu \mathrm{M}$ prothrombin was added and the additional adsorption of at least $30 \mathrm{ng} / \mathrm{cm}^{2}$ was observed. Calciam concentration was $3 \mathrm{mM}$. 

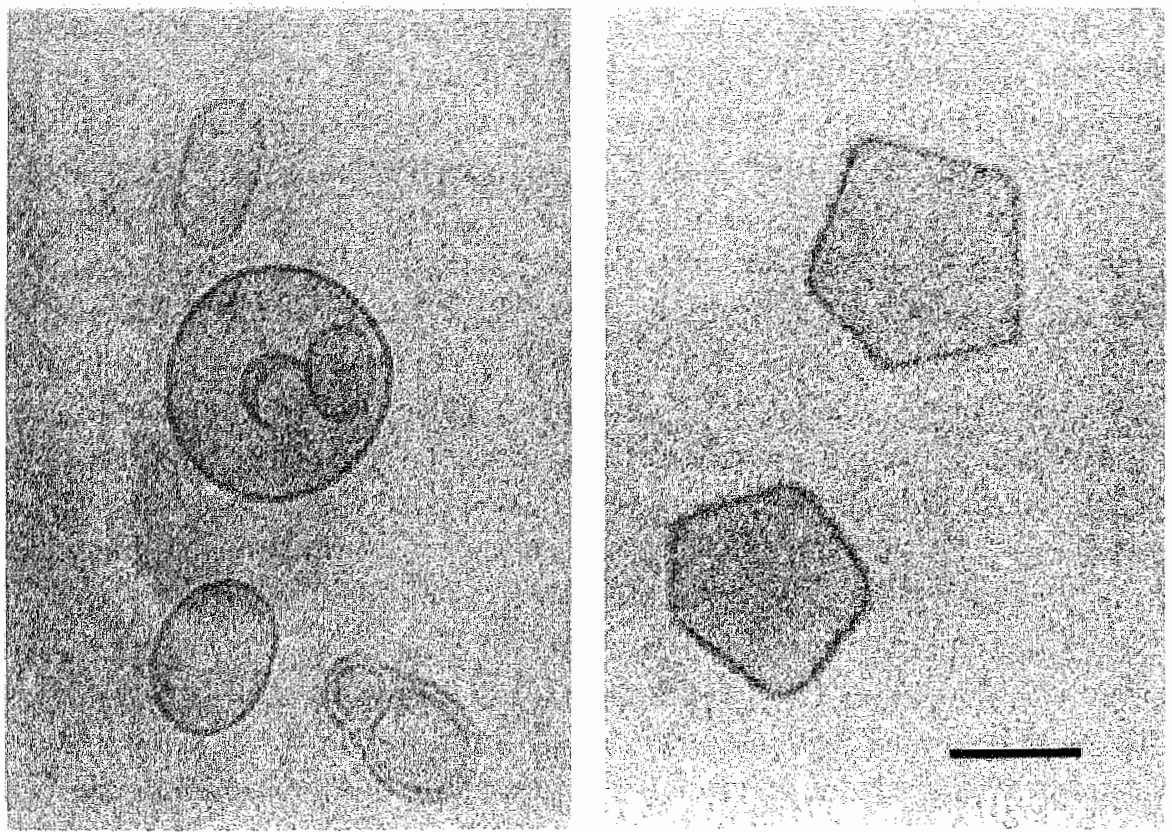

Fig. 7. Visualization of shape changes induced by annexin $V$ binding to large vesicles. Samples of large vesicles, diameter $70-200 \mathrm{~nm}$ and PS/PC concentration of $5 \mathrm{mM}$, were rapidly vitrified in liquid ethane and electron micrographs were taken at $-170^{\circ} \mathrm{C}$. Left panel shows vesicles without annexin $\mathrm{V}$ and the right panel shows vesicles incubated for 10 min at $20^{\circ} \mathrm{C}$ with $200 \mu \mathrm{M}$ annexin $\mathrm{V}$. Buffer contained $3 \mathrm{mM}$ calcium. Bar indicates $100 \mathrm{~nm}$.

similar effects as shown in Fig. 6 can be shown for factor $\mathrm{Xa}$ and factor $\mathrm{Va}$. However, for the picomolar factor $X a$ and $V a$ concentrations, used in the assessment of prothrombinase activities, the adsorptions are correspondingly smaller and cannot be detected by ellipsometry.

Fig. 7 shows that annexin $\mathrm{V}$ forms sheets of clustered protein on surfaces with low curvature. The vesicles assumed bizarre, sharply-edged, shapes like rods, cubes, pyramids, etc. Some of the rods were straight up to $300 \mathrm{~nm}$, with a deviation of less than $3 \mathrm{~nm}$. Although the control vesicles contained occasional bulges or were bilamellar, they never displayed these straight sides. Vesicles in the presence of human serum albumin were not different from control vesicles. 


\section{DISCUSSION}

Ellipsometric determination of annexin $V$ binding to vesicles - As explained in Fig. 1 the measurement of annexin $\mathrm{V}$ binding to vesicles consists of the determination of the free annexin $\mathrm{V}$ concentration in a suspension of vesicles. This concentration of free protein is determined by ellipsometry from the initial transport limited adsorption rate to a $\mathrm{PS} / \mathrm{PC}$ bilayer, which was calibrated by performing control experiments without added vesicles. A first requirement for the validity of the method is that annexin $\mathrm{V}$ bound to vesicles does not contribute to the adsorption on the planar bilayer and this was verified by the observation that addition of an excess ( $10 \mu \mathrm{M} \mathrm{PS} / \mathrm{PC})$, SUV to $15 \mathrm{nM}$ annexin $\mathrm{V}$ completely inhibits the adsorption on a planar bilayer. A second requirement is that the redistribution of annexin $V$ between solution and vesicles is rapid compared to the duration of the initial phase of adsorption to the planar bilayer. This was demonstrated in Fig. 1 for $1 \mu \mathrm{M}$ $\mathrm{PS} / \mathrm{PC}$ SUV and $15 \mathrm{nM}$ annexin V. As both the initial adsorption rate and the rate of equilibrium between free and vesicle bound annexin $V$ are proportional to the concentrations, this must also hold for the higher concentrations, $5 \mu \mathrm{M}$ PS/PC and $100 \mathrm{nM}$ annexin V. This could, however, not be verified directly because the initial adsorption lasts only 20-30 seconds, i.e. 3-4 measurements.

Incomplete inhibition of prothrombinase on small vesicles - As was shown in Fig. 2, inhibition of prothrombinase by annexin $V$ was incomplete on small phospholipid vesicles. This contrasts with results reported by other authors $(2,7,10,11)$, but in these studies higher calcium concentrations (5-10 $\mathrm{mM}$ ) were used and vesicle sizes were not given. The poor inhibition of prothrombinase on SUV is correlated to a high calcium requirement for the binding of annexin $\mathrm{V}$ to these surfaces (Fig. 3). It seems as if the rigid clusters, shown in Fig. 7, are more difficult to form on highly curved surfaces.

Calcium requirement of annexin $V$ binding - The calcium concentration required for binding of annexin $V$ is a function of the membrane content of anionic phospholipid such as PS (5). The PS in small vesicles may be preferentially located in the inner membrane leaflet, and this could explain the reduced binding of annexin $V$. However, for sonicated vesicles it has been 
estimated that PS concentration in the outer leaflet was only $30 \%$ reduced compared to symmetrical distribution (25). This implies that in the SUV preparations used in this study the amount of PS in the outer leaflet would be about $13 \%$. However, only a PS content below $5 \%$ could explain the increased calcium requirement (5). Furthermore, symmetrical distribution, or even preferential accumulation of PG in the outer leaflet, has been reported (2629). Taking sonicated vesicles in stead of planar bilayers, we found a similar shift in the calcium concentration required for half-maximal binding of annexin $\mathrm{V}$ to $\mathrm{PG} / \mathrm{PC}$ vesicles (From $0.15 \mathrm{mM}$ for $20 \% \mathrm{PG} / 80 \% \mathrm{PC}$ planar bilayers to $4.4 \mathrm{mM}$ for $20 \% \mathrm{PG} / 80 \%$ PC vesicles. Results not shown). It is concluded that asymmetrical distribution of lipids in the bilayer cannot explain the observed effects, and that surface-curvature is probably more important.

Reduced binding of annexin $V$ on SUV and LV could be caused by a lower binding affinity, a reduced number of binding sites or both. For SUV we checked the effect of the free annexin $\mathrm{V}$ concentration on the binding to vesicles and observed that increasing the free annexin $V$ concentration from 9 to $70 \mathrm{nM}$ hardly affected the binding. Thus the decreased binding reflects a decrease in the number of binding sites. This is consistent with the high binding-affinity $\left(\mathrm{K}_{\mathrm{d}}<0.1 \mathrm{nM}\right)$ reported for vesicles at $1.2 \mathrm{mM} \mathrm{Ca}^{2+}(4)$, a value 2.3 orders below the concentrations used in Fig. 3.. The maximal surface coverage of $2 \mathrm{mmol}$ of annexin $\mathrm{V}$ per mol of lipid, reported in the same study (4), is close to the value of 2.2 found in the present study for 1 $\mathrm{mM}$ calcium (c.f. Fig. 3).

Displacement of adsorbed coagulation factors by annexin $V$.- Annexin $V$ is able to displace $>90 \%$ of maximal surface coverage of the coagulation factors Xa, Va, and II (Chapter 4). However, Figs 4-6 show that the remaining amounts of adsorbed coagulation factors are sufficient for effective production of thrombin. For prothrombin this result is confirmed by the observation that prothrombin is able to compete for annexin $\mathrm{V}$ binding (4). The residual binding of more than $400 \mathrm{fmol} \cdot \mathrm{cm}^{-2}$, is 10 times lower than the maximal binding of prothrombin of $3500 \mathrm{fmol} \cdot \mathrm{cm}^{-2}$ (30), but for the low prothrombinase activity on the surface it was estimated that a surface concentration of only $2 \mathrm{fmol} \mathrm{cm}^{-2}$ of prothrombin is required for maximal production of thrombin (18). Similarly it was calculated that assembly of prothrombinase is already half-maximal for $0.44 \mathrm{fmol} \cdot \mathrm{cm}^{2}$, which is $5-6$ fold below the quantity factor $\mathrm{Xa}$ retained after displacement by annexin $\mathrm{V} c . f$. 
(Fig. 5). It is concluded that the anticoagulant effect of annexin $V$ cannot be explained by displacement of coagulation factors from the lipid surface.

Formation of ordered clusters of annexin V - As demonstrated in Fig. 7 the cryo-electron micrographs revealed multi-facetted phospholipid structures with sharp edges. These shape changes can only be explained by assuming that large clusters of annexin $V$ induce surface deformation. Mosser et al. (31) have shown that annexin $\mathrm{V}$ binds on planar phospholipid monolayers in a two dimensional array of repeated trimers. Their data could not confirm or reject the hypothesis that the clusters extend to include more than three protein molecules. The straight facets observed in the present study appeared to be limited by the size of the vesicles and sometimes measured more than $100 \mathrm{x}$ $100 \mathrm{~nm}$. This involves up to 400 molecules annexin $V$, as can be calculated from the mean area per annexin $V$ molecule $(5,31)$. No changes in the shape of small sonicated vesicles in the presence of annexin $V$ were observed, even at $10 \mathrm{mM}$ calcium (data not shown). This may be due to the defocus of the objective lens, $(0.5-2 \mu \mathrm{m})$, which is necessary to obtain sufficient contrast. Using such defocus values facilitates the recognition of straight facets but also results in a blurring of the image, which may obscure the high resolution information required to detect the small scale changes anticipated for small vesicles. However, if the vesicle diameter of 20-30 nm of SUV is compared to the average diameter of an annexin $V$ molecule $(5 \mathrm{~nm})$, only 50-100 molecules annexin $\mathrm{V}$ would fit onto one vesicle and the plane of adsorption of each annexin makes an angle of 10-20 degrees with the planes of its neighbors. On large vesicles, the molecules adsorb in extended planes with an average angle between neighboring molecules of less than 1 degree. It is therefore likely that steric constraints counteract clustering of annexin $V$ molecules on highly curved bilayers and this may cause the higher calcium requirement for annexin $\mathrm{V}$ binding observed in Fig. 3.

Inhibition of membrane bound transport of prothrombin - The data presented in Figs. 2-4 show that prothrombinase activity on PS/PC membranes can be completely abolished by annexin $\mathrm{V}$ provided that annexin $\mathrm{V}$ binding to the membranes is maximal. A direct interference of lipid bound annexin $\mathrm{V}$ with prothrombin conversion by the prothrombinase was excluded in experiments similar as shown in Fig. 4, where preadsorption of 0.14-0.17 $\mu \mathrm{g} / \mathrm{cm}^{2}$ annexin $\mathrm{V}\left(70-80 \%\right.$ of $\left.\Gamma_{\max }\right)$ to the PS/PC bilayer prior to prothrombinase assembly did not affect the the prothrombin conversion rate 
(data not shown). These data together with our observation that sufficient coagulation factors remain bound to the membrane for assembly of prothrombinase and for thrombin conversion suggest that the crowding of the surface in itself interferes with these processes (either the assembly and/or conversion). This, however, is not supported by available data. Efficient progress of lipid dependent reactions of the blood coagulation in the presence of high surface concentrations of other high-affinity lipid-binding proteins has been shown. Examples of this poor inhibition are: $50 \%$ inhibition of prothrombinase activity by $5 \mu \mathrm{M}$ prothrombin fragment 1 , and fragment $1-2$ (33), and by $4 \mu \mathrm{M}$ bone gla-protein (34) and less than $50 \%$ inhibition of tissue factor - factor VIIa activity by $0.4 \mu \mathrm{M}$ apolipoprotein A-I, $0.4 \mu \mathrm{M}$ apolipoprotein A-II, $0.7 \mu \mathrm{M}$ C-reactive protein or $0.5 \mu \mathrm{M}$ beta-2-glycoprotein I (35). This poor inhibition by adsorption of independent protein molecules fits well in the recently proposed concept that the lipid membrane accelerates coagulation reactions primarily by providing efficient lateral transport of the reactants $(1,18,36,37)$. It was calculated that due to the high lateral mobility and the high collisional efficiency of two-dimensional diffusion even very low surface concentrations, in the order of $\mathrm{fmol} / \mathrm{cm}^{2}$, of the reactants are sufficient to attain the observed reaction rates. This lateral mobility of isolated molecules also causes continuous rearrangement of adsorbed molecules on the lipid surface and this reshuffling will produce empty spaces on which $e . g$. prothrombin may adsorb (32). In this framework it is attractive to speculate that the exceptionally complete inhibition of prothrombinase by annexin $\mathrm{V}$ is caused by the formation of rigid clusters of annexin $\mathrm{V}$ on the membrane. The empty spaces in the clusters may be large enough to allow binding of coagulation factors, but adsorbed reactants, e.g. prothrombin are unable to diffuse through the surrounding cluster and no collisional complexes will be formed. The present study suggests that this fencing mechanism makes annexin $\mathrm{V}$ an effective anticoagulant.

Physiological importance - Because plasma levels of annexin $V$ are low $(<0.2 \mathrm{nM})(39)$ a significant role of annexin $V$ as circulating anticoagulant is unlikely. On the other hand, annexin $V$ concentrations in cultured endothelial cells are as high as $0.5 \%$ of the total amount of protein (38). Annexin V may, therefore, protect against thrombosis after endothelial cell damage. This study shows that, for a limited procoagulant lipid surface from platelets, only a small amount of annexin $\mathrm{V}$ is required for effective inhibition of 
prothrombinase activity.

\section{REFERENCES}

1. Mann K.G., Nesheim M.E., Church W.R., Haley P., and Krishnaswamy S. (1990) Blood 76, $11-16$.

2. Reutelingsperger C.P.M., Hornstra G., and Hemker H.C. (1985) Eur. J. Biochem. 151, 625-629.

3. Reutelingsperger C.P.M., Kop J.M.M., Hornstra G., and Hemker H.C. (1988) Eur. J. Biochem. 173, 171-178.

4. Tait J.F., Gibson D., and Fujikawa K. (1989) J. Biol. Chem. 264, 7944-7949,

5. Andree H.A.M., Reutelingsperger C.P.M., Hauptmann R., Hemker H.C, Hermens W.T. and Willems G.M. (1990) J. Biol. Chem. 265, 4923-4928.

6. Thiagarajan P., and Tait J.F. (1990) J. Biol. Chem. 265, 1742-17423.

7. Tait J.F., Sakata M., McMullen B.A., Miao C.H., Funakoshi T., Hendrickson L.E., and Fujikawa K. (1988) Biochemistry 27, 6268-6276.

8. Hauptmann R., Maurer-Fogy I., Krystek E., Bodo G., Andree H., and Reutelingsperger C.P.M. (1989) Eur. J. Biochem. 185, 63-71.

9. Iwasaki A., Suda M., Nakao H., Nagoya T., Saino Y., Arai K., Mizoguchi T., Sato F., Yoshizaki H., Hirata M., Miyata T., Shidara Y., Murata M., and Maki M. (1987) J. Biochem. 102, 1261-1273.

10. Chap H., Comfurius P., Bevers E.M., Fauvel J., Vicendo P ", Douste-Blazy L.. and Zwaal R.F.A. (1988) Biochem. Biophys. Res. Commun. 150, 972-978.

11. Funakoshi T., Heimark R.L., Hendrickson L.E., McMullen B.A., and Fujikawa K. (1987) Blochemistry 26,5572-5578.

12. Kondo S., Noguchi M., Funakoshi T., Fujikawa K., and Kisiel W. (1987) Thromb. Res. 48, 449-459.

13. Maurer-Fogy 1., Reutelingsperger C.P.M., Pieters J., Bodo G., Stratowa C., and Hauptmann R. (1988) Eur. J. Biochem. 174, 585-592.

14. Gramzinski R.A., Broze G.J., and Carson S.D. (1989) Blood 73, 983-989.

15. Römisch J., Grote M., Weithmann K.U., Heimburger N., and Amann E. (1990) Blochem. J. 272, 223-229.

16. De Kruijff B., Cullis P.R. and Radda G.K. (1975) Biochim. Biophys. Acta 406, 6-20 .

17. Hope M.J., Bally M.B., Webb G., and Cullis P.R. (1985) Biochim. Biophys. Acta 812, $55-65$.

18. Giesen P.L.A., Willems G.M., and Hermens W.Th. (1991) J. Biol. Chem. 266, 13791382.

19. Lindhout T., Govers-Riemslag J.W.P., Waart van de P., Hemker H.C., and Rosing J. (1982) Biochemistry 21, 5494-5502.

20. Fujikawa K., Legaz M.E., and Davie E.D. (1972) Biochemistry 11, 4892-4899.

21. Cuypers P.A., Corsel J.W., Janssen M.P., Kop J.M.M., Hermens W.Th., and Hemker H.C. (1983) J. Biol. Chem. 258, 2426-2431. 
22. Corsel J.W., Willems G.M., Kop J.M.M., Cuypers P.A., and Hermens W.Th. (1986) J. Colloid Interface 5 ci. 111, 544-554.

23. Bewers EM., Comfurius P., and Zwat R.F.A. (1982) Eur.J. Biochem. 122, 81-85.

24. Frederik P.M., Burger K.N.J., Stuart M.C.A., and Verkleij A.J. (1991) Biochim. Biophys. Acta 1062, 133-141.

25. Kumar A., and Gupta C.M. (1984) Biochim. Biophys. Acta 769, 419-428.

26. Michaelson D.M., Horwitz A.F., and Klein M.P. (1973) Biochemistry 12, 2637-2645.

27. Massori S., and Pascolini D. (1977) Biochemistry $161189-1195$.

28. Lentz B.R., Alford D.R., and Donbrose F.A. (1980) Biochemistry 19, 2555-2559.

29. Nordlund J.R., Schmidt C.F., and Thompson T.E. (1981) Biochemistry 20, 6415-6420.

30. Kop J.M.M., Cuypers P.A., Lindhout T., Hemker H.C., and Hermens W.Th. (1984) J. Bhol. Chem. 259, 13993-13998.

31. Mosser G., Ravanat C., Freyssinet J.-M. and Brisson A. (1991) J. Mol. Biol. 217, 241 245.

32. Willems G.M., Hermens W.Th, and Hemker H.C. (1991) J. Biomater. Sci. Polymer. Edn. 2, 217-226.

33. Govers-Riemslag J.W.P., Speijer H., Zwaal R.F.A., and Rosing J. (1985) Thromb, Res. 38, 375-388.

34. Gendreau M.A., Krishnaswamy S., and Mann K.G. (1989) J. Biol. Chem. 264, 69726978.

35. Carson S.D., and Ross S.E. (1988) Tromb. Res. 50, 679-685.

36. Krishnaswamy S., Jones K.C., Mann K.G. (1988) J. Biol. Chem. 263, 3823-3834.

37. Giesen P.L.A., Willems G.M., Hemker H.C., and Hermens W.Th. (1991) J. Biol. Chem. 266, 18720-18725.

38. Flaherty M.J., West S., Heimark R.L., Fujikawa K., and Tait J.F. (1990) J. Lab. Clin. Med. 115, 174-181. 

. . . . .

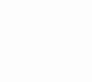
-

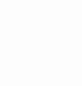




\section{.}




\section{Aggregation of Phospholipid Vesicles by a Chimeric Protein with the N-terminus of Annexin I and core of Annexin $V$}

Harry A.M. Andree, George M. Willems, Rudolf Hauptmann, Ingrid Maurer-Fogy, Marc C.A. Stuart, Wim Th. Hermens, Peter M. Frederik, and Chris P.M. Reutelingsperger

\section{SUMMARY}

A chimeric protein was produced with the $\mathrm{N}$-terminal domain (amino acids 1-45) of annexin I and the core of annexin $V$ (amino acids 19-320) and termed annexin $\mathrm{I}_{\mathrm{N}}-\mathrm{V}_{\mathrm{C}}$. This protein has a similar calcium-requirement for binding to phospholipid bilayers of $20 \%$ phosphatidylserine (PS) / $80 \%$ phosphatidylcholine (PC) as annexin $\mathrm{V}$. In contrast to annexin $\mathrm{V}$ this protein has a strong potency to aggregate vesicles. Electron micrographs showed dramatic enlargement of vesicle size, indicative for membrane fusion. Ellipsometry was employed to show that vesicles adhere to annexin $\mathrm{I}_{\mathrm{N}}-\mathrm{V}_{\mathrm{C}}$ adsorbed on a planar phospholipid bilayer, which indicates the presence of a second phospholipid binding site on annexin $I_{N}-V_{C}$. Vesicle adherence is proportional with the annexin $I_{N}-V_{C}$ surface coverage and can be inhibited by co-adsorption of annex in $\mathrm{V}$ on the planar bilayer or by incubation of the vesicles with coagullation factor $\mathrm{Va}$. Annexin $\mathrm{I}_{\mathrm{N}^{-}} \mathrm{V}_{\mathrm{C}}$, like annexin $V$, does not bind to pure PC bilayers, but annexin $I_{N}-V_{C}$ adsorbed on anionic phospholipid bilayers is able to adhere vesicles prepared from pure PC. This suggests that the second phospholipid binding site is different from the annexin $\mathrm{V}$ phospholipid binding site. Collectively, these data indicate that twodimensional clusters of annexin $\mathrm{I}_{\mathrm{N}}-\mathrm{V}_{\mathrm{C}}$ are involved in vesicle adherence. 


\section{WNTRODUCIION}

The annexins belong to a family of phospholipid binding proteins, that share the structural homology in a conserved core, with 4 or (in the case of annexin VI) 8 internal repeats of about 70 amino acids containing the annexin consensus sequence, and a variable $\mathrm{N}$-terminal tail (1-2).

Several observations support the notion that the $\mathrm{N}$-terminal part of the annexin molecule can influence the calcium-requirement for binding to phospholipids. Phosphorylation of the N-terminus of annexin I (3-4) and annexin II (5) decreases the amount of calcium required for binding (6-7). Limited proteolysis of the $\mathrm{N}$-terminal tail of annexin I also decreases the calciumrequirement for binding (8). Finally, monoclonal antibodies against the $\mathbf{N}$ terminal domain of annexin I did not inhibit phospholipid binding and even decreased the amount of calcium required for binding (9).

Vesicle aggregating properties of several annexins have been reported. Aggregation of chromaffin granules, purified from adrenal medulla, by annexin VII was already described in 1978 (10). Phospholipid vesicle aggregation can be promoted by some annexins (annexin I, II, VII) (10-11), and inhibited by other members of this family (annexin V and VI) (11-12). It was shown that at $\mathrm{pH}=$ 6.0 , only $0.1 \mu \mathrm{M} \mathrm{Ca}^{2+}$ is required for vesicle aggregation and fusion by annexin VII (13). Aggregation (and fusion at $\mathrm{pH}=6.0$ ) of vesicles by a hetero-tetramer of two annexin II molecules and two p11 molecules (14-15) occurs also at micromolar calcium concentrations. Annexin II restores secretion in permeabilized cells, Whereas secretion is inhibited by immunoaffinity purified antibodies against annexin II (16). Some annexins are, therefore, thought to play a role in exocytosis. Annexin $\mathrm{V}$ is a member of the annexin family, which does not promote vesicle aggregation, and in fact is able to impair vesicle aggregation by other annexins.

A protein with the $\mathrm{N}$-terminus of annexin $\mathrm{I}$ and the core of annexin $\mathrm{V}$, annexin $I_{N}-V_{C}$, was constructed (by R.H. and I.M.F. in Vienna), and was expected to have lower calcium-requirement for phospholipid binding. However, the chimera has a similar calcium-requirement for binding to single phosphatidylserine / phosphatidylcholine bilayers as annexin V. In contrast to this latter protein, annexin $I_{N}-V_{C}$ induces vesicle aggregation and fusion. Ellipsometric measurements showed that annexin $\mathrm{I}_{\mathrm{N}}-\mathrm{V}_{\mathrm{C}}$ present on only one of the adhering phospholipid surfaces already is able to induce vesicle adherence. 
This indicates the presence of a second phospholipid binding site in annexin $\mathrm{IN}^{-}$ $V_{C}$ which differs from the annexin $V$ binding site. Aggregation was proportional to the surface coverage of annexin $I_{N}-V_{C}$. Evidence for the formation of phospholipid bound clusters of annexin $I_{N}-V_{C}$ is discussed.

\section{MATERIALS AND METHODS.}

Preparation of phospholipid vesicles and planar bilayers - 1,2-dioleoyl-snglycero-3-phosphatidylserine (PS) was purchased from Avanti Polar Lipids and the corresponding phosphatidylcholine (PC) from Sigma Chemical Co. (P-1013). All experiments were performed with phospholipid mixtures of $20 \% \mathrm{PS} / 80 \%$ PC ( $\mathrm{mol} / \mathrm{mol})$ or pure PC. Small unilamellar vesicles (SUV, $\varnothing 20-40 \mathrm{~nm}$ ) were prepared according to ref. (17) by sonicating a nitrogen-dried phospholipid mixture. Planar phospholipid bilayers were deposited on silicon slides by dipping hydrophylic silicon slides in a stirred vesicles solution (18).

Buffer - Experiments were performed in buffer: $50 \mathrm{mM}$ TRIS/HCl, $\mathrm{pH}=7.5,100 \mathrm{mM} \mathrm{NaCl}$ and $3 \mathrm{mM} \mathrm{CaCl}_{2}$ and $0.5 \mathrm{~g} / \mathrm{l}$ bovine serum albumin (Sigma Chemical Co., A-7030) at $20^{\circ} \mathrm{C}$, unless stated otherwise.

Proteins - Annexin $\mathrm{V}$ was purified from human placental tissue as described (19). Purity of annexins was checked with a SDS-polyacrylamide gel electrophoresis according to Schägger $(20)$ in the presence of $2 \% \mathrm{~B}$ mercaptoethanol, stained with Commassie blue.

Production of annexin $I_{N}-V_{C}$ - A plasmid fragment, obtained after cutting plasmid pRH291 (21) with restriction enzymes PvuII and SphI (Pvull-SphI fragment), contained part of the phoA promotor, the bacterial ribosomal binding site, the entire coding region for annexin $\mathrm{V}$, and a non-translated part. It was subcloned into the commercially available plasmid M13mp18 doubly cut with Smal and SphI. Using the mutagenesis primer EBI-977 (CAACAGA GTCAGGATCGATTCCTCATCTGTGCCC) complementary to annexin V from nucleotide 221-254 (21), and Amersham's in vitro mutagenesis system, mutated CDNA was produced with the indicated Clal-site at the codon for serine-36, without affecting the amino acid sequence. It was sequenced and a large EcoRIHindIII insert was isolated and recloned in Bluescribe M13+ (Stratagen), resulting in pGN31. 
Coding oligonucleotide strands of the N-terminus of annexin I, EBI-982 (CGATTCCTCATCTGTGCCCAAGCCTTTCATAGCCTTCCGAAGAGTTT CTGCATCCGAGGATGGATTGAAGGTAGGATATAGGGGCTCACCGCT GATCCGG) and EBI-988 (GACCACCTTTGGATGACTTCACAGTTTGAA CATATTCCTGCTCTTCATTTTCAATAAACCAGGCCTGCTTGAGGAAT TCTGATACCATTGCCATAAAATCACCTCAACCTC, were phosphorylated by incubation of $1 \mathrm{pmol}$ of each strand for $30 \mathrm{~min}$ at $37^{\circ} \mathrm{C}$ in $6 \mu \mathrm{l} 70 \mathrm{mM}$ TRIS/HCl ( $\mathrm{pH}=7.5$ ), $10 \mathrm{mM} \mathrm{MgCl} 2,5 \mathrm{mM}$ dithiothreitol (DTT), $1 \mathrm{mM}$ rATP and 5 units T4-polynucleotide kinase (New England Biolabs). The reaction was stopped by heating at $95^{\circ} \mathrm{C}$ for $10 \mathrm{~min}$ and $12 \mu \mathrm{l}$ of water was added, containing 1 pmol of the non-coding strands EBI-972 (TCGAGAGGTTGA GGTGATTTTATGGCAATGGTATCAGAATTCCTCAAGCAGGCCTGGTTT ATTGAAAATGAAGAGCAGGAATATGTTCAAACTGTGAAGTCATCCAA) and EBI-978 (AGGTGGTCCCGGATCAGCGGTGAGCCCCTATCCTA CTTCAATCCATCCTCGGATGCAGAAACTCTTCGGAAGGCTATGAAAGG CTIGGGCACAGATGAGGAAT) and approximately $1 \mu \mathrm{g}$ of the XhoI-ClaI fragment of pGN31. the solution was heated to $70^{\circ} \mathrm{C}$ and cooled to room temperature to allow for proper annealing. $12 \mu$ ligase solution $(116 \mathrm{mM}$ TRIS/HCl ( $\mathrm{pH}=7.5), 23 \mathrm{mM} \mathrm{MgCl}, 116 \mathrm{mg} / \mathrm{l}$ bovine serum albumin (Boehringer Mannhein), $46 \mathrm{mM}$ DTT and 3 units T4-ligase (New England Nuclear) was added and the DNA ligated for $16 \mathrm{~h}$ at $14^{\circ} \mathrm{C}$. Competent E. coli JM 101 cells were transformed. A correctly expressed plasmid, checked by sequencing, was selected from the clones and named pGN32.

The XhoI-HinlII insert of pGN32, containing the coding regions of the hybrid annexin, was cloned into pRH284, cut with Xhol and HindIII (21). The resulting plasmid pGN38 expressed annexin $I_{N}-V_{C}$ in high amounts in $E$. coli HB 101 cells, grown as described (21).

$125 /$ annexin $I_{N}-V_{C}-$ Annexin $I_{N}-V_{C}(100 \mu g)$ was added to a vial containing two iodo-beads (Pierce), $1 \mathrm{mCi} 1251$, in $1 \mathrm{ml}$ buffer $(50 \mathrm{mM}$ TRIS $/ \mathrm{HCl}, \mathrm{pH}=7.5,100 \mathrm{mM} \mathrm{NaCl}$ ) and incubated for 15 minutes under continuous stirring. Free 1251 was removed with a gel filtration (G-25) column. This resulted in a specific activity of $4 \times 10^{6} \mathrm{cpm} \cdot \mu \mathrm{g}^{-1}$ annexin $\mathbb{I}_{\mathrm{N}}-\mathrm{V}_{\mathrm{C}}$. Mixtures of $125 \mathrm{I}$-annexin $\mathbb{I}_{\mathrm{N}}-V_{\mathrm{C}}$ and annexin $\mathrm{V}$ were adsorbed to maximal surface coverage as measured with ellipsometry. The slides were removed and the amount of $125 \mathrm{I}$ was determined with a Wallac 1470 Wizard $\gamma$-counter. This procedure showed that the surface concentrations of $125 \mathrm{I}$-annexin $\mathrm{I}_{\mathrm{N}}-\mathrm{V}_{\mathrm{C}}$ 
correspond to the concentration ratio of the two proteins in the buffer (data not shown).

Aggregation of phospholipid vesicles measured with turbidity Aggregation of phospholipid vesicles by annexins was measured essentially as described by Creutz et al. (10). Optical density (O.D.) at $405 \mathrm{~nm}$ was recorded 30 times every 20 seconds $(10 \mathrm{~min})$ in a Cobas Bio auto analyzer. The light absorbance reached a plateau value and is given relative to the blank value of the cuvette. The accuracy of the Cobas Bio photometer signal was better than 0.5 mO.D. The turbidity of solutions of small vesicles $(20-30 \mathrm{~nm})$ used in this study is very small $(<1 \mathrm{mO}$.D.). The formation of small aggregates will therefore induce only small absolute changes in light absorption, which are not easily detectable. The observed changes in optical density reflect the formation of very large aggregates, as was confirmed with electron microscopy.

Ellipsometric determination of protein and phospholipid vesicle adsorption to a planar phospholipid bilayer - A silicon slide covered with a phospholipid bilayer was placed in a quartz cuvette treated with Sigmacote (Sigma Chemical Co., SL-2) containing $5 \mathrm{ml}$ buffer. The solution was stirred at 2400 rotations per minute with a magnetic stirring bar. Annexin adsorptions, at a distance of $1-2 \mathrm{~mm}$ from the stirrer, were measured with ellipsometry (22). For measurements of vesicle adherence, free protein was removed from the cuvette by flushing with 50 $\mathrm{ml}$ buffer. Vesicles were added to the cuvette and the increase in adsorbed mass due to vesicle adherence was measured.

Visualization of phospholipid vesicles with Cryo-electron microscopy Phospholipid vesicles were incubated for at least 10 minutes with annexin in buffer $\left(50 \mathrm{mM}\right.$ TRIS/HCl, $\mathrm{pH}=7.5,100 \mathrm{mM} \mathrm{NaCl}, 3 \mathrm{mM} \mathrm{CaCl}_{2}, \mathrm{~T}=20-22^{\circ} \mathrm{C}$ ). Thin aqueous films were prepared on 700 mesh (hexagonal) specimen grids without any supporting film. These thin films were vitrified in liquid ethane as described previously (23) and observed at $-170^{\circ} \mathrm{C}$ using a Gatan 626 cryo-holder and a Philips CM12 microscope. Electron micrographs were taken at low dose conditions and 1-2 $\mu \mathrm{m}$ defocus was used to improve contrast. They show the suspended material in the hydrated state without any staining. 


\section{RESULTS}

Annexin $I_{N}-V_{C}-$ A mutant protein with amino acids $1-45$ of the $\mathrm{N}$ terminal tail of annexin $I$ and amino acids 19-320 of the core of annexin $V$ was constructed and called annexin $\mathrm{IN}_{\mathrm{N}}-\mathrm{V}_{\mathrm{C}}$. The first $10 \mathrm{~N}$-terminal amino acids of annexin $I_{N}-V_{C}$ were checked (not shown) and matched the $N$ terminus of annexin I. The molecular mass of annexin $I_{N}-V_{C}$ on basis of its amino acid sequence was $39 \mathrm{kDa}$. Fig. 1 shows SDS-polyacrylamide gel electrophoresis of annexin $\mathrm{V}$ and annexin $\mathrm{I}_{\mathrm{N}}-\mathrm{V}_{\mathrm{C}}$. The protein bands correspond to apparent molecular weights of 31 and $34 \mathrm{kDa}$ respectively, consistent with earlier reports (24). The protein preparations were of high purity grade. No evidence for dimerization of annexin $V$ or annexin $\mathbb{I N}_{N}-V_{C}$ was found.

Phospholipid binding of annexin $V$ and annexin $I_{N}-V_{C}$ - Figure 2 presents the binding of annexin $\mathrm{V}$ and annexin $\mathrm{IN}_{\mathrm{N}}-\mathrm{V}_{\mathrm{C}}$ measured with ellipsometry. The adsorption kinetics and maximal binding $\left(\Gamma_{\max }=5.7\right.$ pmol $\cdot \mathrm{cm}^{-2}$ ) of these two proteins to a bilayer of $20 \%$ phosphatidylserine

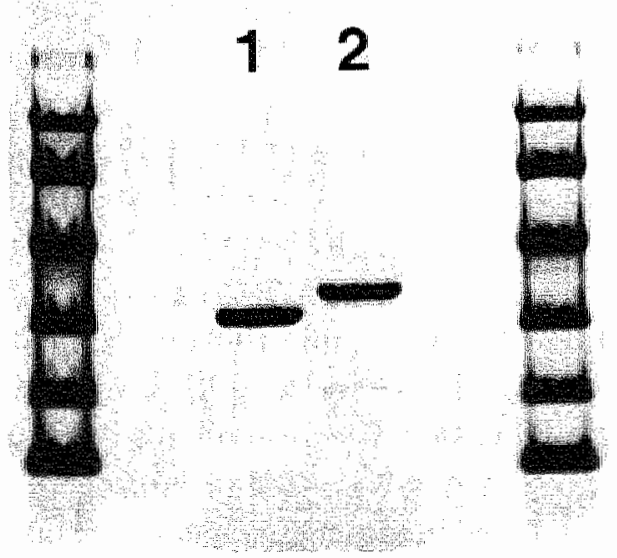

Fig. 1. SDS-PAGE of annexin $I_{N}-V_{C}$ and annexin V. $5 \mu g$ of annexin $V$ (lane 1 ) and annexin $\mathbb{I}_{\mathrm{N}}-\mathrm{V}_{\mathrm{C}}$ (lane 2) in the presence of $2 \%$ B-mercaptoethanol were applied to the gel. The gel was stained with Commassie Blue. Low molecular weight markers (Pharmacia) of 94, 67, $43,30,20.1$ an $14.4 \mathrm{kDa}$ were used as standards. 

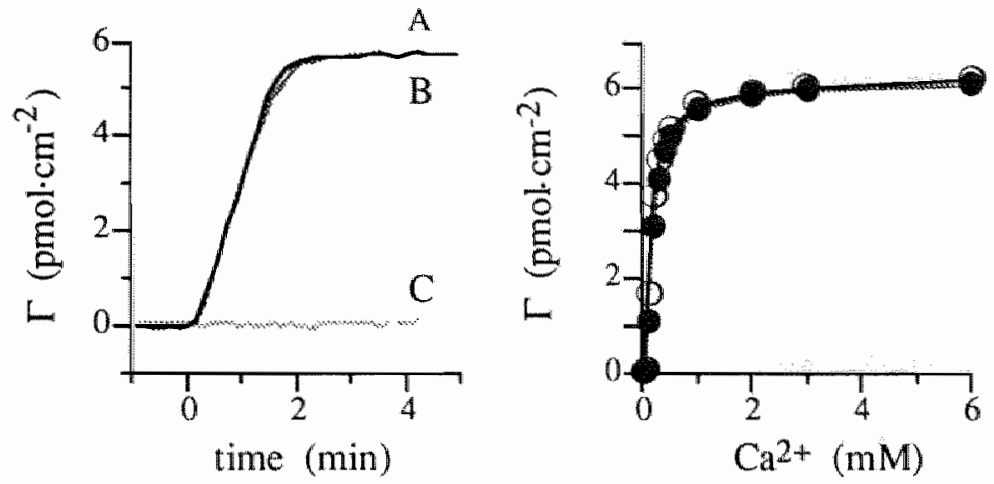

Fig. 2. Binding of annexin $I_{N}-V_{C}$ to phospholipid bilayers. Left panel: Adsorptions of $50 \mathrm{nM}$ annexin $\mathrm{V}(\mathrm{A})$ or $50 \mathrm{nM}$ annexin $\mathrm{I}_{\mathrm{N}^{-}} \mathrm{V}_{\mathrm{C}}(\mathrm{B})$ to a $20 \% \mathrm{PS} / 80 \% \mathrm{PC}$ bilayer are shown. Annexin $\mathrm{I}_{\mathrm{N}}-\mathrm{V}_{\mathrm{C}}$ adsorption to a bilayer of $100 \% \mathrm{PC}(\mathrm{C})$ is negligible. Calcium concentration was $3 \mathrm{mM}$. Right panel: Calcium dependent adsorption of $30 \mathrm{nM}$ annexin $\mathbb{N}_{\mathrm{N}^{-}} \mathrm{V}_{\mathrm{C}}$ (O) or $30 \mathrm{nM}$ annexin $\mathrm{V}(\bullet)$ to a $20 \% \mathrm{PS} / 80 \%$ PC bilayer. Buffer: $50 \mathrm{mM}$ TRIS/HCl, pH $=$ $7.5,100 \mathrm{mM} \mathrm{NaCl}, \mathrm{T}=20^{\circ} \mathrm{C}$.

/ $80 \%$ phosphatidylcholine are nearly identical. The dotted line shows no measurable adsorption of annexin $\mathrm{I}_{\mathrm{N}}-\mathrm{V}_{\mathrm{C}}$ to a $100 \% \mathrm{PC}$ bilayer. The right panel of Fig. 2 shows the effect of calcium on the binding of annexin $\mathrm{V}$ and annexin $\mathrm{I}_{\mathrm{N}}-\mathrm{V}_{\mathrm{C}}$ to $20 \%$ PS / $80 \%$ PC bilayers. Half-maximal calcium concentrations for binding are similar, $0.22 \pm 0.02 \mathrm{mM}$ and $0.17 \pm 0.04 \mathrm{mM}$ for annexin $\mathrm{V}$ and annexin $\mathrm{IN}_{\mathrm{N}}-\mathrm{V}_{\mathrm{C}}$, respectively.

Aggregation of vesicles measured with turbidity- Although annexin $\mathrm{V}$ and annexin $\mathrm{I}_{\mathrm{N}}-\mathrm{V}_{\mathrm{C}}$ have identical phospholipid binding properties to a single phospholipid layer, a clear difference exists in their capacity to aggregate vesicles. Aggregation of vesicles was investigated by measurement of changes in optical density at $405 \mathrm{~nm}$. The left panel of Fig. 3 shows that aggregation of $100 \mu \mathrm{M}$ vesicles starts at $0.6 \mu \mathrm{M}$ annexin $\mathrm{I}_{\mathrm{N}}-\mathrm{V}_{\mathrm{C}}$ and half-maximal change in optical density occurs at a concentration of $1.2 \mu \mathrm{M}$. The concentrations of annexin $I_{N}-V_{C}$ that result in half-maximal change in turbidity and the maximal change in turbidity are linear functions of the phospholipid concentration from $20-100 \mu \mathrm{M}$ (data not shown). The right part of Fig. 3 shows the aggregation of $50 \mu \mathrm{M}$ vesicles by $2 \mu \mathrm{M}$ annexin $\mathrm{I}_{\mathrm{N}}-\mathrm{V}_{\mathrm{C}}$, plotted as 

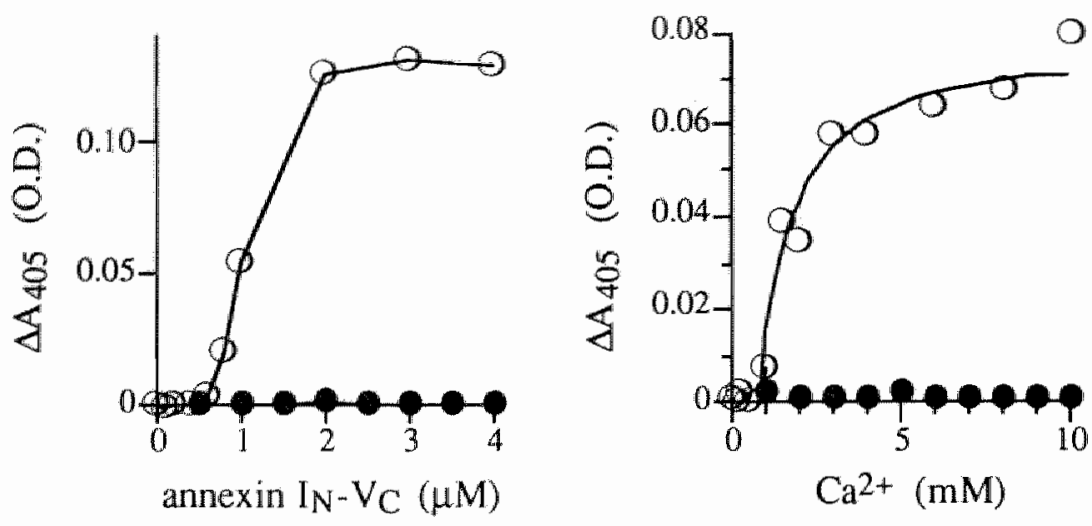

Fig. 3. Vesicle aggregation measured by change of turbidity. Left panel: The aggregation of $100 \mu \mathrm{M}$ phospholipid vesicles as function of the final annexin $\mathrm{I}_{\mathrm{N}^{-}} \mathrm{V}_{\mathrm{C}}(\mathrm{O})$ or annexin $\mathrm{V}$ (-) concentration was measured by the change in optical density at $405 \mathrm{~nm}$. Calcium concentration was $3 \mathrm{mM}$. Right panel: Effect of calcium on the change in turbidity of $50 \mu \mathrm{M}$ vesicles was measured in the presence of $2 \mu \mathrm{M}$ annexin $\mathrm{I}_{\mathrm{N}^{-}} \mathrm{V}_{\mathrm{C}}(\mathrm{O})$ or $2 \mu \mathrm{M}$ annexin $\mathrm{V}$ (๑). Buffer: $50 \mathrm{mM}$ TRIS/HCl, $\mathrm{pH}=7.5,100 \mathrm{mM} \mathrm{NaCl}, 0.5 \mathrm{~g} / 1$ bovine serum albumin, $\mathrm{T}=37$ ${ }^{\circ} \mathrm{C}$.

a function of the calcium concentration. The apparent threshold callcium concentration is $1 \mathrm{mM}$ and half-maximal light scattering occurs at $2 \mathrm{mM}$ calcium. No change in optical density was observed in these experiments if annexin $\mathrm{V}$ in stead of annexin $\mathbb{I}_{\mathrm{N}}-\mathrm{V}_{\mathrm{C}}$ was added.

Vesicle aggregation measured with ellipsometry - In vesicle suspensions it is impossible to control and investigate the effects of different protein surface coverages on both aggregating lipid surfaces. Therefore, we investigated the lipid - annexin $\mathrm{I}_{\mathrm{N}}-\mathrm{V}_{\mathrm{C}}$ - lipid interactions with ellipsometry at a supported planar bilayer. The left panel of Fig. 4 presents measurements of the adherence of vesicles to phospholipid bilayers covered with annexin $I_{N-}$ $V_{C}$. The annexin was adsorbed and subsequently protein was removed from solution by flushing the cuvette with buffer. The high affinity of annexin $\mathrm{IN}_{\mathrm{N}}$ $V_{C}$ for phospholipid binding appears from the minimal desorption observed after flushing ( $<10 \%$ of adsorbed mass) at $3 \mathrm{mM} \mathrm{Ca} 2+$. Then vesicles were added to a final concentration of $5 \mu \mathrm{M}$ and the adsorbed mass was measured in time. It appeared that both the rate of vesicle adherence and the final amount of lipid vesicles adsorbed increased with increasing surface coverage of the bilayer with annexin $\mathrm{I}_{\mathrm{N}}-\mathrm{V}_{\mathrm{C}}$. No vesicle adhesion was observed to a bilayer 

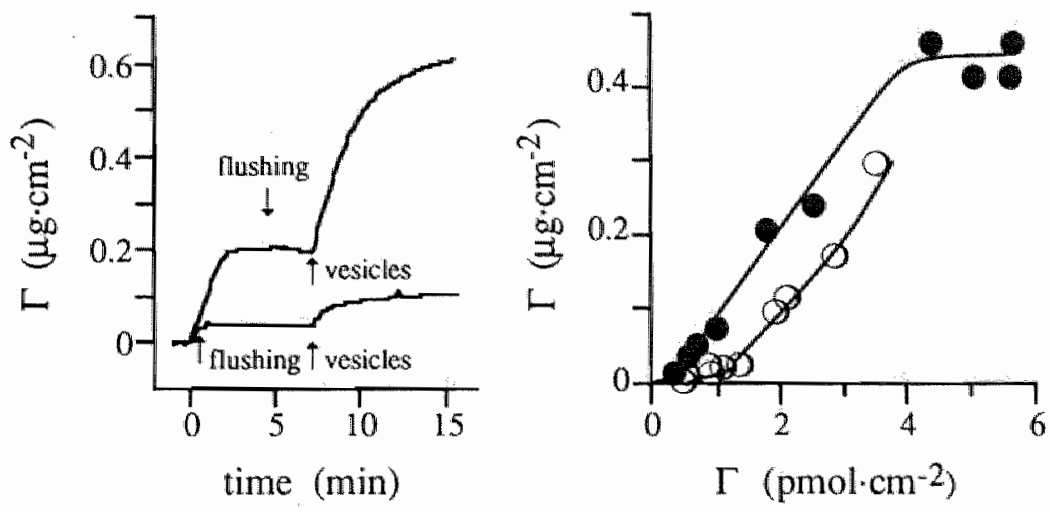

Fig. 4. Adherence of phospholipid vesicles to a phospholipid surface partially covered with annexin $\mathbf{I}_{\mathrm{N}}-\mathrm{V}_{\mathrm{C}}$. Left panel: Adsorption of annexin $\mathrm{I}_{\mathrm{N}}-\mathrm{V}_{\mathrm{C}}$ was stopped by flushing the cuvette with buffer. Adsorption of $5 \mu \mathrm{M}$ vesicles to a bilayer covered with 0.037 $\mu \mathrm{g} \cdot \mathrm{cm}^{-2}\left(=0.95 \mathrm{pmol} \cdot \mathrm{cm}^{-2}\right.$, lower curve $)$ or $0.19 \mu \mathrm{g} \cdot \mathrm{cm}^{-2}\left(=4.9 \mathrm{pmol} \cdot \mathrm{cm}^{-2}\right.$, upper curve $)$ annexin $\mathrm{I}_{\mathrm{N}}-\mathrm{V}_{\mathrm{C}}$ was measured. Right panel: Total adsorption of $5 \mu \mathrm{M}$ vesicles after $8 \mathrm{~min}$. was measured as function of surface coverage $(\bullet)$. Open circles $(O)$ present similar experiments with mixtures of annexin $\mathrm{I}_{\mathrm{N}}-\mathrm{V}_{\mathrm{C}}$ and annexin $\mathrm{V}$. Buffer: $50 \mathrm{mM}$ TRIS/HCl, $\mathrm{pH}=7.5,100 \mathrm{mM}$ $\mathrm{NaCl}, 0.5 \mathrm{~g} / \mathrm{l}$ bovine serum albumin, $\mathrm{T}=20^{\circ} \mathrm{C}$.

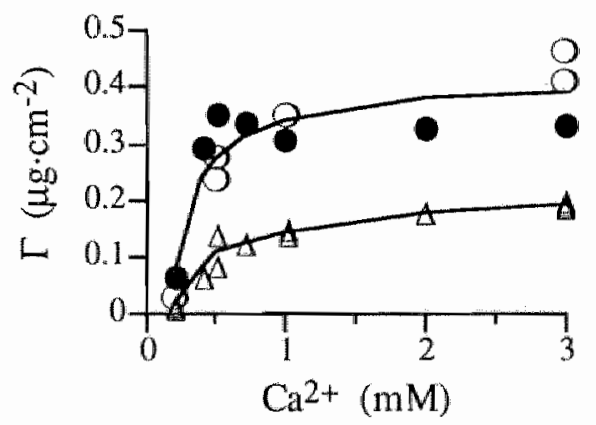

Fig. 5. Calcium-dependent adherence of vesicles to a bilayer coated with annexin $I_{N}-V_{C}$. Annexin $I_{N}-V_{C}$ was added and flushed from the cuvetie and final adsorption is indicated $(\Delta)$. The adherence of $5 \mu \mathrm{M}$ vesicles prepared from $20 \% \mathrm{PS} / 80 \% \mathrm{PC}$ (O) or from 100\% PC (@) was measured. Buffer: $50 \mathrm{mM}$ TRIS/HCl, $\mathrm{pH}=7.5,100 \mathrm{mM} \mathrm{NaCl}$, $0.5 \mathrm{~g} / 1$ bovine serum albumin, $\mathrm{T}=20^{\circ} \mathrm{C}$. 
covered with annexin $\mathrm{V}$ (data not shown). The initial adhesion rate of the vesicles was $2.6 \pm 0.3 \times 10^{-3} \mu \mathrm{g} \cdot \mathrm{cm}^{-2} \cdot \mathrm{s}^{-1}$ (mean \pm S.D.), which approximates the transport-rate limit (see Discussion). Apparently binding of annexin $I_{N}-V_{C}$ resulted in the appearance of a second phospholipid binding site. The right panel of Fig. 4 shows that vesicle adsorption after 8 minutes is virtually a linear function of the surface concentration of annexin $I_{N}-V_{C}$ in the range $0.2-5 \mathrm{pmol} \cdot \mathrm{cm}^{-2}$. In the experiments indicated by open circles, mixtures of annexin $\mathrm{I}_{\mathrm{N}}-\mathrm{V}_{\mathrm{C}}$ and annexin $\mathrm{V}$ were adsorbed up to maximal surface coverage $\left(0.17-0.20 \mu \mathrm{g} \cdot \mathrm{cm}^{-2}\right)$ and the surface concentration of annexin $I_{N}-V_{C}$ was calculated from total adsorption and the protein concentration ratio in the mixture. The validity of this procedure was checked with $125 \mathrm{I}$-annexin $\mathrm{IN}_{\mathrm{N}}-\mathrm{V}_{\mathrm{C}}$, as described in the Methods section. Fig. 4 shows that incorporation of adsorbed annexin $I_{N}-V_{C}$ in a matrix of annexin $V$ results in considerably decreased vesicle adhesion compared to the adhesion at the same surface coverage of annexin $\mathrm{I}_{\mathrm{N}}-\mathrm{V}_{\mathrm{C}}$ without annexin $\mathrm{V}$. Incorporation in the annexin $\mathrm{V}$ matrix abolishes vesicle adhesion nearly completely for surface coverages below $1.5 \mathrm{pmol} \cdot \mathrm{cm}^{-2}$.

The second phospholipid binding site - Figure 5 shows calciumdependent adherence of vesicles of $20 \% \mathrm{PS} / 80 \% \mathrm{PC}$ and vesicles of $100 \% \mathrm{PC}$ to bilayers covered with annexin $I_{N}-V_{C}$. Flushing causes annexin $I_{N}-V_{C}$ desorption at lower calcium concentrations and this explains the reduced

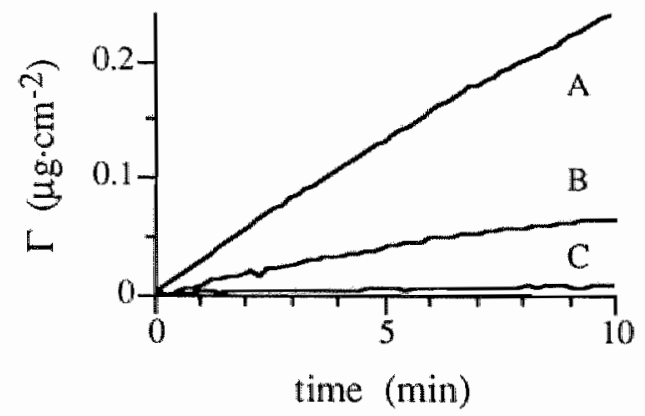

Fig. 6. Inhibition of aggregation by factor Va. Annexin $I_{N}-V_{C}$ was adsorbed (5-5.5 pmol. $\mathrm{cm}^{-2}$ ) and removed from the cuvette. A final concentration of $1 \mu \mathrm{M}$ phospholipid vesicles (20\% PS / $80 \% \mathrm{PC}$ ) was incubated with buffer (A), $5 \mathrm{nM}$ factor $\mathrm{Va}(\mathrm{B})$ or $10 \mathrm{nM}$ factor $\mathrm{Va}$ (C) for 5 minutes. The mixture was then added to the cuvette and adherence is shown. Buffer: $50 \mathrm{mM}$ TRIS/HCl, $\mathrm{pH}=7.5,100 \mathrm{mM} \mathrm{NaCl}, 0.5 \mathrm{~g} / 1$ bovine serum albumin, $3 \mathrm{mM} \mathrm{CaCl}$, $\mathrm{T}=20^{\circ} \mathrm{C}$. 

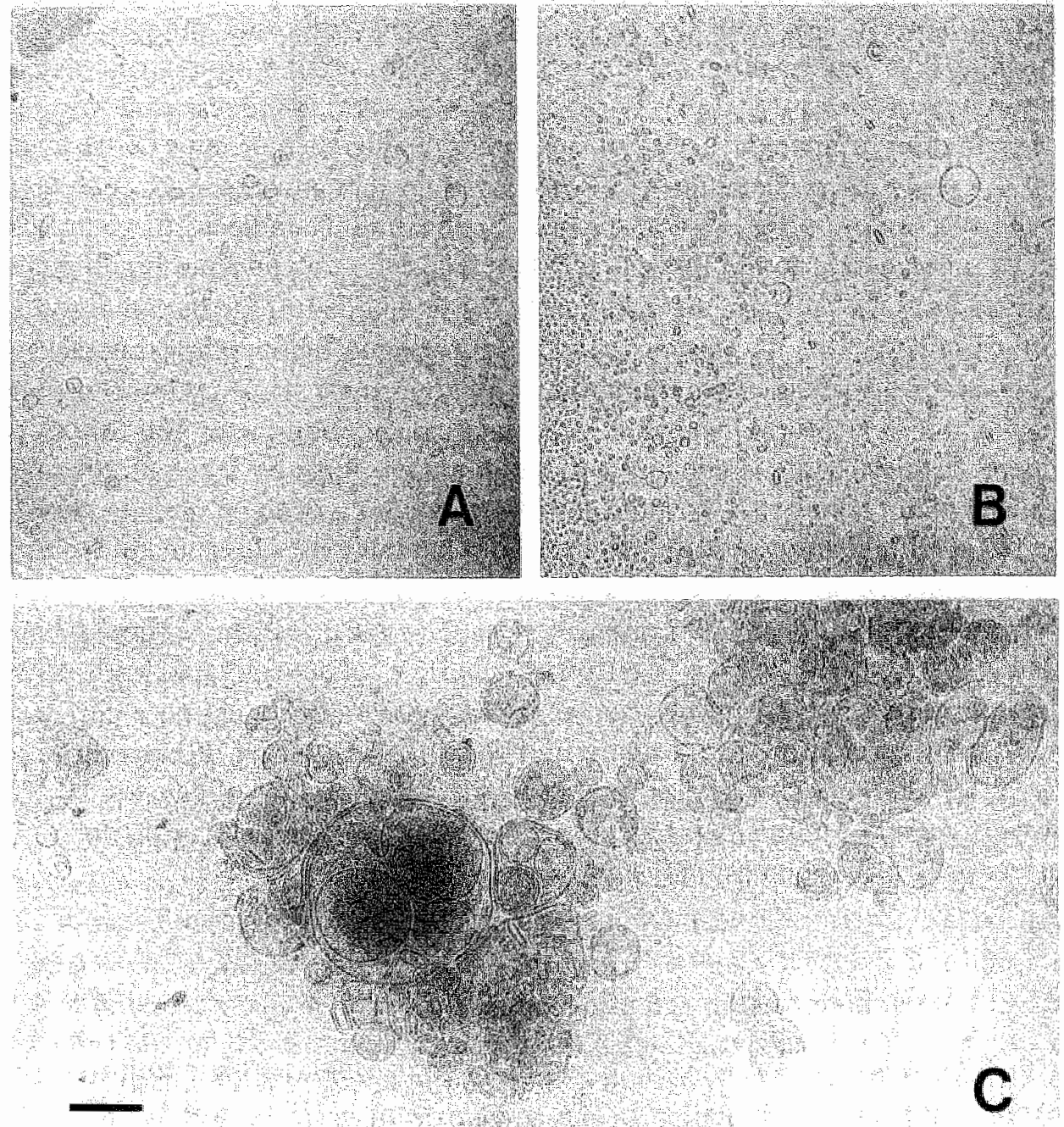

Fig. 7. Cryo-electron micrographs of aggregated vesicles. $1 \mathrm{mM}$ of $20 \%$ PS and $80 \%$ PC vesicles (A), with $20 \mu \mathrm{M}$ annexin $\mathrm{V}$ (B) or with $20 \mu \mathrm{M}$ annexin $\mathrm{IN}_{\mathrm{N}} \mathrm{V}_{\mathrm{C}}$ (C) were vitrified by rapid plunging into liquid ethane and viewed with cryo-electron microscopy. Bar represents $200 \mathrm{~mm}$. Buffer: $50 \mathrm{mM}$ TRIS/HCl, $\mathrm{pH}=7.5,100 \mathrm{mM} \mathrm{NaCl}, 3 \mathrm{mM} \mathrm{CaCl}, \mathrm{T}=20$ ${ }^{\circ} \mathrm{C}$. 
annexin $I_{N}-V_{C}$ binding compared to Fig. 2. Adherence of vesicles was proportional to the annexin $I_{N}-V_{C}$ adsorption and independent of the phospholipid composition of the vesicles. The small amount of vesicle adherence at $0.2 \mathrm{mM} \mathrm{Ca}^{2+}$ is in agreement with the decreased surface concentration of annex in $\mathrm{I}_{\mathrm{N}}-\mathrm{V}_{\mathrm{C}}$. Thus both the adherence of pure $\mathrm{PC}$ vesicles and the much lower calcium-requirement for vesicle adherence as compared to the calcium-requirement for annexin $\mathrm{I}_{\mathrm{N}}-\mathrm{V}_{\mathrm{C}}$ binding indicate that annexin $I_{N}-V_{C}$ once bound to the lipid membrane exposes a second lipid binding site distinct from the annexin $\mathrm{V}$ binding site. These data led to the hypothesis that surface coverage of the vesicle surface with protein hampers the interaction between preadsorbed chimeric protein and vesicles. This hypothesis was checked for vesicles preincubated with blood coagulation factor Va. In Fig. 6, adherence of vesicles is shown to be inhibited for $95 \%$ by incubation of the vesicles with factor $\mathrm{Va}$. This indicates that factor $\mathrm{Va}$ indeed effectively shields the phospholipid surface of the vesicles from interactions with annexin $\mathbb{I}_{\mathrm{N}}-\mathrm{V}_{\mathrm{C}}$.

Visualization of vesicles aggregation - In figure 7 , sonicated vesicle preparations without annexin (upper left panel), with annexin $\mathrm{V}$ (upper right panel) and with annexin $I_{N}-V_{C}$ (lower panel), were investigated with cryoelectron microscopy. Control vesicles were stable and showed no significant increase in size for at least 7 hours (not shown). Adsorption of annexin $V$ to the vesicles did not change size or appearance. The presence of annexin $I_{N}-V_{C}$ (lower panel) induced large multilamellar aggregates, with loss of intervesicular membranes, indicating membrane fusion.

\section{DISCUSSION}

Ellipsometry as new method to study vesicle aggregation - Ellipsometry permits accurate determination of the adherence of vesicles to a macroscopic surface, both for low vesicle and low protein surface concentrations. It is possible to control and measure protein adsorption and relate surface coverage to vesicle adherence. The immobilized protein offers the advantage of separation of events occurring in free solution and at the surface. The presence of multiple phospholipid binding sites on annexin $I_{N}-V_{C}$ was thus easily demonstrated. This approach also allowed the study of interaction of pure $\mathrm{PC}$ vesicles with membrane bound annexin $\mathrm{I}_{\mathrm{N}}-\mathrm{V}_{\mathrm{C}}$. 
Adsorption kinetics of vesicles - With a mean vesicle diameter of $25 \mathrm{~nm}$ and a mean surface area of $0.6 \mathrm{~nm}^{2}$ per phospholipid molecule, one vesicle contains about 4800 phospholipid molecules. Therefore, $5 \mu \mathrm{M}$ phospholipid is equivalent to $1.04 \mathrm{nM}$ vesicles. The theoretical transport rate limit of vesicles, for the stirring conditions used in the ellipsometer, was determined by comparison with prothrombin adsorption. Values of the diffusion constants for vesicles of $D=1.7 \times 10^{-7} \mathrm{~cm}^{2} \cdot \mathrm{s}^{-1}$ and for prothrombin of $D=6.2 \times 10^{-7}$ $\mathrm{cm}^{2} \cdot \mathrm{s}^{-1}$ were used. The transport rate limit of $5 \mu \mathrm{M}$ phospholipid vesicles thus calculated was $2.5 \times 10^{3} \mu \mathrm{g} \cdot \mathrm{cm}^{-2} \cdot \mathrm{s}^{-1}$. A bilayer fully covered with annexin $\mathrm{IN}_{\mathrm{N}}$ $V_{C}$ bound $0.45 \mu \mathrm{g} \cdot \mathrm{cm}^{-2}$ vesicles within minutes with an initial adsorption rate of $2.6 \times 10^{3} \mu \mathrm{g} \cdot \mathrm{cm}^{-2} \cdot \mathrm{s}^{-1}$ approximately equal to the diffusion limit. After flushing of the cuvette, less than 1 molecule of annexin $I_{N}-V_{C}$ was present to every 30 vesicles. This excludes a contribution of annex in $I_{N}-V_{C}$ adsorption to the observed vesicle adsorption rate.

Protein-protein interactions - versus multiple phospholipid binding sites - It could be hypothesized that vesicle aggregation occurs through interaction of annexin $I_{N}-V_{C}$ present on both the adhering phospholipid surfaces. In contrast, phospholipid-bound annexin $I_{N}-V_{C}$ could bind vesicles without substantial amounts of annexin $I_{N}-V_{C}$ in the buffer, indicating that aggregation occurs through direct interaction of annexin $I_{N}-V_{C}$ with the opposing phospholipid. This could be due to adsorption of annexin $\mathrm{I}_{\mathrm{N}}-\mathrm{V}_{\mathrm{C}}$ dimers. Annexin VII shows calcium-dependent self-association, which was proposed as a mechanism for its aggregation (26). Annexins show weak monomer-dimer equilibria with $\mathrm{K}_{\mathrm{d}}$ values of $0.3-1.3 \times 10^{-3} \mathrm{M}$ (27) exceeding the protein concentrations used in the present study by $3-6$ orders of magnitude. Annexin $V$ was shown to adsorb as a protein monolayer (28-29), and in view of the similar values observed for $\Gamma_{\max }$ this is also likely to be true for annexin $I_{N}-V_{C}$. It is concluded that formation of annexin $I_{N}-V_{C}$ dimers, in solution or at the surface, is not a plausible model for vesicle aggregation. This leads to the model that a second phospholipid binding site is present on annexin $\mathrm{I}_{\mathrm{N}} \cdot \mathrm{V}_{\mathrm{C}}$ once adsorbed on phospholipid membranes.

The second phospholipid binding site differs from the annexin $V$ phospholipid binding site - Pure PC membranes show no annexin $\mathbb{I}_{N}-V_{C}$ binding, while vesicles of pure $P C$ adhere to preadsorbed annexin $I_{N}-V_{C}$. This indicates a different phospholipid specificity of the second phospholipid binding site compared to the annexin $\mathrm{V}$ binding site. Similar binding of $\mathrm{PC}$ 
vesicles to rabbit lung annexins $I$ and 33000 phospholipid-binding-protein (=annexin VIII) adsorbed on anionic liposomes was demonstrated earlier (30). We observed only an indirect effect of the $\mathrm{Ca}^{2+}$ concentration on the vesicle adherence as the $\mathrm{Ca}^{2+}$ concentration appeared only to controle annexin $\mathrm{I}_{\mathrm{N}}-\mathrm{V}_{\mathrm{C}}$ adsorption. Therefore, it is concluded that the second phospholipid binding site probably has a reduced calcium-requirement compared to the annexin $\mathrm{V}$ phospholipid binding site.

Clustering of annexin $I_{N^{-}} V_{C}$ - Considerably more calcium is required for aggregation of vesicles measured with turbidity (Fig. 3) than for adherence of vesicles measured in the ellipsometer (Fig. 5). In a previous paper we reported that annexin $\mathrm{V}$ requires $3 \mathrm{mM} \mathrm{Ca} 2+$ for half-maximal binding to small vesicles. This is $10-15$ times more than required for halfmaximal binding to the planar bilayers $(0.2 \mathrm{mM})$. We also showed that lipidbound annexin $\mathrm{V}$ forms planar rigid clusters on phospholipid membranes with low curvature. It was suggested that high curvature counteracts the formation of such clusters and that this explains the higher calcium requirement for binding to high curvature surfaces (Chapter 5). The increased calcium concentration required for aggregation, compared to the adherence of vesicles to the bilayer, probably reflects the calcium requirement for binding to high curvature membranes. Vesicle adherence was proportional to the surface coverage of annexin $I_{N}-V_{C}$. If one single annexin $I_{N}-V_{C}$ (surface area 25 $\mathrm{nm}^{2}$ ) would bind one vesicle (surface area $600 \mathrm{~nm}^{2}$ ), maximal binding of vesicles would occur at approximately $5 \%$ of the maximal surface coverage of annexin $I_{N}-V_{C}$. Since considerably more annexin $I_{N}-V_{C}$ is required, it is suggested that multiple annexin $\mathbb{I}_{N}-V_{C}$ molecules are involved in adhering a single vesicle either by increasing the affinity for the vesicles or by formation of large ( $>25$ molecules) protein islands. Annexin $\mathrm{V}$ co-adsorption next to annexin $I_{N}-V_{C}$ can be assumed to result in a random "spacing" of annexin $I_{N}$ $V_{C}$ on the surface, interfering with annexin $I_{N}-V_{C}$ clustering. The inhibitory effect of co-adsorption of annexin $\mathrm{V}$, therefore, suggests that clusters of annexin $\mathrm{I}_{\mathrm{N}}-\mathrm{V}_{\mathrm{C}}$ are involved in the aggregation process.

Aggregation by another chimera of anmexin $I$ and $V$ - Ernst et al. constructed a chimeric protein with amino acids 4.1-118 of annexin I, containing the first repeat, and amino acids 92-320 of annexin $\mathrm{V}$. This protein aggregated phospholipid vesicles suggesting a specific function of the first repeat of annexin I for vesicle aggregation (31). The present study shows, that 
replacement of the $\mathrm{N}$-tail also induced the vesicle aggregating potency. The chimera of Ernst et al., however, is devoid of its $\mathrm{N}$-tail. Thus it is plausible that neither the $\mathrm{N}$-terminus nor the first repeat, but rather a more global molecular conformation modulates the aggregating functions.

Membrane fusion - Membrane fusion was also observed for several members of the annexin family (annexin I, II, and VII). These proteins required low calcium concentrations to induce fusion (13-14). In these reports vesicles were used with a high percentage of PS or PE, and mixtures were perturbated with arachidonic acid or experiments were performed at low $\mathrm{pH}$. Vesicle fusion could be inhibited by addition of phosphatidylcholine. It is not clear whether addition of PC inhibited vesicle fusion or just decreased binding of annexin. The size of vesicles in the present study was stable for at least 7 hours as determined with cry-electron microscopy. Vesicles with $80 \%$ PC at neutral $\mathrm{pH}$ are aggregated by annexin $\mathbb{I}_{\mathrm{N}}-V_{\mathrm{C}}$. These aggregates grew up to 1 $\mu \mathrm{m}$ in size and became multilamellar. These observations indicate specific membrane fusion by annexin $\mathrm{IN}_{\mathrm{N}}-\mathrm{V}_{\mathrm{C}}$, which is presently under further investigation.

Conciusions - A chimera of amino acids 1-45 of annexin I and amino acids 19-320 of annexin $V$ was constructed (annexin $I_{N}-V_{C}$ ). This protein bound to single phospholipid bilayers at similar calcium concentrations as annexin $\mathrm{V}$, but aggregated and fused vesicles. Annexin $\mathrm{I}_{\mathrm{N}}-\mathrm{V}_{\mathrm{C}}$ contains a second phospholipid binding site capable of binding pure PC vesicles. Aggregation probably requires two-dimensional clusters of adsorbed annexin $\mathrm{I}_{\mathrm{N}}-\mathrm{V}_{\mathrm{C}}$

\section{REFERENCES}

1. Geisow M.J. (1986) FEBS. lett. 203, 99-203.

2. Geisow M.J., Fritsche U., Hexham J.M., Dash B., and Johnson T. (1986) Nature 320 , 636-638.

3. De B.K., Misono K.S., Lukas T.J., Moczkowski B., and Cohen S. (1986) J. Biol. Chem. 261, 13784-13792.

4. Pepinsky R.B., and Sinclair L.K. (1986) Nature 321, 81-84.

5. Glenney J.R., and Tack B.F. (1985) Proc. Natl. Acad. Sci. USA 82, 7884-7888.

6. Glenney J.R. (1986) J. Biol. Chem. 261, 7247-7252.

7. Schlaepfer D.D., and Haigler H.T. (1987) J. Biol. Chem. 262, 6931-6937. 
8. Ando Y., Imamura S., Hong, Y.-M., O M.K., Kkunaga T., Kannagi R. (1989) J. Biol. Chem. 264, 6945-6955.

9. Glenney J.R., and Zokas L. (1988) Biochemistry 27, 2069-2076.

10. Creutz C.E., Pazoles C.J. and Pollard H.B. (1978) J. Biol. Chem. 253, 2858-2866.

11. Blackwood R.A., and Ernst J.D. (1990) Biochem. J. 266, 195-200.

12. Oshry L., Meers P., Mealy T., and Tauber A.I. (1991) Biochim. Biophys. Acta 1066, 239-244

13. Nir S., Stutzin A., and Pollard H.B. (1987) Biochim. Biophys. Acta 903, 309.318.

14. Drust D.S., and Creutz C.E. (1988) Nature 331, 88-91.

15. Powell M.A., and Glenney J.R. (1987) Biochem. J. 247, 321.328.

16. Ali S.M., Geisow M.J., and Burgoyne R.D. (1989) Nature 340, 313-315.

17. Kruijff de B., Cullis P.R., and Radda G.K. (1975) Biochim. Biophys. Acta 406, 6-20.

18. Giesen P.L.A., Willems G.M., Hermens W.Th. (1991) J. Biol. Chem. 266, 1379-1382.

19. Reutelingsperger C.P.M., Kop J.M.M., Hornstra G., and Hernker H.C. (1988) Eur. J. Biochem. 173, $171-178$.

20. Schägger H., and Jagow von G. (1987) Analytical Biochemistry 166, 368-379.

21. Maurer-Fogy I., Reutelingsperger C.P.M., Pieters J., Bodo G., Stratowa C., and Hauptmann R (1988) Eur. J. Biochem. 174, 585-592.

22. Cuypers P.A., Corsel J.W., Janssen M.P., Kop J.M.M., Hermens W.Th. and Hemker H.C. (1983) J. Biol. Chem. 258, 2426-2431.

23. Frederik P.M., Burger K.N.J., Stuart M.C.A., and Verkleij A.J. (1991) Biochim. Biophys. Acta 1062, 133-141.

24. Reutelingsperger C.P.M., Hornstra G., and Hemker H.C. (1985) Eur. J. Biochem. 151, 625-629.

25. Giesen P.L.A. (1992) Thesis, Cardiovascular Research Institute Maastricht, University of Limburg, The Netherlands.

26. Creutz C.E., Pazoles C.J., and Pollard H.B. (1979) J. Biol. Chem. 254, 553-558.

27. Ahn N.G., Teller D.C., Bienkowski M.J., McMullen B.A., Lipkin E.W., and Haën de C. (1988) J. Biol. Chem. 263, 18657-18663.

28. Andree H.A.M., Reutelingsperger C.P.M., Hauptmann R., Hemker H.C., Hermens W.Th., and Willems G.M. (1990) J. Biol. Chem. 265, 4923-4928.

29. Mosser G., Ravanat C., Freyssinet J.-M., and Brisson A.J. (1991) J. Mol. Biol. 217, $241-245$

30. Tsao F.H.C. (1990) Biochim. Biophys. Acta 1045, 29-39.

31. Ernst J.D., Hoye E., Blackwood R.A., and Mok T.L. (1991) J. Biol. Chem. 266, 66706673. 




\section{Summary and Concluding Remarks}

Blood coagulation consists of a series of enzymatic reactions. The activation of factor $\mathrm{X}$ by tissue factor-factor VIIa, and by the factor VIIIa-IXa complex and of prothrombin by the factor $\mathrm{Va}-\mathrm{Xa}$ (prothrombinase) complex are greatly stimulated by the presence of (anionic) phospholipids, which may be provided by subendothelium and activated blood platelets. The enhancement of these blood coagulation reactions can be counteracted by phospholipid-binding proteins, competing with the coagulation factors for the phospholipid membranes. This thesis is focused on the phospholipid binding properties of annexin $V(1)$, the most potent of these inhibitors, and describes its mechanism of action.

Phospholipid binding of the coagulation factor prothrombin - The rate of protein adsorption on a macroscopic surface is often diffusion or transport limited. In Chapter 2, adsorption kinetics of prothrombin to $40 \%$ phosphatidylserine (PS) / 60\% phosphatidylcholine (PC) bilayers were measured with an accurate and fast technique: off-null ellipsometry. Observed adsorption kinetics were interpreted by means of a new model-free analysis. The adsorption rate is equal to the transport coefficient times the concentration difference between the bulk and the solution immediately adjacent to the lipid surface. The latter concentration is governed by the amount of lipid bound prothrombin conforming to the classical Langmuir isotherm. With a known value of maximal surface coverage of a protein this allows determination of the dissociation constant from the adsorption kinetics of a single experiment. This method yielded a $\mathrm{K}_{\mathrm{d}}$ of prothrombin for a $40 \% \mathrm{PS} / 60 \% \mathrm{PC}$ surface $(31 \mathrm{nM})$ in excellent agreement with values determined from measurements of equilibrium adsorptions. Deviations from this simple adsorption model are observed for surface coverage exceeding $50 \%$ of maximal binding, presumably caused by steric hindrance, or surface exclusion.

Phospholipid binding of annexin $V$ - Properties of annexin $\mathrm{V}$ binding to phospholipid bilayers are studied in Chapter 3 . Binding of annexin $V$ to phospholipids requires calcium and appeared completely reversible. The amount of $\mathrm{Ca}^{2+}$ needed for half-maximal binding but not the maximal binding $\left(\Gamma_{\max }\right)$ depends on the phospholipid composition. Calcium is essential and cannot be 
replaced by other divalent ions. However, zinc ions had a synergistic effect on calcium mediated binding. The apparent dissociation constant of annexin $\mathrm{V}$ is very low $\left(K_{d}<0.2 \mathrm{nM}\right)$. The adsorption rate remains equal to the transport rate limit up to surface coverages of $75 \%$ of $\Gamma_{\max }$. The lacking of surface exclusion effects, that reduce the adsorption rate for randomly adsorbed proteins by several orders suggests clustering of adsorbed annexin $V$ molecules (2). Also a stoichiometry of 2 annexin $\mathrm{V}$ molecules binding to 1 PS molecule was found, consistent with formation of annexin $V$ clusters. Chapter 3 shows the high affinity of annexin $V$ for phospholipids, sufficiently for its in vitro activities, but too much calcium is required to support a hypothetical intracellular function related to membrane binding.

Factor Va displacement by annexin $V$ - The high affinity of annexin $V$ for phospholipid surfaces suggests it to compete effectively with proteins with a lower binding affinity for the lipid membrane as was indeed demonstrated for prothrombin and factor $\mathrm{Xa}$ (3-4). Blood coagulation factor Va, however, has a similarly high affinity for phospholipid membranes. In Chapter 4 the question was addressed whether annexin $V$ was able to displace factor $V a$ from the phospholipid bilayer. Annexin V rapidly displaced $>97 \%$ of factor Va from a $20 \%$ PS $/ 80 \%$ PC surface. It was concluded that either annexin $\mathrm{V}$ binds much tighter to phospholipids than factor $\mathrm{Va}$, or the displacement does not conform to the classical concept of competition for independent binding sites. Factor $\mathrm{Va}$ displacement curves showed a transient adsorption peak. Factor Va desorption rates could be deduced from analysis of the kinetics of the transient adsorption peaks. Factor $V a$ desorption rates at surface concentrations $<0.03 \mu \mathrm{g} / \mathrm{cm}^{2}$ appeared to be independent of the annexin $V$ concentration. Analysis of the displacement curves produced an intrinsic desorption rate constant for factor $\mathrm{Va}$ of $\mathrm{k}_{\mathrm{off}}=0.023 \pm 0.007 \mathrm{~s}^{-1}$ (mean \pm S.D.). For surface concentrations exceeding $0.03 \mu \mathrm{g} / \mathrm{cm}^{2}$ the desorption rate of factor $\mathrm{Va}$ became dependent on the annexin $\mathrm{V}$ concentration and the resulting $k_{\text {off }}$ value increased by a factor ten. Using adsorption kinetics, a value of $\mathrm{K}_{\mathrm{d}}=0.1 \mathrm{nM}$ of factor $\mathrm{Va}$ for $20 \% \mathrm{PS} / 80 \% \mathrm{PC}$ could be estimated in global agreement with earlier reports (5-6).

Clustering of annexin $V$ and inhibition of prothrombinase complex activity - Chapter 5 shows complete inhibition by annexin $V$ of prothrombinase activity on planar surfaces, and poor inhibition of prothrombinase on surfaces with high curvature. The inhibition appeared to be calcium dependent (ten times more calcium was required for inhibition of prothrombinase on small vesicles 


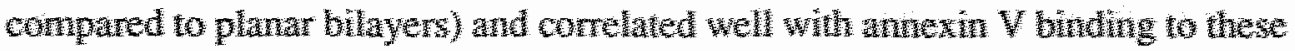

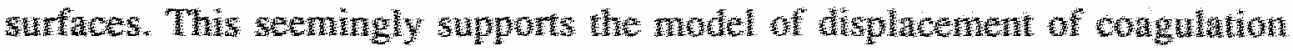

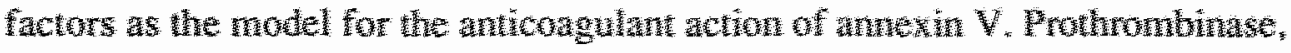

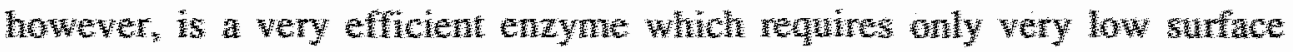

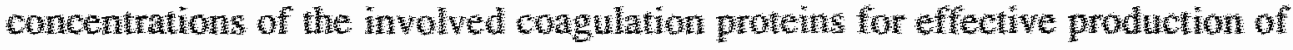

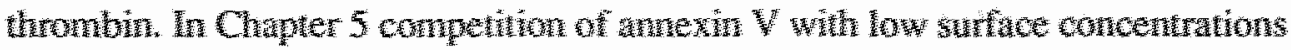
of factors $V$ a, $X$ and wathombin was medsured. Dispucement of these

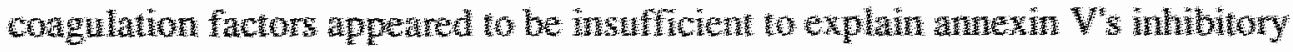
effect. The solution to this apparent diserenancy was provided by electron

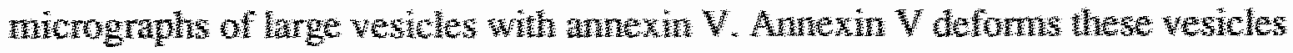

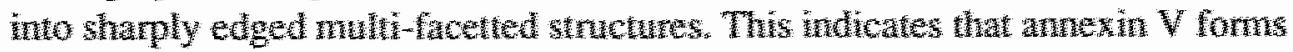

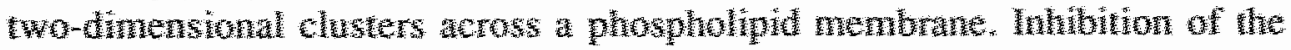

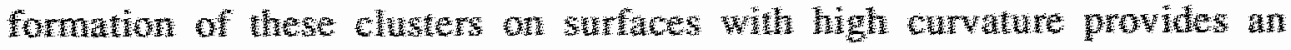

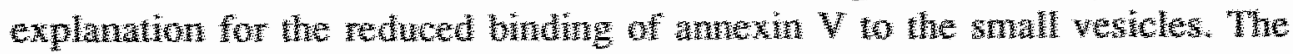

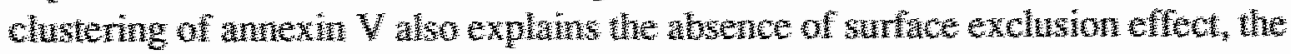

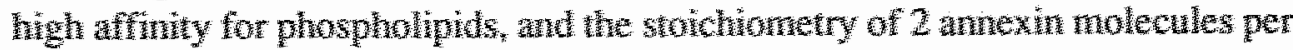

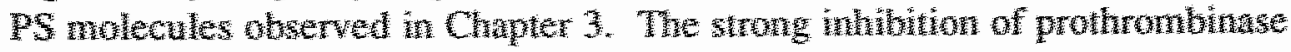

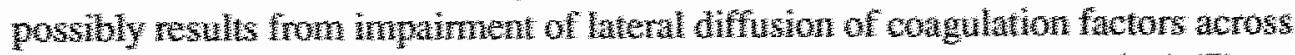
the surface (e.

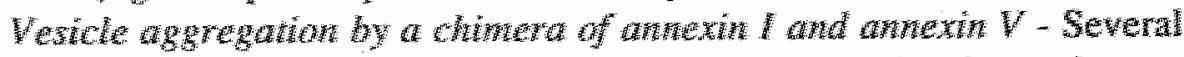

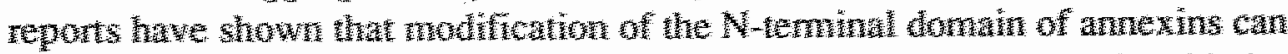

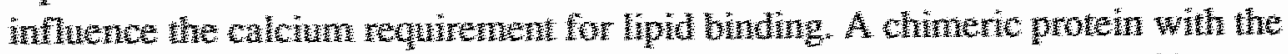

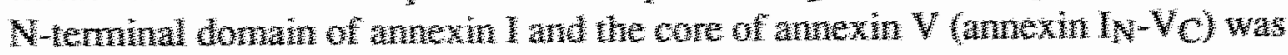

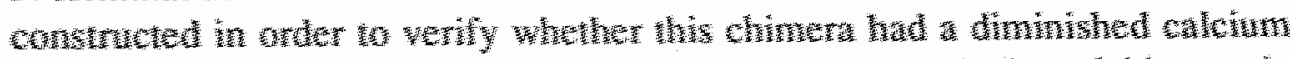

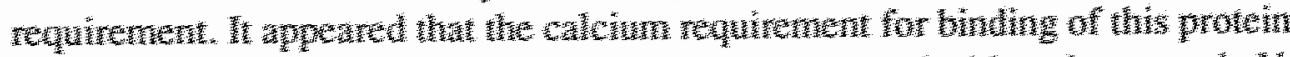

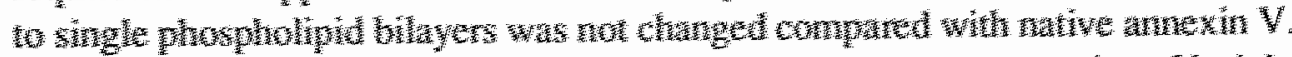

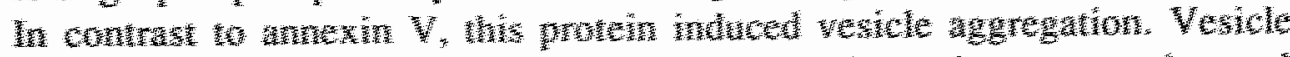

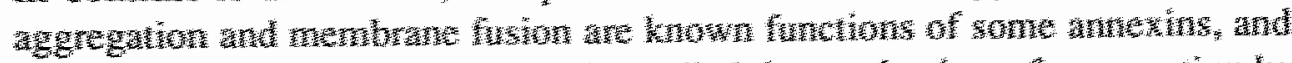

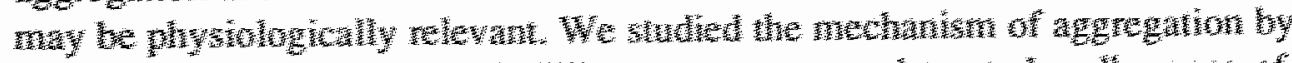

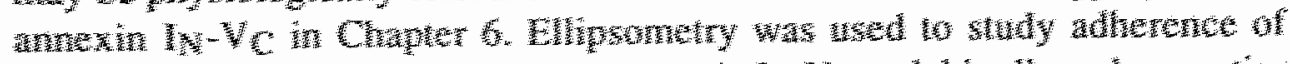

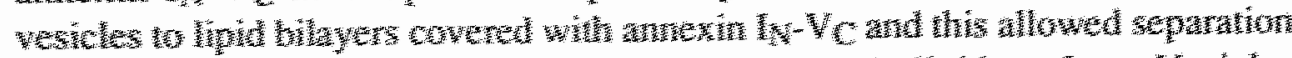

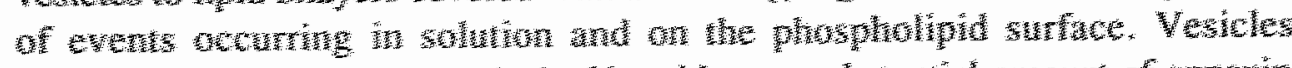

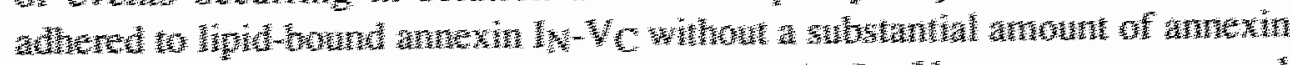

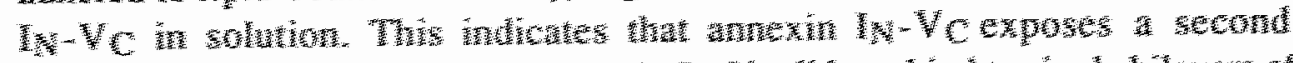

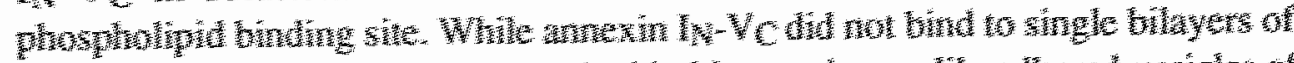

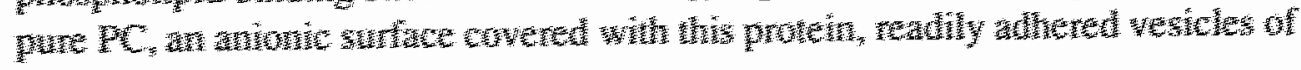


pure PC. This indicates that the second phospholipid binding site differs from the annexin $V$ phospholipid binding site. Vesicle adherence was correlated to annexin $\mathrm{IN}_{\mathrm{N}}-\mathrm{V}_{\mathrm{C}}$ surface coverage and could be inhibited by co-adsorption of annexin $\mathrm{V}$. The data collectively indicate that annexin $\mathbb{N}_{\mathrm{N}}-\mathrm{V}_{\mathrm{C}}$ clusters are responsible for the in vitro aggregating capacity of this protein. Electron micrographs showed that annexin $\mathrm{I}_{\mathbb{N}}-\mathrm{V}_{\mathrm{C}}$ induced vesicle fusion. It would be interesting to see whether the mechanism of vesicle aggregation found for annexin $\mathrm{IN}_{\mathrm{N}}-\mathrm{V}_{\mathrm{C}}$ also hold for other members of the annexin family.

Physiological significance - Despite the wealth of data gathered in vitro, the physiological function of annexin $V$ remains unknown. Whether intracellular condition change to allow annexin $V$ binding or annexin $V$ 's structure changes to increase its affinity for membranes is not known. If annexin $\mathrm{V}$ does not bind to membranes, due for instance to the low intracellular calcium concentrations, its suggested in vitro activities, like inhibition of phospholipase $A_{2}$, inhibition of coagulation, formation of calcium channels, protection against membrane fusion, transport of intracellular vesicles, cannot be performed. There may still be an undiscovered mechanism, which modulates binding of annexin $\mathrm{V}$. The large amounts of annexins in cells, up to $0.5 \%$ of total protein weight, and the absence of discovered deficiencies, indicate a crucial role of these proteins for cell survival. The inhibition of prothrombinase by annexin $V$ clusters presented in this thesis is based on experiments on model membranes. A cell membrane is far more complicated, containing receptor molecules and transmembrane proteins. Although, it is known that annexin $V$ effectively inhibits prothrombinase at these surfaces, it is not clear whether annexin $V$ forms clusters or if clusters are involved in the anticoagulant action on these membranes.

Annexin $V$ as anticoagulant - The plasma concentration of annexin $V$ in normal healthy volunteers is very low $(0-5 \mathrm{ng} / \mathrm{ml})(8)$. Addition of $5 \mathrm{ng} / \mathrm{ml}$ annexin $\mathrm{V}$ to pooled plasma of healthy volunteers, inhibited prothrombinase activity for $50 \%$. This inhibition could be abolished by addition of PS/PC vesicles. The effect of addition of $5 \mathrm{ng} / \mathrm{ml}$ annexin $\mathrm{V}$ to plasma is much smaller than the variability in the amount of procoagulant surfaces. Particularly in patients just after major surgery the amount of procoagulant surface is increased by a factor ten (9). Although these measurements may be blurred by the venapuncture they make a role of annexin $\mathrm{V}$ as a nomal systemic inhibitor of blood coagulation unlikely. Endothelial cells, however, contain $5 \mathrm{mg}$ annexin V/g protein. Release of this amount of annexin V,e.g. after cell death, inay certainly affect local blood 
coagulation reactions. It can be speculated that deficiencies of annexin $\mathrm{V}$ could explain some cases of recurrent thrombosis.

Annexin V can be used as a tool for the research in basic mechanisms. Its high affinity for phospholipids makes it an excellent marker for the exposure of anionic phospholipids. Its strong inhibition of phospholipid dependent reactions makes it a good tool for the study of the mechanisms of these reactions. Its virtually constant adsorption rate turns it into a good model protein for the study of adsorption kinetics and flow conditions.

\section{REFERENCES}

1. Reutelingsperger C.P.M., Hornstra G., and Hemker H.C. (1985) Eur. J. Biochem, 151, 625-629.

2. Willems G.M., Hermens W.Th., and Hemker H.C. (19912) J. Biomater. Sci. Polymer. Edn. 2, 217-226.

3. Reutelingsperger C.P.M., Kop J.M.M., Hornstra G., and Hemker H.C. (1988) Eur.J. Biochem. 173, 171-178.

4. Tait J.F., Gibson D., and Fujikawa K. (1989) J. Biol. Chem. 264, 7944-7949.

5. Pusey M.L., Mayer L.D., Wei G.J., Bloomfield V.A., and Nelsestuen G.L. (1982) Biochemistry 21, 5262-5269.

6. Kop J.M.M., Willems G.M., and Hermens W.Th. (1989) J.Colloid Interface Sci. 133, 369-376.

7. Giesen P.L.A., Willems G.M., and Hernens W.Th. (1991) J. Biol. Chem. 266, 13791382.

8. Flaherty M.J., West S.,Heimark R.L., Fujikawa K., and Tait J.F. (1990) J. Lab. Clin. Med. 115, 174-181.

9. Andree H.A.M., Hemker H.C., Peltenburg H.G., Willems G.M., and Reutelingsperger C.P.M. (1991) Immunologie und Blutgerinnung, V. Tilsner \& F.R. Matthias, Editiones <Roche $>$ Basel, pp. 173-186. 


\section{Samenvatting en Slotopmerkingen}

Bloedstolling bestaat uit een serie van opeenvolgende enzym reacties. De activaties van factor $\mathrm{X}$ door het weefsel factor-factor VIla complex, van factor $\mathrm{X}$ door het factor VIIIa-IXa complex en van protrombine door het factor $\mathrm{Va}$-Xa (protrombinase) complex worden sterk vesneld door de aanwezigheid van (negatief geladen) fosfolipiden. Deze kunnen worden geleverd door subendotheel en geactiveerde bloedplaatjes. De vesnelling van de bloedstollingsreacties kan worden tegengegaan door fosfolipide bindende eiwitten, die met de stollingeiwitten competeren voor de aanwezige hoeveelheid membraanoppervlak. Dit proefschrift behandelt de fosfolipide-bindende eigenschappen van annexine $\mathrm{V}$, een van de sterkste remmers van dit type, en zijn werkingsmechanisme.

Fosfolipide binding van protrombine - De snelheid van eiwit binding (adsorptie) op een macroscopisch oppervlak is vaak beperkt door de transport snelheid van het eiwit naar het oppervlak. In hoofdstuk 2 worden de adsorptiesnelheden van protrombine naar een dubbellaag van $40 \%$ fosfatidylserine (PS) / $60 \%$ fosfatidylcholine (PC) gemeten met een nauwkeurige en snelle techniek: "off-null ellipsometry". De gemeten bindingssnelheden werden geanalyseerd zonder een van te voren vastgesteld model. De adsorptiesnelheid is gelijk aan de transportcoëfficient maal het concentratieverschil tussen de bulk en de oplossing vlak bij het oppervlak. De laatste concentratie wordt bepaald door de hoeveelheid protrombine op het oppervlak, in overeenstemming met het klassieke Langmuir model. Met een bekende waarde van maximale binding van een eiwit kan de bindingsconstante uit de adsorptiekinetiek van een enkel bindingsexperiment bepaald worden. Deze methode leverde een $\mathrm{K}_{\mathrm{d}}$ van protrombine voor $40 \% \mathrm{PS} / 60 \%$ PC oppervlak (31 $\mathrm{nM}$ ) op overeenkomstig evenwichtsmetingen. Afwijkingen van dit eenvoudige bindingsmodel boven $50 \%$ oppervlaktebezetting worden waarschijnlijk bepaald door sterische hindering of oppervlakte exclusie effecten.

Fosfolipide binding van annexine $V$ - Bindingseigenschappen van annexine $V$ voor fosfolipide dubbellagen zijn onderzocht in hoofdstuk 3. Binding van annexine $\mathrm{V}$ aan fosfolipiden behoeft calcium en is compleet omkeerbaar. De hoeveelheid calcium die nodig is voor half-maximale binding maar niet de maximale oppervlaktebezetting hangt af van de samenstelling van het 
fosfolipidemengsel. Calcium is essentieel en kan niet vervangen worden door andere tweewaardige ionen, maar zink ionen hebben een synergistisch effect op calcium afhankelijke binding. De schijnbare dissociatieconstante van annexine $\mathrm{V}$ is erg laag $(<0.2 \mathrm{nM})$, en de adsorptiesnelheid is dientengevolge gelijk aan de transportsnelheid tot een oppervlakte bezetting van $75 \%$ van maximaal. De afwezigheid van oppervlakte exclusie effecten, die in het geval van willekeurig adsorberende molekulen de adsorptiesnelheid verschillende orden laat dalen, duidt op reorganisatie van geadsorbeerde annexine $V$ moleculen in een tweedimensionaal rooster (2). De verhouding van 2 annexine $V$ moleculen die aan 1 PS molekuul binden is ook in overeenstemming met de roostervorming. Hoofdstuk 3 toont de hoge affiniteit van annexine $V$ voor fosfolipiden, voldoende voor zijn in vitro activiteit, maar te veel calcium is nodig om zijn aan intracellulaire membraanbinding verbonden hypothetische functies aan te tonen.

Factor Va verdringing door annexine $V$ - De hoge bindingsaffiniteit van annexine $\mathrm{V}$ voor fosfolipide membranen suggereert dat dit eiwit een effectieve verdringer van stolfactoren is, zoals inderdaad voor protrombine en factor $\mathrm{Xa}$ al is aangetoond $(3,4)$. Bloedstollingsfactor $\mathrm{Va}$ heeft echter een vergelijkbare affiniteit voor fosfolipiden. In hoofdstuk 4 werd de vraag gesteld of annexine $V$ in staat was om factor Va te verdringen. Meer dan $97 \%$ van een aan een $20 \%$ PS / $80 \% \mathrm{PC}$ membraan gebonden factor $\mathrm{Va}$ werd door annexine $\mathrm{V}$ verdrongen. Hieruit kan worden geconcludeerd dat of annexine $V$ veel sterker aan membranen bind of dat verdringing niet het klassieke model van competitie voor onafhankelijke bindingsplaatsen volgt. Factor Va verdringingscurven laten een tijdelijke adsorptiepiek zien. Factor Va desorptiesnelheden konden uit deze verdringingspiek berekend worden. Factor $\mathrm{Va}$ desorptiesnellheden waren voor een oppervlakte bezetting van minder dan $0.03 \mu \mathrm{g} / \mathrm{cm}^{2}$, onafhankelijk van de toegevoegde annexine $V$ concentratie. Analyse van de desorptiecurven leverde een intrinsieke waarde van desorptiesnelheidsconstante op: $\mathrm{k}_{\text {off }}=0.023 \pm 0.007$ $\mathrm{s}^{-1}$ (gemiddelde \pm standaard deviatie). Voor oppervlaktebezetting boven 0.03 $\mu \mathrm{g} / \mathrm{cm}^{2}$ werd de desorptiesnelheid een functie van de annexine $\mathrm{V}$ concentratie en de bijbehorende $k_{\text {off }}$ ging een factor 10 omhoog. Gebruik makende van de adsorptiekinetiek kon een $\mathrm{K}_{\mathrm{d}}$ van factor Va voor $20 \% \mathrm{PS}$ en $80 \% \mathrm{PC}$ van $0.1 \mathrm{nM}$ geschat worden overeenkomstig met eerdere rapporten $(5,6)$.

Roostervorming van annexine $V$ en remming van protrombinase activiteit Hoodstuk 5 toont een complete remming van protrombinase activiteit door annexine $\mathrm{V}$ op vlakke dubbellagen, en een slechte remming op oppervlakken met 
een grote kromming. De remming bleek claium afhankelijk, tien keer meer calcium was er nodig om protrombine te remmen op kleine vesikels vergeleken met vlakke lagen en dit correleerde goed met de binding van annexine $\mathrm{V}$ op deze oppervlakken. Dit steunt schijnbaar het verdringingsmodel als mechanisme voor de annexine $V$ werking. Protrombinase is echter een zeer efficiënt enzym, dat al bij zeer lage oppervlaktebezetting van de verschillende componenten al een maximale trombinevormingssnelheid geeft. In hoofdstuk 5 wordt dan ook de verdringing van lage oppervlaktebezettingen van de stollingsfactoren door annexine $\mathrm{V}$ bestudeerd. verdringing van de stolfactoren blijkt onvoldoende om de antistollende werking van annexine $V$ te verklaren. De oplossing van deze schijnbare discrepantie komt van electronen microscopische opname van grote vesikels in de aanwezigheid van annexine $V$. Dit eiwit vervormt de vesikels naar scherp gehoekte structuren met platte facetten. Dit geeft aan dat membraangebonden annexine $\mathrm{V}$ een rooster vormt dat star genoeg is om deze vormveranderingen te induceren. Remming van deze roostervorming op oppervlakken met sterke kromming levert een verklaring voor de verminderde binding op de kleine vesikels. De roostervorming verklaart ook de afwezigheid van oppervlakte exclusie effecten, de hoge affiniteit van annexine voor fosfolipiden en de binding van 2 annexines per molekuul PS. De sterke remming van protrombinase wordt mogelijk veroorzaakt door de remming lateraal transport van stollingseiwitten over het oppervlak (b.v. transport van protrombine naar het protrombinase complex) (7).

Vesikelaggregatie door een chimeer van annexine I en $V$ - Verschillende studies hebben aangetoond dat een verandering van de $\mathrm{N}$-terminus van annexines de calcium afhankelijkheid van de binding van het eiwit voor fosfolipiden kan veranderen. Een chimeer met het $\mathrm{N}$-domein van annexine I en de kern van annexine $\mathrm{V}$ (annexine $\mathrm{I}_{\mathrm{N}}-\mathrm{V}_{\mathrm{C}}$ ) werd gemaakt om een dergelijk effect aan te tonen. Het bleek dat dit eiwit een gelijke hoeveelheid calcium nodig had om aan een enkele membraan te binden als annexine $\mathrm{V}$. In tegenstelling tot annexine $\mathrm{V}$ induceerde dit eiwit vesikel aggregatie en membraan fusie. Dit zijn functies die voor een aantal annexines een fysiologische relevantie kunnen hebben. We onderzochten in hoofdstuk 6 het aggregatiemechanisme van annexine $\mathrm{I}_{\mathrm{N}}-\mathrm{V}_{\mathrm{C}}$. Ellipsometrie werd gebruikt om de hechting van vesikels aan lipide dubbellagen bedekt met annexine $I_{N}-V_{C}$ en te meten. Vesikels bonden aan lipide-gebonden annexine $I_{N}-V_{C}$ zonder een noemenswaardige concentratie annexine $I_{N}-V_{C}$ in oplossing. Dit duidt op de expositie van een tweede fosfolipide bindingsplaats. 
Ofschoon annexine $\mathrm{IN}_{\mathrm{N}}-\mathrm{V}_{\mathrm{C}}$ niet bond aan enkele lagen van puur $\mathrm{PC}$, bonden vesikels van dit fosfolipide wel aan een PS/PC membraan bedekt met annexine $\mathbb{N}_{\mathrm{N}}-\mathrm{V}_{\mathrm{C}}$. Dit wijst op een andere fosfolipide specificiteit van de tweede bindingsplaats. Vesikelhechting was een functie van de annexine $I_{N}-V_{C}$ oppervlaktebezetting en kon geremd worden door co-adsorptie met annexine $\mathrm{V}$. De gezamenlijke data wijzen erop dat roostervorming betrokken is bij de in vitro aggregerende werking van annexine $\mathrm{I}_{\mathrm{N}}-\mathrm{V}_{\mathrm{C}}$. Het is interessant om te onderzoeken of het mechanisme dat ten grondslag ligt aan vesikel aggregatie door annexine $\mathrm{I}_{\mathrm{N}^{-}}$ $V_{C}$ ook van toepassing is op andere annexines.

Fysiologisch belang - Ondanks de weelde aan in vitro metingen blijft de fysiologische functie van annexine $\mathrm{V}$ onbekend. Het is ook niet bekent of verandering van de intracellulaire condities of veranderingen van de annexine $V$ structuur zelf membraan binding mogelijk maken. Als annexine $\mathrm{V}$ niet aan membranen bind dan kunnen zijn suggereerde in vitro activiteiten zoals, remming van fosfolipase $A_{2}$, remming van de bloedstolling, vorming van calcium kanalen, bescherming tegen membraan fusie, transport van intracellulaire vesikels, niet in werking treden. De grote hoeveelheid annexine $V$ in cellen tot $0.5 \%$ van de totale hoeveelheid eiwit en de afwezigheid van deficiënties, duiden een essentiële rol voor het overleven van de cel. De remming van protrombinase zoals beschreven in dit proefschrift is gebaseerd op metingen op modelmembranen. Een cel membraan is ingewikkelder, met receptor- en transmembraaneiwitten. Ofschoon annexine $V$ in staat is protrombinase op deze oppervlakken effectief te remmen, is niet bekend of annexine $V$ roostervorming op deze membranen optreedt en zo ja of deze roosters noodzakelijk zijn voor zijn activiteit.

Annexine $V$ als antistoller - De concentratie annexine $V$ in plasma van normale vrijwilligers is laag $(0-5 \mathrm{ng} / \mathrm{ml})(8)$. Toevoeging van $5 \mathrm{ng} / \mathrm{ml}$ annexine $\mathrm{V}$ aan plasma remde protrombinase activiteit voor $50 \%$. Deze remming kan door toevoeging van $\mathrm{PS} / \mathrm{PC}$ vesikels te niet worden gedaan. Het effect van $5 \mathrm{ng} / \mathrm{ml}$ annexine $\mathrm{V}$ is veel kleiner dan de variatie in de hoeveellheid procoagulant oppervlak aanwezig in plasmamonsters. Met name in monsters van patiënten vlak na een grote chirurgische ingreep kan de totale hoeveelheid procoagulant oppervlak met een factor 10 zijn toegenomen (9). Alhoewel deze metingen beïnvloed kunnen worden door de venapunctie, maken ze een rol voor annexine $\mathrm{V}$ als systemische remmer van de bloedstolling toch onwaarschijnlijk. Endotheelcellen aan de andere kant bevatten $5 \mathrm{mg}$ annexine V/g eiwit. Vrijkomen van deze hoeveelheid annexine V, b.v. na celdood, kan zeker plaatselijk de 
bloedstolling beinvloeden. Er kan gespeculeerd worden dat deficiènties van annexin $V$ een aantal gevallen van trombose gaan verklaren.

Annexine $\mathrm{V}$ kan in onderzoek gebruikt worden als gereedschap om basale mechanismen te bestuderen. Zijn hoge affiniteit voor membranen maakt het een goede indicator voor de expositie van negatief geladen fosfolipiden. Zijn sterke remming van fosfolipide afhankelijke reacties staat het bestuderen van het effect van oppervlakken in deze reacties toe. Zijn bijna constante adsorptiesnelheid maakt het een goed modeleiwit om bindingssnelheden en stromingscondities te meten.

\section{REFERENTIES}

1. Reutelingsperger C.P.M., Hornstra G., and Hemker H.C. (1985) Eur. J. Biochem. 151, 625-629.

2. Willems G.M., Hermens W.Th., and Hemker H.C. (1991) J. Biomater. Sci. Polymer. Edn. 2, 217-226.

3. Reutelingsperger C.P.M., Kop J.M.M., Hornstra G., and Hemker H.C. (1988) Eur. J. Biochem. 173, 171-178.

4. Tait J.F., Gibson D., and Fujikawa K. (1989) J. Biol. Chem. 264, 7944-7949.

5. Pusey M.L., Mayer L.D., Wei G.J., Bloomfield V.A., and Nelsestuen G.L (1982) Biochemistry 21, 5262-5269.

6. Kop J.M.M., Willems G.M., and Hermens W.Th. (1989) J.Colloid Interface Sci. 133, 369-376.

7. Giesen P.L.A., Willems G.M., and Hermens W.Th. (1991) J. Biol. Chem. 266, 13791382.

8. Flaherty M.J., West S.,Heimark R.L., Fujikawa K., and Tait J.F. (1990) J. Lab. Clin. Med. 115, 174-181.

9. Andree H.A.M., Hemker H.C., Peltenburg H.G., Willems G.M., and Reutelingsperger C.P.M. (1991) Immunologie und Blatgerinnung, V. Tilsner \& F.R. Matthias, Editiones $<$ Roche $>$ Basel, pp. 173-186. 


\section{Curriculum Vitae}

Harry Andree werd geboren op 26 September 1963 te Kerkrade. Hij behaalde in 1981 het atheneum B diploma aan de scholengemeenschap "Sancta Maria College" te Kerkrade. In dat jaar startte hij zijn studie geneeskunde aan de Rijksuniversiteit Limburg. Hij behaalde zijn artsendiploma in september 1987. Hij tradt daarna in dienst van de Rijksunversiteit Limburg als Assistent In Opleiding. Het werk van de afgelopen vier jaar heeft tot dit proefschrift geleid. 


\section{Publications}

1. Binding of Vascular Anticoagulant $\alpha$ (VAC $\alpha$ ) to planar phospholipid bilayers. H.A.M. Andree, C.P.M. Reutelingsperger, R. Hauptmann, H.C. Hemker, W.Th. Hermens, and G.M. Willems (1990) J. Biol. Chem. 265, 4923-4928.

2. Anwendung der Ellipsometrie zur Untersuchung von Biomaterialien. H.C. Hemker, H.A.M. Andree, P.L.A. Giesen (1990) Hämostaseologie 10, 71-76.

3. Vascular Anticoagulant $\beta$ : A novel human $\mathrm{Ca}^{2+} /$ phospholipid binding protein that inhibits coagulation and phosphollipase $A_{2}$ actiwity. R. Hauptmann, I. Maurer-Fogy, G. Bodo, H.A.M. Andree, C.P.M. Reutelingsperger (1989) Eur. J. Biochem. 185, 6371.

4. Mode of action of annexin V (Vascular Anticoagulant alpha), a protein synthesized by the vessel wall. R. v. Gool, H.A.M. Andree, H.C. Hemker, C.P.M. Reutelingsperger (1990) New trends in Haemostasis: J. Harrenberg, D.L. Heene, G. Stehle, G. Schettler (eds.) Springer, Berlin, 136-151.

5. Annexin $V$ (Vascular Anticoagulant alpha). Its mechanism of anticoagulation and its perspectives as a future antithrombotic drug. H.A.M. Andree, H.C. Hemker, H.G. Peltenburg, G.M. Willems, C.P.M. Reutelingsperger (1991) Immulologie und Blutgerinnung, V. Tilsner, F.R. Mathias (eds.) Roche Interaktiv, Grenzach-Wyhlen, FRG, 173-186.

6. Testing of protein adsorption models by off-null ellipsometry: Determination of binding constants from a single adsorption curve, H.A.M. Andree, W.Th. Hermens, and G.M. Willems, Colloids and Surfaces in press.

7. Clustering of lipid-bound annexin V explains its anticoagulant effect. H.A.M. Andree, M.C.A. Stuart, W.Th. Hermens, C.P.M. Reutelingsperger, H.C. Hemker, P.M. Frederik, and G.M. Willems, submitted.

8. Quantification of exocytosis in human platelets surface-labeled with the fluorescent probe 1[4-(Trimethylammonio)phenyl]-6-phenyl-1,3,5-hexatriene. Significance of intracellular $\left[\mathrm{Ca}^{2+}\right]$. J.W.M. Heemskerk, M.A.H. Feijge, H.A.M. Andree, and S.O. Sage, submitted.

9. Aggregation of Phospholipid Vesicles by a Chimeric Protein with the $\mathrm{N}$-terminus of Annexin $I$ and the Core of Annexin V. H.A.M. Andree, G.M. Willems, R. Hauptmann, 1. Maturer-Fogy, M.C.A Stuart, W.Th. Hermens, P.M. Frederik, and C.P.M. Reutelingsperger, in preparation 


\section{Abstracts:}

1. Bindingseigenschappen van Vasculair Anticoagulans (VAC) aan dubbellagen van fosfolipiden. H.A.M. Andree, C.P.M. Reutelingsperger, R. Hauptmann, W.Th. Hermens, and G.M. Willems (1988) Thrombose and Artherosclerose, verslag $6 \mathrm{e}$ amstol symposium Amsterdam september.

2. Recombinant annexin V (Vascular Anticoagulant alpha, VACa) inhibition of factor Va activity in the prothrombinase complex. H.A.M Andree, C.P.M. Reutelingsperger, R. Hauptmann, W.Th. Hermens, G.M. Willems (1990) International Symposium on Biotechnology of Plasma Proteins: Haemostasis, Thrombosis and Iron Proteins, Florence (Italy) April 9-11.

3. Binding of recombinant annexin V (Vascular Anticoagulant $\alpha$, VAC $\alpha$ ) to planar phospholipid bilayers. H.A.M. Andree, C.P.M. Reutelingsperger, R. Hauptmann, W.Th. Hermens, and G.M. Willems (1.990) International Symposium on Biotechnology of Plasma Proteins: Haemostasis, Thrombosis and Iron Proteins, Florence (Italy) April 9-11.

4. Annexin $V$ (Vascualr Anticoagulant alpha) inhibition of the prothrombinase complex activity. H.A.M. Andree, C.P.M. Reutelingsperger, R. Hauptmann, W.Th. Hermens, and G.M. Willems (1990) British Journal of Haematology 76, supplement 1, Joint meeting of BSHT and NVTH, 17-18 September.

5. Kinetics of annexin $\mathrm{V}$ binding to phospholipid bilayers indicate clustering of adsorbed molecules. H.A.M. Andree, C.P.M. Reutelingsperger, W.Th. Hermens, and G.M. Willems (1991) X11/ th congress of the international society on thrombosis and haemostasis $6,1209$.

6. Mearsurement of protein sorption kinetics with off-null ellipsometry. H.A.M. Andree, W.Th. Hermens, and G.M. Willems (1991) XIIt congress of the international society on thrombosis and haemostasis 6,1311 .

7. Aggregation of unilamellar phospholipid vesicles induced by annexin $V$ and annexin VIII (1991) H.A.M. Andree, G.M. Willems, C.P.M. Reutelingsperger, R. Hauptmann, and P.M. Frederik (1991) $7^{\text {th }}$ International Conference on Surfaces and Colloid Science, 7-13 Juli, Compiègne, France.

8. Estimation of protein binding constants from initial sorption kinetics with off-null ellipsometry. H.A.M. Andree, C.P.M. Reutelingsperger, W.Th. Hermens, and G.M. Willems (1991) $7^{\text {th }}$ International Conference on Surfaces and Colloid Science, 7-13 Juli, Compiègne, France.

9. Clustering of lipid-bound annexin $V$ explains its anticoagulant effect. H.A.M. Andree, M.C.A. Stuart, W.Th. Hermens, C.P.M. Reutelingsperger, H.C. Hemker, P.M. Frederik, G.M. Willems (1991) Surface Mediated Hemostatic Processes, Leaven, Belgium, 13 December. 



\section{Dankwoord}

Vrijwel elk promotieonderzoek is een samenwerking van een heel onderzoeksteam. In mijn geval heeft een zeer groot aantal mensen op de een of andere manier bijgedragen aan dit proefschrift. Toch wil ik nog even een aantal mensen in het bijzonder noemen.

Allereerst gaat mijn dank uit naar George Willems. Zonder jouw continue begeleiding en geniale bijdragen zou dit proefschrift er waarschijnlijk niet zijn. Ik verwacht nog vaak op jouw wetenschappelijke ideeën een beroep te kunnen doen.

Wim Hermens, je hebt ook een aanzienlijke bijdrage geleverd door de vele discussies die we gevoerd hebben en je bent een grote steun geweest bij het schrijven van de publicaties.

Ik wil Coen Hemker bedanken voor het vertrouwen dat hij mij schenkt, voor het scheppen van het juiste onderzoeksklimaat, en voor het motieveren van mijn verdere loopbaan.

Rita Janssen, je hebt me het werken in een lab. geleerd en stond me altijd terzijde als er weer een flinke serie proeven gedaan moest worden.

Peter Giesen, jou bedank ik voor je samenwerking en collegialiteit.

Een bijzondere band heb ik gehad met de mensen van het VAC project. Chris Reutelingsperger, jij hebt een belangrijke bijdrage geleverd aan de wetenschappelijke inhoud van het proefschrift. Cécile Maassen wil ik danken voor haar morele steun en praktische hulp.

Ook de mensen van electronen microscopie mag ik natuurlijk niet vergeten. In het bijzonder noem ik Peter Frederik, voor zijn wetenschappelijke inbreng maar ook voor de geleverde illustraties, en Marc Stuart voor het maken van de electronen microscopy opnamen.

Prof van der Vusse, prof. Nemerson, prof. Freyssinet, prof. Zwaal en dr. Reutelingsperger bedank ik voor de snelle en soepele wijze waarop ze dit proefschrift hebben beoordeeld. Met name prof. Nemerson ben ik dankbaar voor zijn uitnodiging om in zijn lab. te komen werken.

Rudi Hauptmann en Ingrid Maurer-Fogy (Bender \& Co.) ben ik erkentelijk voor hun prettige samenwerking en voor het leveren van de recombinante eiwitten. 
Harry Bakker en Bert Andree bedank ik voor hun bereidwilligheid om de taak van paranimf voor hun rekening te nemen.

Verder, bedank ik nog Jos en Bernadette, Marie Louise, Han en iedereen van de vakgroep biochemie, het secretariaat van CARIM, en de mensen van de electronische en technische werkplaats.

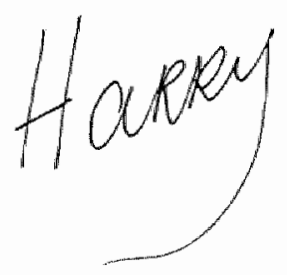




\section{Abbreviations and glossary}

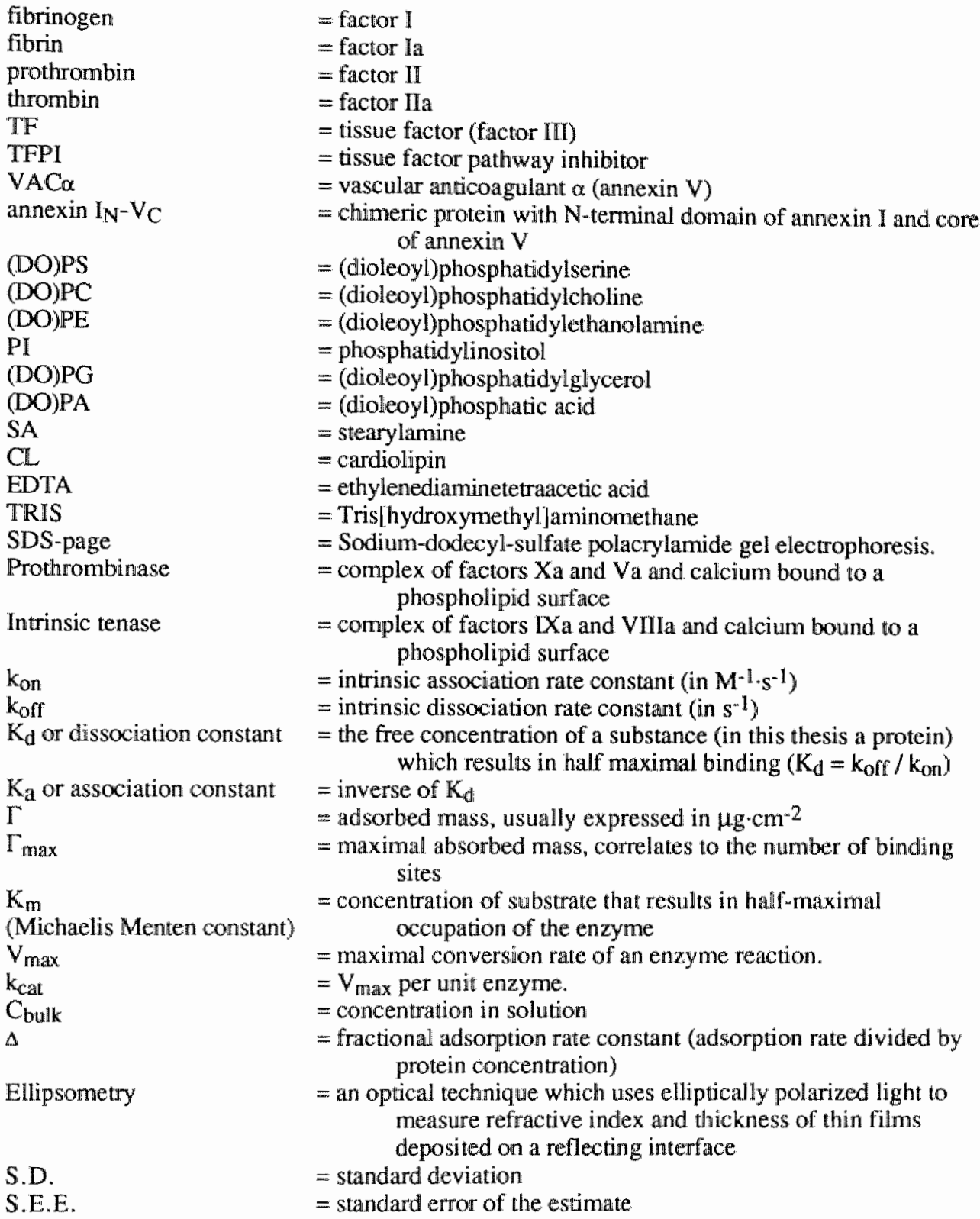

